\title{
Efeitos renais e sobre a concentração do hormônio antidiurético pelo uso de dexmedetomidina em cães anestesiados e submetidos à isquemia renal
}

Dissertação apresentada ao Programa de PósGraduação em Anestesiologia da Faculdade de Medicina de Botucatu, Universidade Estadual Paulista, UNESP, para obtenção de título de Mestre em Anestesiologia

Prof .Dr. Geraldo Rolim Rodrigues Orientador

Botucatu - SP 


\section{Dedico este trabalho}

\section{À minha esposa Yara,}

por ser meu grande amor e minha grande amiga

Às minhas filhas Natália e Marina, por serem minha razão de lutar incansavelmente

Aos meus pais Orrélio e Euridice, por me ensinarem o caminho do conhecimento, sempre com muito carinho e paciência

Aos meus irmãos Edileuza e Aurélio, por me compreenderem e sempre apoiarem as minhas decisões 


\section{Agradecimento especial}

\section{Ao Professor Doutor Geraldo Rolim Rodrigues,}

meu orientador e grande amigo, que com sua vasta sabedoria, muito contribuiu para minha vida profissional. O meu muito obrigado por me conduzir à conquista de mais um sonho. 


\section{Agradecimentos}

Agradecemos a todos que colaboraram com a realização deste trabalho, direta ou indiretamente, e em particular:

- Aos meus sócios Orrélio, João Bosco e Gilberto, que me apoiaram e supriram minha ausência necessária para realização deste trabalho.

- Aos meus colegas de trabalho do Hospital Estadual de Bauru, que compreenderam minhas dificuldades e me pouparam para que eu pudesse desenvolver melhor esta pesquisa.

- Ao Professor Titular José Reinaldo Cerqueira Bráz, por me ajudar na elaboração do artigo para publicação originário desta dissertação.

- Ao Professor Titular Pedro Thadeu Vianna, pelo incentivo à realização deste trabalho.

- Ao Professor Substituto Doutor Leandro Gobbo Bráz, pela sua amizade e orientações acadêmicas.

- À Prof ${ }^{a}$ Dr ${ }^{\mathrm{a}}$ Lídia Raquel de Carvalho, do Departamento de Bioestatística do Instituto de Biociências de Botucatu, Unesp, pela orientação estatística e análise dos dados.

- Aos Funcionários do Laboratório Experimental do Departamento de Anestesiologia da Faculdade de Medicina de Botucatu, UNESP, Mariana Gobbo Braz, Jurandir Antônio, e, em especial, ao Cristiano Correa de Oliveira, pela inestimável ajuda na realização deste trabalho.

- À funcionária do departamento de anestesiologia Neli Aparecida Pavan, pela sua dedicação e eficiência na transmissão das informações.

- À funcionária Joana Jacirene Costa Teixeira, por ser responsável pela revisão, impressão e encadernação deste trabalho.

- Aos funcionários da Secretaria e do Serviço de Computação do Departamento de Anestesiologia da Faculdade de Medicina de Botucatu, Unesp, Sônia Maria Martins da Silva, Danilo Godoy, pelo carinho e respeito dispensado. 


\section{Sumário}

1 INTRODUÇÃO E LITERATURA............................................................. 10

2 OBJETIVO............................................................................... 14

3 MATERIAL E MÉTODO................................................................. 15

3.1 Animais Utilizados....................................................... 15

3.2 Grupos Experimentais........................................................ $\quad 15$

3.3 Sequência Experimental............................................................. 16

3.4 Atributos Estudados............................................................. 19

3.5 Momentos Estudados......................................................... 21

3.6 Técnicas Utilizadas................................................................. 22

3.7 Métodos Utilizados.............................................................. 25

3.8 Fórmulas Empregadas....................................................... 26

3.9 Método Estatístico................................................................ 29

4 RESULTADOS.......................................................................... $\quad 30$

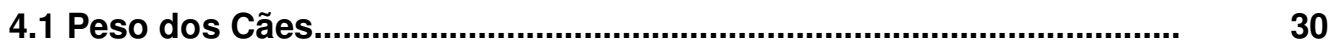

4.2 Comprimento dos Cães......................................................................... 31

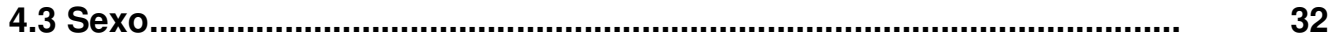

4.4 Superfície Corporal.................................................................................. 33

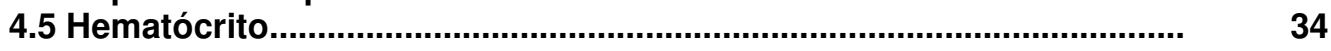

4.6 Saturação de Pulso de Oxigênio.............................................................. 35

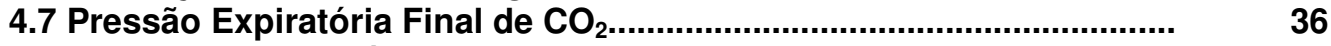

4.8 Temperatura Esofágica................................................................... 37

4.9 Freqüência Cardíaca.............................................................................. 38

4.10 Pressão Arterial Média.......................................................................... 39

4.11 Pressão Média do Átrio Direito.......................................................... 40

4.12 Pressão Média da Artéria Pulmonar..................................................... 41

4.13 Pressão de Oclusão da Artéria Pulmonar.......................................... 42

4.14 İndice Cardíaco.................................................................................

4.15 Índice de Resistência Vascular Sistêmica............................................. 44

4.16 Vasopressina.................................................................... 45

4.17 Resistência Vascular Renal................................................... 46

4.18 Fluxo Sangüíneo Renal....................................................... 47

4.19 Depuração de Para-Aminohipurato de Sódio...................................... 48

4.20 Depuração de Creatinina............................................................. 49

4.21 Fração de Filtração................................................................ 50

4.22 Débito Urinário................................................................... 51

4.23 Sódio Plasmático................................................................. 52

4.24 Potássio Plasmático............................................................. 53

4.25 Osmolalidade Plasmática.................................................... 54

4.26 Osmolalidade Urinária....................................................... 55

4.27 Depuração Osmolar............................................................ 56

4.28 Depuração de Água Livre.................................................. 57

4.29 Depuração de Sódio........................................................... 58

4.30 Excreção Fracionária de Sódio.......................................................... 59

4.31 Excreção Urinária de Sódio................................................... $\quad 60$

4.32 Excreção Urinária de Potássio............................................... 61

4.33 Depuração de Potássio........................................................ 62

4.34 Excreção Fracionária de Potássio.......................................... 63

4.35 Microscopia de Luz dos Rins............................................................. 64

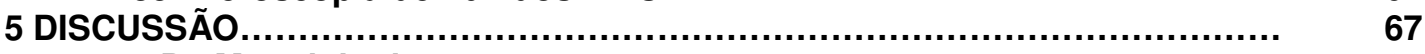

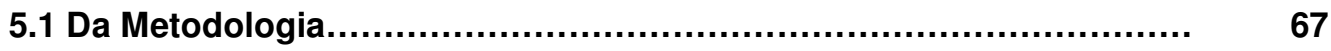

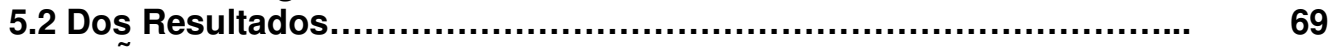

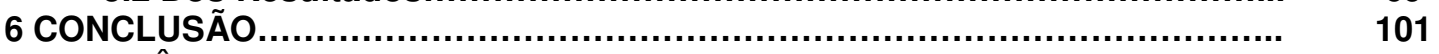

7 REFERÊNCIAS..................................................................................... 102

8 APÊNDICE........................................................................... 120 
Rocha MVN. Efeitos renais e sobre a concentração do hormônio antidiurético pelo uso de dexmedetomidina em cães anestesiados e submetidos à isquemia renal. Estudo experimental em cães anestesiados. Botucatu. 2010. 149p. Dissertação (Mestrado em Anestesiologia) - Faculdade de Medicina de Botucatu, Universidade Estadual Paulista "Júlio de Mesquita Filho".

\section{RESUMO}

A dexmedetomidina, como faz a clonidina, teria potencial para proteção renal durante eventos isquêmicos e reduzir a incidência de insuficiência renal aguda. O objetivo deste estudo foi verificar as ações da Dexmedetomidina sobre a concentração plasmática do hormônio antidiurético (HAD) e sua efetividade em proteger o rim de lesões relacionadas ao evento isquemia-reperfusão em cães. O experiemento incluiu vinte cães, anestesiados, submetidos à nefrectomia direita e isquemia renal esquerda durante 30 minutos, com posterior reperfusão e estudo histopatológico do rim. Foram observadas possíveis alterações morfofuncionais, além das repercussões renais e da concentração plasmática de HAD, pela administração de dexmedetomidina $\left(2 \mu \mathrm{g} \cdot \mathrm{kg}^{-1}\right)$. Foram estudados os seguintes atributos: freqüência cardíaca, pressão arterial média, pressão da artéria pulmonar, pressão de oclusão da artéria pulmonar, débito cardíaco, fluxo sangüíneo renal, resistência vascular renal; hematócrito, $\mathrm{Na}^{+}, \mathrm{K}^{+}$, osmolaridade plasmática; depurações ( $\mathrm{PAH}$, creatinina, osmolar, água livre, $\mathrm{Na}^{+}, \mathrm{K}^{+}$) fração de filtração, volume e osmolaridade urinárias, excreções urinárias e fracionárias de sódio e de potássio; temperatura esofágica e exame histopatológico do rim. Atributos foram pesquisados em 5 momentos: M1 Após término do período de estabilização; M2 - 15 min após a infusão em estudo; M3 - 15 min após despinçamento da artéria renal (DAR) e 60 min da infusão em estudo; M4 - 30 min após DAR; M5 - 45 minutos após DAR. O índice cardiaco apresentou redução estatisticamente significativa no momento 2 do grupo da dexmedetomidina, quando comparado com o momento inicial. A resistência vascular sistêmica apresentou aumento significativo no M2 do G2 até o momento final. A Diurese apresentou G2>G1 no M5. O HAD variou a 
partir de M3 aumentando nos demais momentos em ambos os grupos. As varáveis $C_{c r}, C_{k}, C_{o s m}$ e $U_{k} V$ apresentaram redução significativa em M3 e voltando aos níveis iniciais após reperfusão nos dois grupos estudados. $\mathrm{A}_{\mathrm{H} 2 \mathrm{O}}$ apresentou elevação significativa em M3 e mantida até M5, resultado observado tanto no G1 como no G2. Tanto FSR, Uosm como $\mathrm{C}_{\mathrm{PAH}}$ apresentaram redução significativa no $\mathrm{M} 3$ em ambos os grupos e essa redução se manteve até o momento final. A análise dos resultados das lâminas demonstrou dilatação tubular em todos os cães, tanto do grupo controle (G1), quanto do grupo dexmedetomidina (G2). Dez lâminas dos cães do G1 e nove do G2 mostraram degeneração tubular, cinco lâminas do $G 1$ e seis do $G 2$ mostraram necrose, e finalmente, oito lâminas do $G 1$ e nove do $G 2$ demonstraram células inflamatórias. Conclui-se que a administração de dexmedetomidina não interferiu nos mecanismos de proteção renal, que envolvem HAD, das repercussões da isquemia-reperfusão em cães anestesiados.

Palavras-chave: Dexmedetomidina; vasopressina; isquemia renal em cães. 
Rocha MVN. Effects of dexmedetomidine on kidneys and vasopressine plasma concentration in anesthetized dogs submitted to renal ischemia. Experimental study in anesthetized dogs. Botucatu 2010.149p. Dissertação (Mestrado em Anestesiologia) - Faculdade de Medicina, Campus de Botucatu, Universidade Estadual Paulista "Júlio de Mesquita Filho".

\section{ABSTRACT}

Dexmedetomidine, like clonidine, would have potential for renal protection during ischemic events with consequent reduction of acute renal insufficiency incidence. The present study aimed to verify the hemodynamic effects and actions of dexmedetomidine on plasma concentration of vasopressine or antidiuretic hormone $(\mathrm{ADH})$ and its effectiveness in protecting the kidney from lesions related to ischemia-reperfusion event in dogs. Method: The experiment included twenty anesthetized dogs, submitted to right nephrectomy and left renal ischemia for 30 minutes with further reperfusion and renal histophatological study. There were observed possible morpho-functional alterations, besides renal repercussions and $\mathrm{ADH}$ plasmatic concentration by administration of dexmedetomidine $(2 \mu \mathrm{g} \cdot \mathrm{kg}-1)$. The following attributes were studied: heart rate, mean arterial pressure, pulmonary artery pressure, righit atrial pressure, pulmonary artery occlusion pressure, cardiac output, renal blood flow, renal vascular resistance; hematocrit, $\mathrm{Na}+\mathrm{K}+$, plasma osmolarity; depurations ( $\mathrm{PAH}$, creatinine, osmolar, free water, $\mathrm{Na}+\mathrm{K}+$ ) filtration fraction, urinary osmolarity and volume, urinary excretions and fractions of sodium and potassium; esophageal temperature and histopathological kidney exam. Attributes were researched at 5 moments: M1 - After the end of the stabilization period; M2 - After injection of solution in the study; M3 - After 15 min of renal artery unclamping (RAU) and 60 min of saline or dex infusion; M4 - After 30 min of RAU; M5 - After 45 minutes of RAU. Cardiac Index presented significant reduction at $\mathrm{M} 2$ of dexmedetomidine group when compared with initial moment. VRI presented significant increasing at M2 of G2 until the final moment. Diuresis presented G2>G1 at M5. ADH varied starting from M3, increasing at the other 
moments in both groups. The variables $\mathrm{C}_{\mathrm{Cr}}, \mathrm{C}_{\mathrm{K}}, \mathrm{C}_{\mathrm{Osm}}$ and $\mathrm{U}_{\mathrm{K}} \mathrm{V}$ presented significant reduction at $\mathrm{M} 3$ and returning to the initial values after reperfusion in both groups. The $\mathrm{C}_{\mathrm{H} 2 \mathrm{O}}$ presented significant elevation at $\mathrm{M} 3$ and this elevation held until M5, observed in groups 1 and 2. The variables $U_{\text {Osm, }} \mathrm{C}_{\mathrm{PAH}}$ and RBF presented significant reduction at $\mathrm{M} 3$ in both groups and this reduction held until the final moment. The blade analysis results presented tubular swelling in all dogs in both groups, $G 1$ and G2. Ten blades of the G1 dogs and nine of the G2 presented tubular degeneration, five blades of $\mathrm{G} 1$ and six of $\mathrm{G} 2$ presented necrosis and finally, eight blades of G1 and nine of G2 presented inflammatory cells. It is concluded that administration of dexmedetomidine did not interfere in mechanisms of renal protection that involve $A D H$, from repercussions of ischemia-reperfusion in anesthetized dogs.

Key-words: Dexmedetomidine, vasopressin and renal ischemia in dogs 


\section{INTRODUÇÃO E LITERATURA}

A isquemia renal seguida de reperfusão sanguínea pode causar insuficiência renal aguda temporária ou irreversível (De Broe et al., 2004), evento que pode implicar na necessidade de terapia renal substitutiva. Esta síndrome isquemia/reperfusão é ocorrência não rara em cirurgias urológicas ou vasculares onde se faz necessária obstrução temporária do fluxo na artéria renal e/ou aorta, ou então após manobras de ressucitação cardio-respiratórias com hipotensão sistêmica. Isquemia implica na interrupção do fluxo sanguíneo com depleção de oxigênio e nutrientes, manutenção do metabolismo anaeróbico e aumento de catabólitos. É comumente ter em mente que a natureza da lesão celular do túbulo renal na isquemia, inclui tanto a morte celular, irreversível (por necrose ou apoptose) quanto à lesão sub-letal, reversível, que causa disfunção celular (Bonventre et al., 2004; Brezis, 1993). A instalação de anóxia inicia uma seqüência de eventos lesivos para a célula, a começar pela interrupção da fosforilação oxidativa. Enquanto no metabolismo aeróbico formam-se 38 moléculas de adenosina tri-fosfato (ATP) por molécula de glicose, na glicólise anaeróbica são geradas apenas duas moléculas de ATP. Assim, a depleção do ATP renal é rápida (Jones, 1986; Weinberg et al., 1991). A redução das reservas de ATP gera pelo menos duas seqüelas, que são a disfunção das bombas de íons ATP-dependente $\left(\mathrm{Na}^{+} / \mathrm{K}^{+}\right.$-ATPase) na membrana celular e o aumento de hipoxantina, produto da degradação do ATP, que ao ser convertida em xantina através da enzima xantina oxidase, libera radicais superóxidos. A enzima superóxido dismutase converte estes radicais superóxidos em peróxido de hidrogênio, o qual é posteriormente convertido na mais reativa espécie de oxigênio, o radical hidroxila $(\mathrm{OH})$. As espécies reativas de oxigênio têm vários efeitos deletérios sobre as células, incluindo a oxidação lipídica, oxidação de proteínas celulares e lesão do DNA (Ichikawa et al., 1994)

A inibição funcional da $\mathrm{Na}^{+} / \mathrm{K}^{+}$-ATPase torna a célula incapaz de manter sua composição iônica, ocasionando a perda de potássio e magnésio intracelular, com acúmulo citoplasmático de sódio, cloreto e cálcio (Perdrizet, 1996). A perda da capacidade da membrana em regular o volume celular, 
resulta no aumento da água intracelular e edema, fato que contribui para a obstrução da luz dos túbulos renais com posterior aumento de pressão intraluminar, proporcionando um feedback tubuloglomerular com extravasamento do filtrado para o interstício renal (Mason, 1986),

A reperfusão, que consiste no restabelecimento do fluxo sanguíneo ao órgão isquêmico, deve ser considerada como situação à parte. Embora em modelos experimentais seja difícil separar a lesão provocada pela isquemia em si daquela que ocorre durante a reperfusão, sabe-se que esta separação é arbitrária e artificial, já que recuperação da isquemia é impossível se não ocorrer reperfusão. Segundo o paradoxo do oxigênio a célula não sobrevive sem adequada oxigenação, mas sofre quando, após privação, o suprimento de oxigênio é restabelecido (Bowers et al., 1993; Haimovic, 1990; Lond et al., 1996, Jassen et al., 1998; Perdrizet, 1996)

A insuficiência renal aguda per-operatória é responsável por metade das indicações de diálise aguda. Nos últimos anos houve avanços nos cuidados pré e per-operatórios, porém ainda não foi observada redução significativa destas complicações. Shroyer et al. (2003) em uma revisão observaram em 500.000 casos uma taxa de 3,53\% de insuficiência renal. Godet et al. (1997) relataram incidência de $25 \%$ de insuficiência renal aguda em 475 pacientes submetidos à cirurgia de aneurismectomia de aorta, dos quais $8 \%$ necessitaram de diálise.

A mortalidade em pacientes com insuficiência renal aguda ainda é muito alta, o que justifica as inúmeras pesquisas realizadas neste campo. Foi descrito por Chertow et al. (1998), mortalidade acima de 50\% dos pacientes com insuficiência renal aguda. Crawford et al. (1986) em um estudo com 605 pacientes submetidos a cirurgia de aneurismectomia tóraco-abdominal reportaram uma incidência de $6 \%$ de necessidade de hemodiálise e observaram que a falência renal pós-operatória estava associada a uma mortalidade significantemente maior. Svennson et al (1995) estudaram 1509 pacientes submetidos à aneurismectomia de aorta abdominal com incidência de $18 \%$ de falência renal, concluindo que este é um fator preditivo de mortalidade em 30 dias. 
Os fármacos agonistas alfa 2 -adrenérgicos têm sido capazes de reduzir a incidência de insuficiência renal aguda isquêmica. Solez et al. (1980) relataram que a clonidina foi capaz de diminuir a incidência e gravidade da insuficiência renal aguda em coelhos desidratados, submetidos à isquemia renal por meio de pinçamento da artéria renal esquerda e nefrectomia direita. $O$ grupo que recebeu clonidina apresentou maior depuração de creatinina, maior débito urinário, maior depuração de água livre e maior fluxo sanguíneo para região medular externa renal após alívio do pinçamento da artéria renal, quando comparado ao grupo controle. Em cães, a administração de clonidina venosa resultou em aumento da taxa de filtração glomerular (Strandhoy et al., 1982), e do fluxo sanguíneo para medula renal (Kover et al., 1989) e aumento do débito urinário.

Kulka et al. (1996) realizaram trabalho prospectivo randomizado, no qual compararam clonidina com placebo como medicação pré-anestésica em paciente submetidos à circulação extracorpórea. Estes autores observaram que no grupo que recebeu clonidina houve maior depuração de creatinina, após 12 $\mathrm{h}$ do término da cirurgia, sugerindo proteção renal.

A dexmedetomidina, enantiômetro dextrógiro da medetomidina, é um alfa-2 agonista mais seletivo que a clonidina, com relação de seletividade a2: a1 de 1620:1, contra 220:1 (Virtanen $\mathrm{R}$ et al., 1988) respectivamente. Em voluntários sadios, a dexmedetomidina decresce em até $90 \%$ a concentração plasmática de catecolaminas (Scheinin et al., 1987, Ebert et al., 2000). Talke et al. (2000) observaram em pacientes submetidos à cirurgia vascular, diminuição na freqüência cardíaca e níveis 2 a 3 vezes menores de noradrenalina no grupo que recebeu dexmedetomidina em comparação com o placebo.

Normalmente, a homeostase renal é mantida por meio de balanço perfeito entre as ações vasoconstritoras e vasodilatadoras das diversas substâncias produzidas local ou sistematicamente, entretanto, na isquemia, há quebra deste equilíbrio, com predomínio dos efeitos vasoconstritores, que se traduzem em elevação da resistência vascular renal, diminuição do ritmo de filtração gromerular, do fluxo sanguíneo renal e do volume urinário (Maddox e Brenner, 2000). 
As alterações urinárias provocadas pelos agentes alfa2-agonistas podem ser decorrentes da diminuição da resposta ao trauma, com diminuição das catecolaminas plasmáticas (Kulka et al., 1996), por sua ação sobre a diminuição da secreção do hormônio antidiurético (Peskind et al., 1987), e ação sobre a liberação de peptídeo natridiurético (Chenn et al,1989). Rouch et al. (1997) relataram em modelo experimental de túbulo coletor isolado de rato, que a dexmedetomidina inibiu a absorção de água mediada pelo hormônio antidiurético.

Villela et al. (2005) sugeriram que dexmedetomidina, assim como clonidina, apresentaria potencial para proteção renal durante eventos isquêmicos. Também refletiram sobre a necessidade de modelos experimentais para testar tal hipótese. 


\section{OBJETIVO}

Esta pesquisa teve como objetivo avaliar a capacidade da dexmedetomidina em minimizar os efeitos deletérios à isquemia-reperfusào renal, quando utilizada em cães anestesiados nas doses semelhantes às usadas na anestesiologia clínica, envolvendo principalmente os mecanismos do hormônio antidiurético. 


\section{MATERIAL E MÉTODO}

\subsection{Animais Utilizados}

Após aprovação do Comitê de Ética em Experimentação Animal, da Faculdade de Medicina de Botucatu, UNESP, foram utilizados 20 cães adultos, machos e fêmeas, sem raça definida, de pesos variados, fornecidos pelo Biotério do Campus de Botucatu da Universidade Estadual Paulista "Júlio de Mesquita Filho".

\subsection{Grupos Experimentais}

Foram criados dois grupos de estudo, que obedeceram ao critério de sorteio, de modo encoberto com dez animais em cada grupo.

Grupo 1-(G1) Formado por 10 cães em jejum alimentar de aproximadamente 14 horas, mas com livre acesso à água. Após pesagem, foram anestesiados com propofol (6 mg. $\mathrm{kg}^{-1}$ ) e citrato de fentanil $\left(5 \mu \mathrm{g} \cdot \mathrm{kg}^{-1}\right)$. Intubação orotraqueal e manutenção anestésica com brometo de rocurônio e isoflurano respectivamente, ventilação mecânica, monitorização ventilatória, hemodinâmica e da função renal. Logo após a indução e intubação traqueal, os cães foram submetidos à lombotomia direita para retirada do rim e lombotomia esquerda para canulização ureteral e clampeamento da artéria renal por 30 minutos. Todos os animais receberam injeção de $20 \mathrm{~mL}$ de solução de cloreto de sódio, em 10 minutos, seguida de injeção de $20 \mathrm{~mL}$ da mesma solução em 1 hora.

Grupo 2 - (G2) Neste grupo, os 10 cães foram submetidos aos mesmos procedimentos do grupo 1 , porém receberam $20 \mathrm{~mL}$ de 
solução de cloreto de sódio contendo dexmedetomidina 2 $\mu . \mathrm{kg}$ de peso corporal, em dez minutos, seguida de injeção de $20 \mathrm{~mL}$ da mesma solução em 1 hora.

\subsection{Seqüência Experimental}

3.3.1 Jejum alimentar de 12 horas, com livre acesso a água.

3.3.2 Pesagem do animal.

3.3.3 Indução da anestesia intravenosa com $\left(6 \mathrm{mg} \cdot \mathrm{kg}^{-1}\right)$ e fentanila $\left(5 \mu \mathrm{g} \cdot \mathrm{kg}^{-1}\right)$.

3.3.4 Posicionamento do animal na goteira de Claude Bernard.

3.3.5 Intubação orotraqueal e instalação de ventilação mecânica controlada com volume corrente de $20 \mathrm{~mL} . \mathrm{kg}^{-1}$ e freqüência respiratória de 12 a 16 ciclos. $\mathrm{min}^{-1}$, com o objetivo de manter a pressão expiratória final de $\mathrm{CO}_{2}$ $\left(\mathrm{P}_{\mathrm{ET}} \mathrm{CO}_{2}\right)$ entre 35 a $45 \mathrm{mmHg}$. A manutenção foi feita com isoflurano, 1,7 CAM (concentração alveolar mínima) durante o preparo cirúrgico do animal e, após infiltração das feridas cirúrgicas com ropivacaína a $0,2 \%$, reduzida para 0,6 CAM até o final do experimento, utilizando-se vaporizador calibrado específico da Ohmeda, com monitorização da fração inspirada e expirada do anestésico e de $\mathrm{O}_{2}$, através de módulo de análise de gases e agentes halogenados.

3.3.6 Instalação do biomonitor AS 3 da Datex-Engstrom para leitura e registro dos parâmetros ventilatórios, hemodinâmicos e de temperatura.

3.3.7 Medida da distância entre a extremidade do focinho e o ânus, pela superfície ventral, para determinação do comprimento animal.

3.3.8 Instalação do eletrocardiógrafo de três canais (derivação DII), do sensor do termômetro no terço inferior do esôfago, do captor da amostra de gases inspirados e expirados junto à válvula em $\mathrm{Y}$ do circuito respiratório, para análise da $\mathrm{P}_{\mathrm{ET}} \mathrm{CO}_{2}$ e de sensor do oxímetro de pulso $\left(\mathrm{SpO}_{2}\right)$, colocado na língua do animal.

3.3.9 Dissecção e cateterismo da veia femoral esquerda com cateter de polietileno PE 240 e início da injeção contínua da solução de Ringer com lactato $\left(18 \mathrm{~mL} \cdot \mathrm{kg}^{-1} \cdot \mathrm{h}^{-1}\right)$ e administração de brometo de rocurônio na 
dose inicial de 0,6 mg.kg-1 seguida de injeção contínua de $10 \mu \mathrm{g} \cdot \mathrm{kg}^{-1} \cdot \mathrm{min}^{-1}$, utilizando-se bomba de infusão.

3.3.10 Dissecção e cateterismo da artéria femoral esquerda com cateter de polietileno PE 240 para medida contínua da pressão arterial média.

3.3.11 Dissecção e cateterismo da veia femoral direita para coleta de sangue para dosagens plasmáticas de para-aminopurato de sódio, creatinina, sódio, potássio, hematócrito, hormônio antidiurético e osmolaridade.

3.3.12 Dissecção e cateterismo da veia jugular externa direita para passagem do introdutor 8,5 e passagem de cateter de Swan Ganz 7 F, até a artéria pulmonar, para medida do débito cardíaco por termodiluição e da medida da pressão do átrio direito (PAD).

3.3.13 Lombotomia direita.

3.3.14 Nefrectomia direita.

3.3.15 Lombotomia esquerda.

3.3.16 Exposição da artéria renal esquerda para posterior colocação do clamp vascular atraumático pemanecendo aberto até 0 momento do clampeamento.

3.3.17 Cateterização do ureter esquerdo.

3.3.18 Diminuição da CAM de isoflurano de 1,7 para 0,6.

3.3.19 Após trinta minutos da solução de Ringer, injeção da solução prime de para-aminohipurato de sódio (PAH) e creatinina, e, a seguir, infusão contínua da solução de PAH e creatinina.

3.3.20 Fim do período de preparação cirúrgica.

3.3.21 Início do período de estabilização hemodinâmica com duração de 30 minutos.

3.3.22 Ao término do período de estabilização, inicia-se o primeiro momento (M1) de depuração do experimento, com duração de 15 minutos.

3.3.23 Coleta de sangue venoso e determinação da freqüência cardíaca $(F C)$, pressão arterial média (PAM), pressão atrial $D(P A D)$, pressão da artéria pulmonar (PAP), pressão de oclusão da artéria pulmonar (POAP), débito cardíaco (DC), saturação de oxigênio com oximetria de pulso $\left(\mathrm{SpO}_{2}\right)$, dióxido de carbono expirado $\left(\mathrm{P}_{\mathrm{ET}} \mathrm{CO}_{2}\right)$, e temperatura esofageana. 
3.3.24 Estudo da função renal: esvaziamento vesical imediatamente antes do início do momento de estudo, coleta de urina por 15 minutos, esvaziamento vesical e determinação do volume urinário ao fim do período.

3.3.25 Injeção da solução de dexmedetomidina ou cloreto de sódio a 0,9\% em 10 minutos, seguida da administração dessa mesma solução, conforme o grupo estudado, durante 1 hora.

3.3.26 Ao término da injeção da primeira solução, com duração de 10 minutos, inicia-se o segundo momento do experimento (M2), com duração de 15 minutos.

3.3.27 Coleta de sangue venoso e determinação da freqüência cardíaca $(F C)$, pressão arterial média (PAM), pressão atrial $D(P A D)$, pressão da artéria pulmonar (PAP), pressão de oclusão da artéria pulmonar (POAP), débito cardíaco (DC), saturação de oxigênio com oximetria de pulso $\left(\mathrm{SpO}_{2}\right)$, dióxido de carbono expirado $\left(\mathrm{P}_{\mathrm{ET}} \mathrm{CO}_{2}\right)$, e temperatura esofageana.

3.3.28 Estudo da função renal: esvaziamento vesical imediatamente antes do início do momento de estudo, coleta de urina por 15 minutos, esvaziamento vesical e determinação do volume urinário ao fim do período.

3.3.29 Clampeamento da artéria renal esquerda, em ambos os grupos, por um período de 30 minutos, imediatamente após o término do segundo momento (M2) de depuração.

3.3.30 Desclampeamento da artéria renal esquerda.

3.3.31 Imediatamente após o desclampeamento da artéria renal esquerda, inicia-se o terceiro momento (M3) do experimento, com 15 minutos de duração.

3.3.32 Coleta de sangue venoso e determinação da pressão arterial média (PAM), pressão atrial $D(P A D)$, freqüência cardíaca $(F C)$, pressão arterial média (PAM), pressão atrial $D(P A D)$, pressão da artéria pulmonar (PAP), pressão de oclusão da artéria pulmonar (POAP), débito cardíaco (DC), saturação de oxigênio com oximetria de pulso $\left(\mathrm{SpO}_{2}\right)$, dióxido de carbono expirado $\left(\mathrm{P}_{\mathrm{ET}} \mathrm{CO}_{2}\right)$, e temperatura esofageana. 
3.3.33 Estudo da função renal: esvaziamento vesical imediatamente antes do início do momento de estudo, coleta de urina por 15 minutos, esvaziamento vesical e determinação do volume urinário ao fim do período.

3.3.34 Imediatamente após o fim da infusão da solução de dexmedetomidina, coincidindo com fim do terceiro momento (M3) do experimento e 30 minutos após o desclampeamento da artéria renal esquerda, inicia-se 0 quarto momento (M4) do experimento, com 15 minutos de duração.

3.3.35 Coleta de sangue venoso e determinação da freqüência cardíaca (FC), pressão arterial média (PAM), pressão atrial $D(P A D)$, pressão da artéria pulmonar (PAP), pressão de oclusão da artéria pulmonar (POAP), débito cardíaco (DC), saturação de oxigênio com oximetria de pulso $\left(\mathrm{SpO}_{2}\right)$, dióxido de carbono expirado $\left(\mathrm{P}_{\mathrm{ET}} \mathrm{CO}_{2}\right)$, e temperatura esofageana.

3.3.36 Estudo da função renal: esvaziamento vesical imediatamente antes do início do momento de estudo, coleta de urina por 15 minutos, esvaziamento vesical e determinação do volume urinário ao fim do período.

3.3.37 Após quarenta e cinco minutos do desclampeamento da artéria renal esquerda, inicia-se o quinto momento do experimento.

3.3.38 Coleta de sangue venoso e determinação da freqüência cardíaca $(F C)$, pressão arterial média (PAM), pressão atrial $D(P A D)$, pressão da artéria pulmonar (PAP), pressão de oclusão da artéria pulmonar (POAP), débito cardíaco (DC), saturação de oxigênio com oximetria de pulso $\left(\mathrm{SpO}_{2}\right)$, dióxido de carbono expirado $\left(\mathrm{P}_{\mathrm{ET}} \mathrm{CO}_{2}\right)$, e temperatura esofageana.

3.3.39 Estudo da função renal: esvaziamento vesical imediatamente antes do início do momento de estudo, coleta de urina por 15 minutos, esvaziamento vesical e determinação do volume urinário ao fim do período.

3.3.40 Retirada do rim para estudo histopatológico.

3.3.41 Sacrifício do animal por sobre dose anestésica. 


\subsection{Atributos Estudados}

\subsubsection{Atributos Demográficos}

a) Comprimento do animal $(\mathrm{cm})$

b) Peso do animal (kg)

c) Superfécie corporal $\left(\mathrm{m}^{2}\right)$

d) Sexo do animal

\subsubsection{Atributos Hemodinâmicos}
a) Freqüência cardíaca (FC)
b) Pressão arterial média (PAM)
c) Pressão atrial direito (PAD)
d) Índice cardíaco (IC)
e) Índice de resistência vascular sistêmica(IRVS)

\subsubsection{Atributos Renais}
a) Débito urinário (DU)
b) Osmolaridade urinária (Uosm)
c) Depuração para-aminohipurato de sódio ( $\left.\mathrm{C}_{\mathrm{PAH}}\right)$
d) Depuração de creatinina $\left(\mathrm{C}_{\mathrm{Cr}}\right)$
e) Fração de Filtração (FF)
f) Depuração osmolar (Cosm)
g) Depuração de água livre $\left(\mathrm{C}_{\mathrm{H} 2 \mathrm{O}}\right)$
h) Excreção urinária de sódio $\left(U_{\mathrm{Na}} \mathrm{V}\right)$
i) Depuração de sódio $\left(\mathrm{C}_{\mathrm{Na}}\right)$
j) Excreção fracionária de sódio $\left(E F_{\mathrm{Na}}\right)$
k) Excreção urinária de potássio $\left(U_{k} V\right)$
l) Depuração de potássio( $\left(C_{k}\right)$
m) Excreção fracionária de potássio $\left(E_{k}\right)$
n) Fluxo sanguíneo renal (FSR)
o) Resistência vascular renal (RVR) 


\subsubsection{Atributos Ventilatórios e de Oxigenação}

a) Pressão expiratória final de $\mathrm{CO}_{2}\left(\mathrm{P}_{\mathrm{ET}} \mathrm{CO}_{2}\right)$

b) Saturação de pulso de oxigênio $\left(\mathrm{SpO}_{2}\right)$

\subsubsection{Temperatura}

a) Temperatura esofágica $(T)$

\subsubsection{Sanguíneos}

a) Hematócrito (HT)

b) Potássio plasmático (K)

c) Sódio plasmático $(\mathrm{Na})$

d) Osmolaridade plasmática ( $\left.\mathrm{P}_{\mathrm{Osm}}\right)$

e) Hormônio antidiurético (HAD)

\subsection{Momentos Estudados}

Os dados relativos aos atributos estudados (figura 1) foram obtidos nos seguintes momentos, com 15 minutos de duração cada um:

M1 - Após o término do período de estabilização hemodinâmica.

M2 - Após 15 min do início da infusão em estudo.

M3 - Após 15 minutos do despinçamento arterial renal e 60 min da infusão em estudo.

M4 - Após 30 minutos do despinçamento arterial renal.

M5 - Após 45 minutos do despinçamento arterial renal. 


\section{Seqüência experimental:}

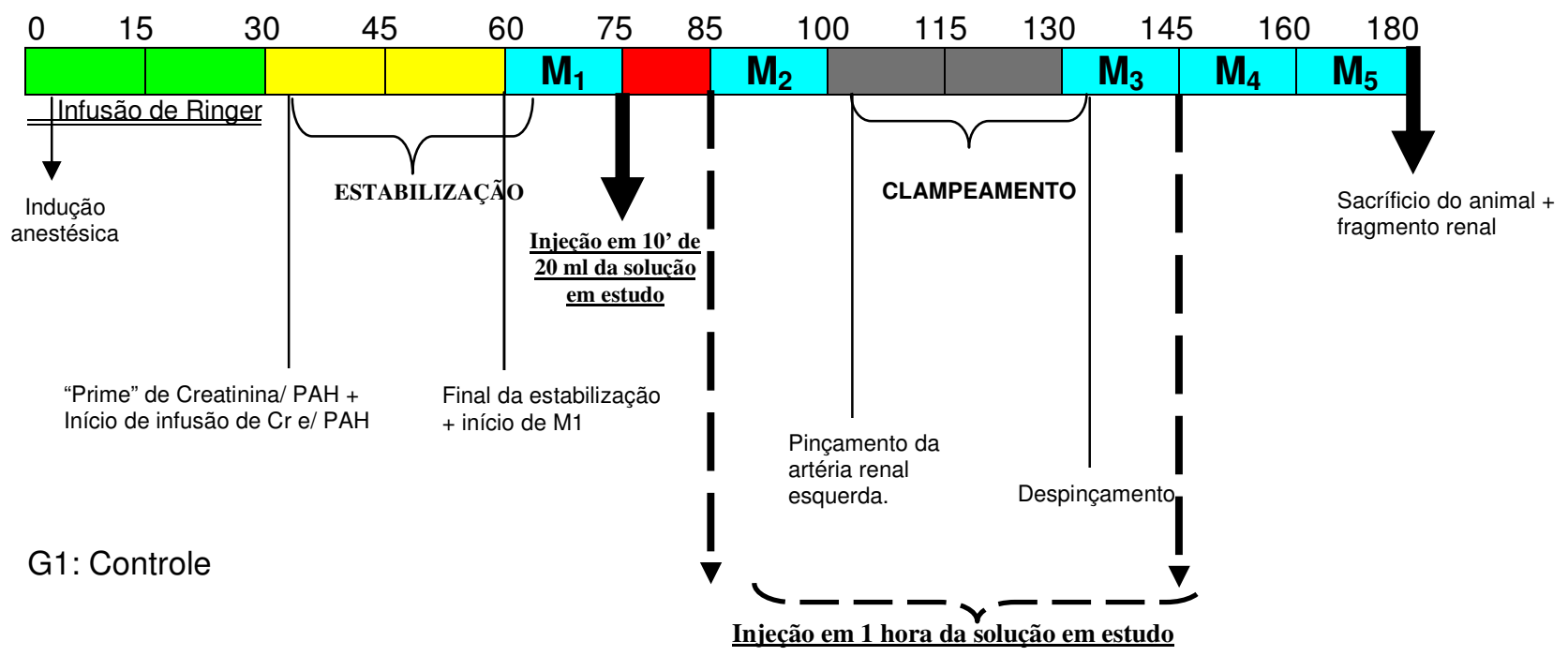

G2: Dexmedetomidina $2 \mu \mathrm{g} \cdot \mathrm{kg}^{-1}$

Figura 1. Esquema da seqüência experimental.

\subsection{Técnicas Utilizadas}

\subsubsection{Preparo do animal}

a) Após período de jejum de 14 horas, porém com livre acesso à água, os cães foram anestesiados com injeção intravenosa de propofol, na dose de 6 $\mathrm{mg} \cdot \mathrm{kg}^{-1}$, citrato de fentanil, na dose de $5 \mu \mathrm{g} \cdot \mathrm{kg}^{-1}$ de peso corporal, e colocados em decúbito dorsal horizontal sobre a goteira de Claude Bernard. Foi realizada intubação traqueal mediante laringoscopia direta, utilizando-se tubo traqueal com balonete de baixa pressão e alta complacência, com diâmetro interno de 8,5-9,0 mm. Iniciou-se ventilação mecânica controlada, ciclada a volume, com ar comprimido $\left(1,2 \mathrm{~L}\right.$. $\left.\mathrm{min}^{-1}\right)$ e oxigênio $\left(0,8 \mathrm{~L}\right.$. $\left.\mathrm{min}^{-1}\right)$. Para este fim foi empregado o aparelho de anestesia Ohmeda, modelo Excel 210 SE (EUA), com ventilador Ohmeda 7900(Finlândia). A ventilação foi realizada com fração inspirada de oxigênio de $40 \%$, volume corrente de 20 mL. $\mathrm{kg}^{-1}$ de peso corporal e freqüência respiratória de 12 a 16 movimentos por minutos, monitorada pelo módulo de ventilação do aparelho MS 3 da Datex-Engstrom (Finlândia) para manter a $\mathrm{P}_{\mathrm{ET}} \mathrm{CO}_{2}$ entre 35 e 45 
$\mathrm{mmHg}$. A inalação do isoflurano foi feita pelo uso de vaporizador calibrado, específico para esse agente halogenado, da Ohmeda (EUA). As concentrações inspiradas e expiradas do isoflurano, $\mathrm{O}_{2}$ e $\mathrm{CO}_{2}$ foram monitoradas pelo módulo de Analisador de Gases do aparelho MS 3 da Datex-Engstrom (Finlândia).

b) Foram realizados disseccção e cateterismo das veias femorais direita e esquerda e da artéria femoral esquerda, as quais foram cateterizadas com cateter de polietileno PE 240. Dissecção e cateterismo da veia jugular externa direita para passagem do introdutor 8,5 e passagem do cateter de Swan Ganz 7F até a artéria pulmonar, para medida do débito cardíaco por termodiluição e da pressão do átrio direito (PAD). Pelo cateter da veia femoral direita foram administradas soluções de Ringer, na velocidade de $18 \mathrm{~mL} . \mathrm{kg}^{-1} \cdot \mathrm{h}^{-1}$ e de PAH e creatinina durante todo o experimento. Nesta mesma via foi administrado brometo de rocurônio na dose inical de 0,6 mg.kg ${ }^{-1}$, seguido de injeção contínua de $10 \mu \mathrm{g} \cdot \mathrm{kg} \cdot \mathrm{min}^{-1}$, utilizando-se bomba de infusão.

A artéria femoral esquerda foi utilizada para mensuração da pressão arterial média, sendo ligada ao transdutor de pressão conectado ao aparelho Datex-Engstrom AS/3 tipo D-VCN (Finlândia). Por esta artéria, também foi colhida amostra de sangue para gasometria. O cateter da veia femoral esquerda foi utilizado para coleta de sangue. A reposição do sangue para as amostras foi feita com igual volume da solução de Ringer heparinizada, que também lavou os cateteres.

c) Após tricotomia da região, foi realizada lombotomia à direita para nefrectomia e lombotomia à esquerda para cateterização do ureter e dissecção do pedículo renal, para exposição da artéria renal esquerda e passagem de um clamp vascular não-traumático, o qual permaneceu aberto até o momento da ligadura da artéria renal dos cães por 30 minutos. $O$ cateterismo ureteral, por sua vez, foi realizado com sonda de polivinil de número 6 ou 8 , a depender do calibre do ureter. 


\subsubsection{Administração de Líquidos e Soluções}

A hidratação dos animais foi realizada pela veia femoral esquerda com solução de Ringer com lactato, a um fluxo de injeção de $18 \mathrm{~mL} \cdot \mathrm{kg}^{-1} \cdot \mathrm{h}^{-1}$, até o término do preparo cirúrgico, que teve duração de cerca de 15 minutos. Em seguida, foi injetado o "prime" de creatinina $\left(30 \mathrm{mg}^{-1} \mathrm{~kg}^{-1}\right)$ e para-aminohipurato de sódio (4 mg. $\left.\mathrm{kg}^{-1}\right)$, sendo que foi mantida a hidratação, até o final do experimento, com solução de creatinina a 0,6\% e de PAH a 0,24\% em Ringer com lactato a um fluxo de injeção de $6 \mathrm{~mL} \cdot \mathrm{kg}^{-1} \cdot \mathrm{h}^{-1}$, equivalendo à administração de $0,6 \mathrm{mg} \cdot \mathrm{kg}^{-1} \cdot \mathrm{min}^{-1}$ de creatinina e de $0,24 \mathrm{mg} \cdot \mathrm{kg}^{-1} \cdot \mathrm{min}^{-1}$ de $\mathrm{PAH}$, utilizando-se bomba de injeção Santronic.

\subsubsection{Medidas dos Atributos Estudados}

a) Durante o experimento, para medida e registro da freqüência cardíaca, PAM e da PAD, foi utilizado o módulo específico do aparelho MS 3 da DatexEngstrom (Finlândia).

b) Medidas do débito cardíaco foram realizadas pela técnica de termodiluição, sendo que foi considerada a média de três medidas subseqüentes, empregando-se o módulo de débito cardíaco do aparelho MS 3 da DatexEngstrom (Finlândia), utilizando-se soro fisiológico gelado como indicador, no volume de $10 \mathrm{~mL}$ através de cateter de Swan-Ganz.

c) Medidas da saturação de pulso de oxigênio $\left(\mathrm{SpO}_{2}\right)$ e da pressão expirada final de dióxido de carbono $\left(\mathrm{P}_{\mathrm{ET}} \mathrm{CO}_{2}\right)$, que foi obtida pela análise de amostra do ar expirado junto à válvula em y do circuito respiratório, sendo que foram empregados módulos específicos do aparelho MS 3 da Datex-Engstrom (Finlândia), para medidas e registros desses atributos.

d) A medida e o registro da temperatura esofageana foram obtidos por sensor apropriado, posicionado no terço inferior do esôfago, acoplado ao módulo específico do aparelho MS 3 da Datex-Engstrom (Finlândia).

e) A medida do hematócrito foi realizada no sangue coletado do cateter instalado na veia femoral direita, em dois tubos capilares, sendo levados à microcentrífuga Centremico da Fanem (Brasil), por 5 minutos, onde a leitura 
foi realizada com a régua marca Celm e a unidade expressa em porcentagem.

f) Medida de depuração: na metade do período de depuração foram colhidos $10 \mathrm{~mL}$ de sangue da veia femoral direita, em tubos de centrífuga contendo duas gotas de heparina cada um. Durante cada período de depuração, com 15 minutos de duração a urina foi coletada em provetas graduadas.

g) Para dosagem plasmática do hormônio antidiurético foram coletados $5 \mathrm{ml}$ de sangue da veia femoral direita em tubos com 2 gotas de heparina, centrifugados a em centrífuga refrigerada Eppendorf 580R (USA) a 4 graus $\mathrm{C}$, separado o plasma e mantido congelado a -20 graus $\mathrm{C}$, até realização da dosagem do hormônio antidiurético.

h) Exame Histopatológico: no início do experimento, imediatamente após a nefrectomia direita, foram retirados fragmentos para microscopia de luz.

No término do experimento, o rim esquerdo foi retirado, separando-se fragmentos para exame histopatológicos. Para microscopia de luz, um fragmento de cada rim foi colocado em formol a 10\%, após fixação por no mínimo 24 horas, os fragmentos foram desidratados em etanol absoluto $(99,5 \%)$, diafanizados em xilol, embebidos e incluídos em parafina. Foram feitos cortes de $3 \mu \mathrm{m}$ e corados com hematoxilina-eosina (HE), ácido periódico de Schiff (PAS), tricrômico de Masson e ácido periódico de methenamina-prata (PAMS).Os cortes histológicos foram examinados pela seguinte seqüência: glomérulos, vasos, túbulos e interstício.

\subsubsection{Sacrifício do Animal}

Terminado o experimento o animal foi sacrificado com sobredose anestésica.

\subsection{Métodos Utilizados}

a) Hematócrito

O hematócrito foi determinado pelo método de micro-hematócrito (Wintrobe, 1967), utilizando-se o aparelho Centremicro da Fanem (Brasil). 
b) Para-aminohipurato (PAH)

Para dosagem do PAH foi utilizado o método descrito por Malnic (1986), empregando-se o espectofotômetro 20 Genesys da Spectronic Instruments (USA).

c) Creatinina

A dosagem foi realizada segundo o método proposto pro Schock e Camarra (1957) e adotado por Malnic (1986), utilizando-se o espectofotômetro 20 Genesys da Spectronic Instruments (USA).

d) Sódio e Potássio

Para a dosagem do sódio e potássio plasmáticos e urinários foi empregado o aparelho Analisador de Eletrólitos 9180 da AVL Instruments (USA).

e) Osmolalidade Urinária e Plasmática

Na determinação da osmolalidade plasmática e urinária, foi utilizado o osmômetro Osmette II da precision System (USA), que se baseia no método de diminuição de ponto de congelamento (Bowman et al., 1954), sendo expresso o resultado em mOsm. $\mathrm{kg}^{-1}$ de $\mathrm{h}_{2} \mathrm{O}$.

f) Dosagem Plasmática do Hormônio Antidiurético

A dosagem plasmática do hormônio antidiurético foi realizada através da técnica de radioimunoensaio.

\subsection{Fórmulas Empregadas}

Os atributos que não foram determinados diretamente, foram obtidos por meio das fórmulas a seguir:

\section{a) Índice Cardíaco}

$I C=D C / S C$ 
IC=Índice Cardíaco

DC=Débito Cardíaco

SC=Superfície Corpórea

b) Índice de Resistência Vascular Sistêmica (IRVS)

IRVS $=[(P A M-P A D) / I C] \times 79,92$

IRVS=Índice de resistência vascular sistêmica (dina.s. $\mathrm{cm}^{-5} \cdot \mathrm{m}^{-2}$ )

PAM=Pressão arterial média

$P A D=$ Pressão do átrio direito $(\mathrm{mmHg})$

IC=Índice Cardíaco (L. $\left.\mathrm{min}^{-1} \cdot \mathrm{m}^{2}\right)$

c) Depuração (D)

$\mathrm{D}=(\mathrm{U} \times \mathrm{V}) / \mathrm{P}$

$\mathrm{D}=$ Depuração $\left(\mathrm{mL} \cdot \mathrm{min}^{-1}\right)$

$\mathrm{U}=$ Concentração da substância na urina $\left(\mathrm{mg} \cdot \mathrm{mL}^{-1}\right)$

$\mathrm{V}=$ Volume urinário $\left(\mathrm{mL} \cdot \mathrm{min}^{-1}\right)$

$\mathrm{P}=$ Concentração da substância no plasma $\left(\mathrm{mg} \cdot \mathrm{mL}^{-1}\right)$

\section{d) Depuração Osmolar (Dosm)}

Dosm $=($ Uosm $\times$ V) $/$ Posm

Dosm=Depuração Osmolar $\left(\mathrm{mL} \cdot \mathrm{min}^{-1}\right)$

$\mathrm{V}=$ Volume urinário $\left(\mathrm{mL} \cdot \mathrm{min}^{-1}\right)$

Uosm=Osmolalidade urinária (mOsm.kg de $\mathrm{H}_{2} \mathrm{O}^{-1}$ )

Posm=Osmolalidade plasmática (mOsm.kg.de $\mathrm{H}_{2} \mathrm{O}^{-1}$ )

\section{e) Depuração de Água Livre $\left(\mathrm{DH}_{2} \mathrm{O}\right)$}

$\mathrm{DH}_{2} \mathrm{O}=\mathrm{V}$-Dosm

$\mathrm{DH}_{2} \mathrm{O}=$ Depuração de água livre $\left(\mathrm{mL} \cdot \mathrm{min}^{-1}\right)$

$\mathrm{V}=$ Volume urinário $\left(\mathrm{mL} \cdot \mathrm{min}^{-1}\right)$

Dosm=Depuração osmolar $\left(\mathrm{mL} \cdot \mathrm{min}^{-1}\right)$ 
f) Fração de Filtração (FF)

$\mathrm{FF}=\mathrm{DCr} / \mathrm{DPAH}$

$\mathrm{FF}=F$ ração de filtração

Dcr=Depuração de creatinina $\left(\mathrm{mL} \cdot \mathrm{min}^{-1}\right)$

DPAH=Depuração de para-aminohipurato de sódio $\left(\mathrm{mL} \cdot \mathrm{min}^{-1}\right)$

\section{g) Excreção Fracionária (EF)}

$E F=D \times 100 / D C r$

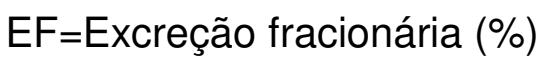

$\mathrm{D}=$ Depuração do eletrólito $\left(\mathrm{mL} \cdot \mathrm{min}^{-1}\right)$

$\mathrm{DCr}=$ Depuração de creatinina $\left(\mathrm{mL} \cdot \mathrm{min}^{-1}\right)$

\section{h) Excreção Urinária ( $\mu$ Eq. min $\left.^{-1}\right)$}

$\mathrm{EU}=\mathrm{U} \times \mathrm{V}$

$\mathrm{EU}=\mathrm{Excreção} \mathrm{urinária}\left(\mu \mathrm{Eq} \cdot \mathrm{min}^{-1}\right)$

$\mathrm{U}=$ Concentração do eletrólito na urina $\left(\mu \mathrm{Eq} \cdot \mathrm{min}^{-1}\right)$

$\mathrm{V}=$ Volume urinário $\left(\mathrm{mL} \cdot \mathrm{min}^{-1}\right)$

\section{i) Fluxo Sanguíneo Renal}

$\mathrm{FSR}=\mathrm{DPAH} / 1-\mathrm{Ht}$

FSR=Fluxo sanguíneo renal $\left(\mathrm{mL} \cdot \mathrm{min}^{-1}\right)$

DPAH=Depuração de para-aminohipurato de sódio $\left(\mathrm{mL} \cdot \mathrm{min}^{-1}\right)$

$\mathrm{Ht}=$ Hematócrito $(\%)$

\section{j) Resistência Vascular Renal (RVR)}

$\mathrm{RVR}=\mathrm{PAM} / \mathrm{FSR}$

$\mathrm{RVR}=$ Resistência vascular renal $\left(\mathrm{mmHg} \cdot \mathrm{mL}^{-1} \cdot \mathrm{min}^{-1}\right)$

PAM=Pressão arterial média $(\mathrm{mmHg})$

FSR=Fluxo sanguíneo renal $\left(\mathrm{mL} \cdot \mathrm{min}^{-1}\right)$

\section{k) Superfície Corporal (BSA)}

Obtida através da equação proposta por du Bois: 
BSA=Compr. $\times 0,725 \times \mathrm{P} \times 0,425 \times 0,007184$

Compr.=Comprimento do cão $(\mathrm{cm})$

$\mathrm{P}=$ peso $(\mathrm{kg})$

\subsection{Método Estatístico}

Foi utilizada a análise de perfil (MORRISON, 1967) para cada variável, com os testes das hipóteses seguintes.

$\mathrm{Ho}_{1}$ Interação entre grupos e momentos. Esta hipótese verifica se os perfis dos três grupos podem ser considerados similares

$\mathrm{Ho}_{2}$ Diferença entre os perfis. Esta hipótese verifica se os grupos, no caso de serem similares, diferem entre si no conjunto dos cincos momentos.

$\mathrm{Ho}_{3}$ Diferença entre momentos. Esta hipótese verifica se, no caso de os perfis serem aceitos como similares, existe diferença entre as médias dos momentos para o conjunto dos três grupos. Diferença entre grupos, em cada um dos momentos, separadamente. Diferença entre momentos, em cada um dos grupos, separadamente.

Em todas as análises estatísticas $\mathbf{P}$, fixou-se em 0,05 ou $5 \%(\alpha<$ ou $=0,05)$ o nível de rejeição da hipótese de nulidade, assinalando-se com um asterisco os valores significantes.

Os contrastes entre médias de grupos foram verificados calculandose a diferença mínima significativa, para $\alpha=0,05$, pelo método de TUKEY. 


\section{RESULTADOS}

\subsection{Peso dos Cães}

Tabela 1. Peso (kg). Média e desvio padrão dos valores obtidos em cada grupo experimental

\begin{tabular}{lrr}
\hline Grupo & Média & \multicolumn{1}{l}{ DP } \\
\hline G1 & 21,40 & 4.65 \\
\hline G2 & 18,40 & 2.84 \\
\hline
\end{tabular}

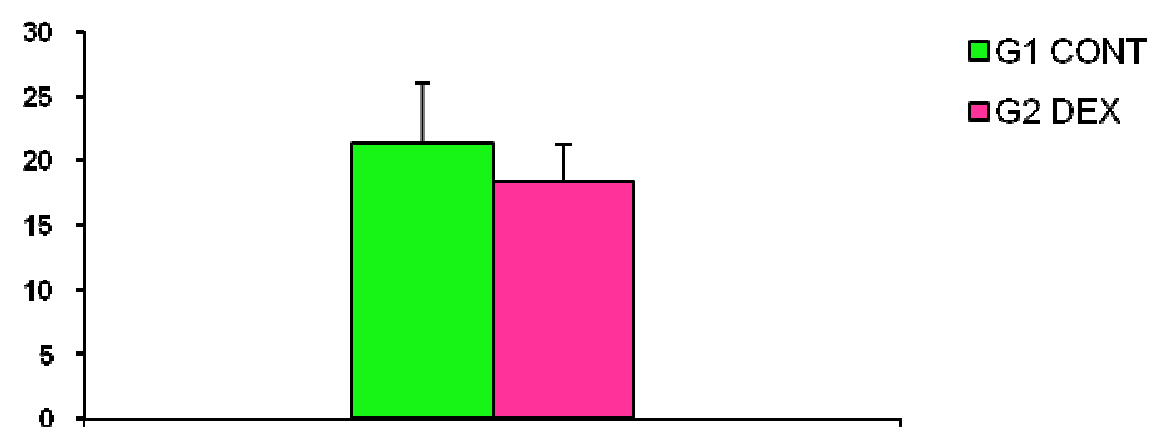

Figura 2. Peso dos cães. Média e desvio padrão dos valores obtidos nos dois grupos estudados.

Quadro 1. Peso dos cães. Hipótese testada e comentários

\begin{tabular}{l|l|l}
\hline Hipótese & Estatística & Comentários \\
Diferença entre os grupos & $p>0,05$ & $\mathrm{G} 1=\mathrm{G} 2$ \\
\hline
\end{tabular}

Comentários gerais: na tabela 1 e figura 2 houve distribuição normal. Portanto, foram utilizados média e desvio padrão, como parâmetros estatísticos. Os testes das hipóteses, previamente estabelecidas, demonstraram que não houve alteração significativa do peso entre os grupos. 


\subsection{Comprimento dos cães}

Tabela 2. Comprimento dos cães $(\mathrm{cm})$. Média e desvio padrão dos valores obtidos em cada grupo experimental

\begin{tabular}{lrr}
\hline Grupo & Média & \multicolumn{1}{l}{ DP } \\
\hline G1 & 102,50 & 9.13 \\
\hline G2 & 93,15 & 15,22 \\
\hline
\end{tabular}

\section{Comprimento dos cães}

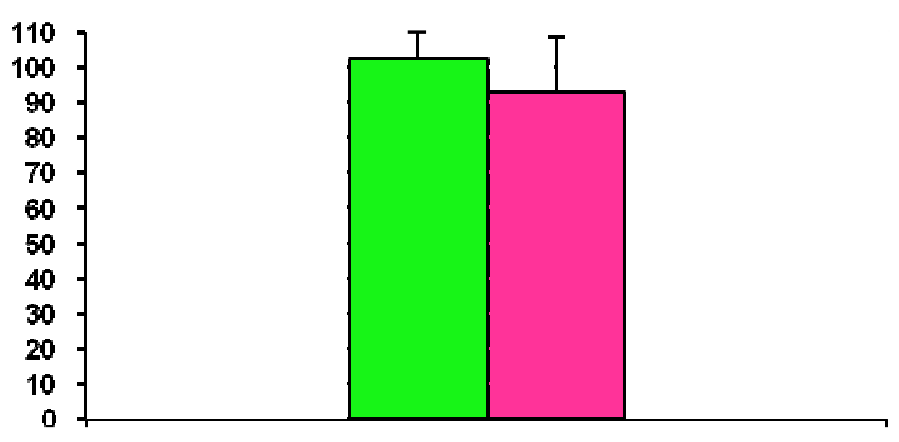

Figura 3. Comprimento dos cães. Média e desvio padrão dos valores obtidos nos dois grupos estudados.

Quadro 2. Comprimento dos cães. Hipótese testada e comentários

\begin{tabular}{l|l|l}
\hline Hipótese & $\begin{array}{l}\text { Estatística } \\
p>0,05\end{array}$ & $\begin{array}{l}\text { Comentários } \\
\text { Diferença entre os grupos }\end{array}$ \\
\hline
\end{tabular}

Comentários gerais: na tabela 2 e figura 3 houve distribuição normal. Portanto, foram utilizados média e desvio padrão, como parâmetros estatísticos. Os testes das hipóteses, previamente estabelecidas, demonstraram que não houve alteração significativa do comprimento entre os grupos. 


\subsection{Sexo}

Tabela 3. Proporção de machos e fêmeas nos dois grupos experimentais

\begin{tabular}{ccc}
\hline Grupos & \multicolumn{2}{c}{ Sexo } \\
\cline { 2 - 3 } & Macho & Fêmea \\
\hline G1 & 5 & 5 \\
G2 & 4 & 6 \\
\hline
\end{tabular}

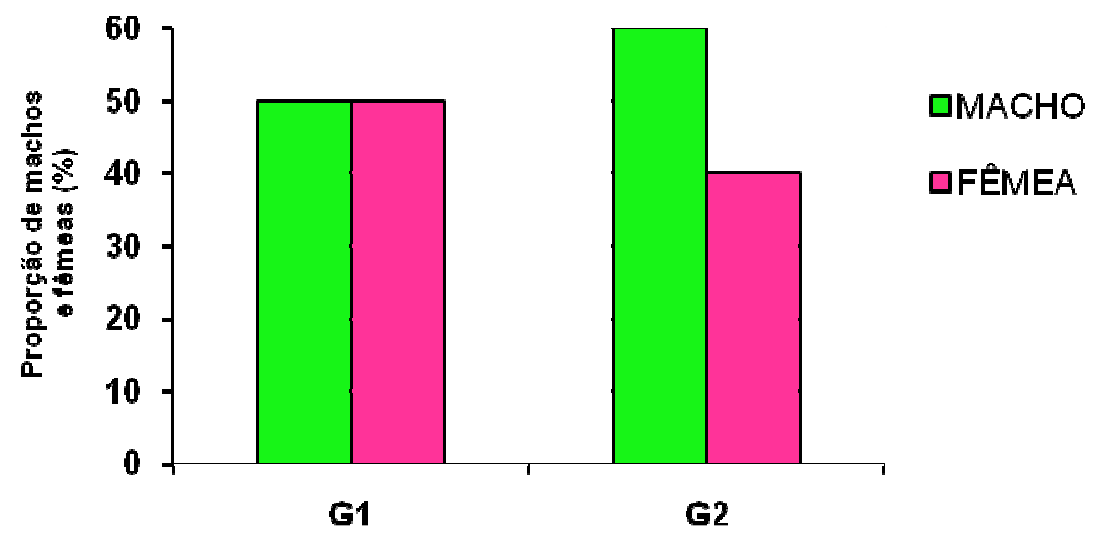

Figura 4. Proporção de machos e fêmeas nos dois grupos estudados.

Quadro 3. Proporção de machos e fêmeas. Hipótese testada e comentários

\begin{tabular}{l|l|l}
\hline Hipótese & Estatística & Comentários \\
Diferença entre os grupos & $p>0,05$ & $G 1=G 2$ \\
\hline
\end{tabular}

Comentários gerais: na tabela 3 e figura 4 houve distribuição normal. Portanto, foram utilizados média e desvio padrão, como parâmetros estatísticos. Os testes das hipóteses, previamente estabelecidas, demonstraram que não houve alteração significativa do sexo entre os grupos 


\subsection{Superfície Corporal}

Tabela 4. Superfície corporal dos cães $\left(\mathrm{m}^{2}\right)$. Média e desvio padrão dos valores obtidos em cada grupo experimental

\begin{tabular}{c|c}
\hline Grupo & Superfície Corporal $\left(\mathbf{m}^{2}\right)$ \\
\hline G1 & $0.75 \pm 0.11$ \\
\hline G2 & $0.66 \pm 0.10$ \\
\hline
\end{tabular}

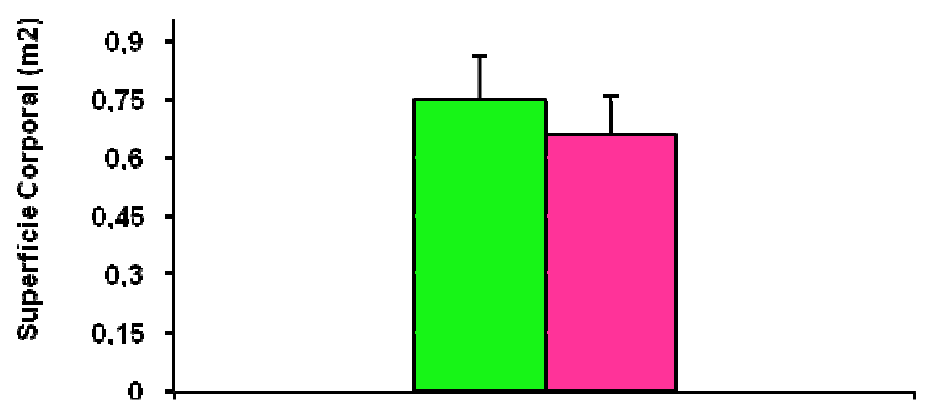

口G1 CONT

口G2 DEX

Figura 5. Superfície corporal dos cães. Média e desvio padrão dos valores obtidos nos dois grupos estudados.

Quadro 4. Superfície corporal dos cães. Hipótese testada e comentários

\begin{tabular}{l|l|l}
\hline Hipótese & Estatística & Comentários \\
Diferença entre os grupos & $p>0,05$ & $G 1=G 2$ \\
\hline
\end{tabular}

Comentário geral: na tabela 3 e figura 4 houve distribuição normal. Portanto, foram utilizados média e desvio padrão, como parâmetros estatísticos. Os testes das hipóteses, previamente estabelecidas, demonstraram que não houve alteração significativa do sexo entre os grupos. 


\subsection{Hematócrito}

Tabela 5 Hematócrito (\%). Média e desvio padrão dos valores obtidos em cada momento nos dois grupos experimentais

\begin{tabular}{ccc}
\hline & \multicolumn{2}{c}{ Grupos } \\
\cline { 2 - 3 } Momentos & G1 & G2 \\
\hline M1 & $44,8 \pm 8,3$ & $39,7 \pm 13,2$ \\
M2 & $46,4 \pm 9,0$ & $40,9 \pm 10,5$ \\
M3 & $45,8 \pm 8,6$ & $38,2 \pm 9,8$ \\
M4 & $44,0 \pm 8,0$ & $39,0 \pm 9,1$ \\
M5 & $44,1 \pm 6,9$ & $38,6 \pm 9,9$ \\
\hline
\end{tabular}

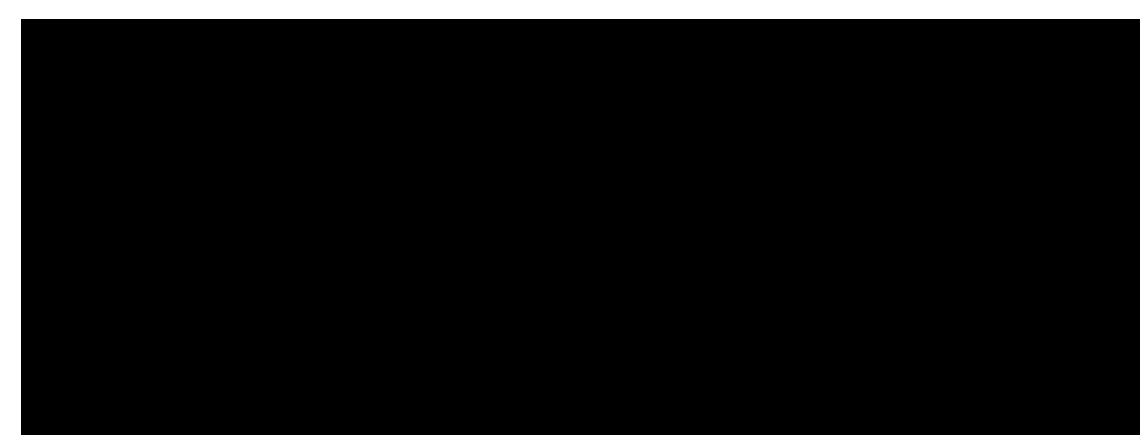

Figura 6. Hematócrito dos cães. Média e desvio padrão dos valores obtidos nos dois grupos estudados.

Quadro 5. Hematócrito dos cães. Hipótese testada e comentários

Hipótese

H01- Interação entre os grupos e momentos

H02- Efeito entre grupos no conjunto dos momentos H03- Diferença entre momentos no conjunto dos grupos

\begin{tabular}{l|l}
\hline Estatística & Comentários \\
$p>0,05$ & Perfis similares \\
$p>0,05$ & Perfis iguais \\
& Momentos não diferem \\
\hline
\end{tabular}

Comentários gerais: na tabela 4 e figura 5 houve distribuição normal. Portanto, foram utilizados média e desvio padrão, como parâmetros estatísticos. Os testes das hipóteses, previamente estabelecidas, demonstraram que não houve alteração significativa do hematócrito em nenhum momento ou grupo estudado durante todo experimento. 


\subsection{Saturação de Pulso de Oxigênio}

Tabela 6. Saturação de pulso de oxigênio (\%). Média e desvio padrão dos valores obtidos em cada momento nos dois grupos experimentais

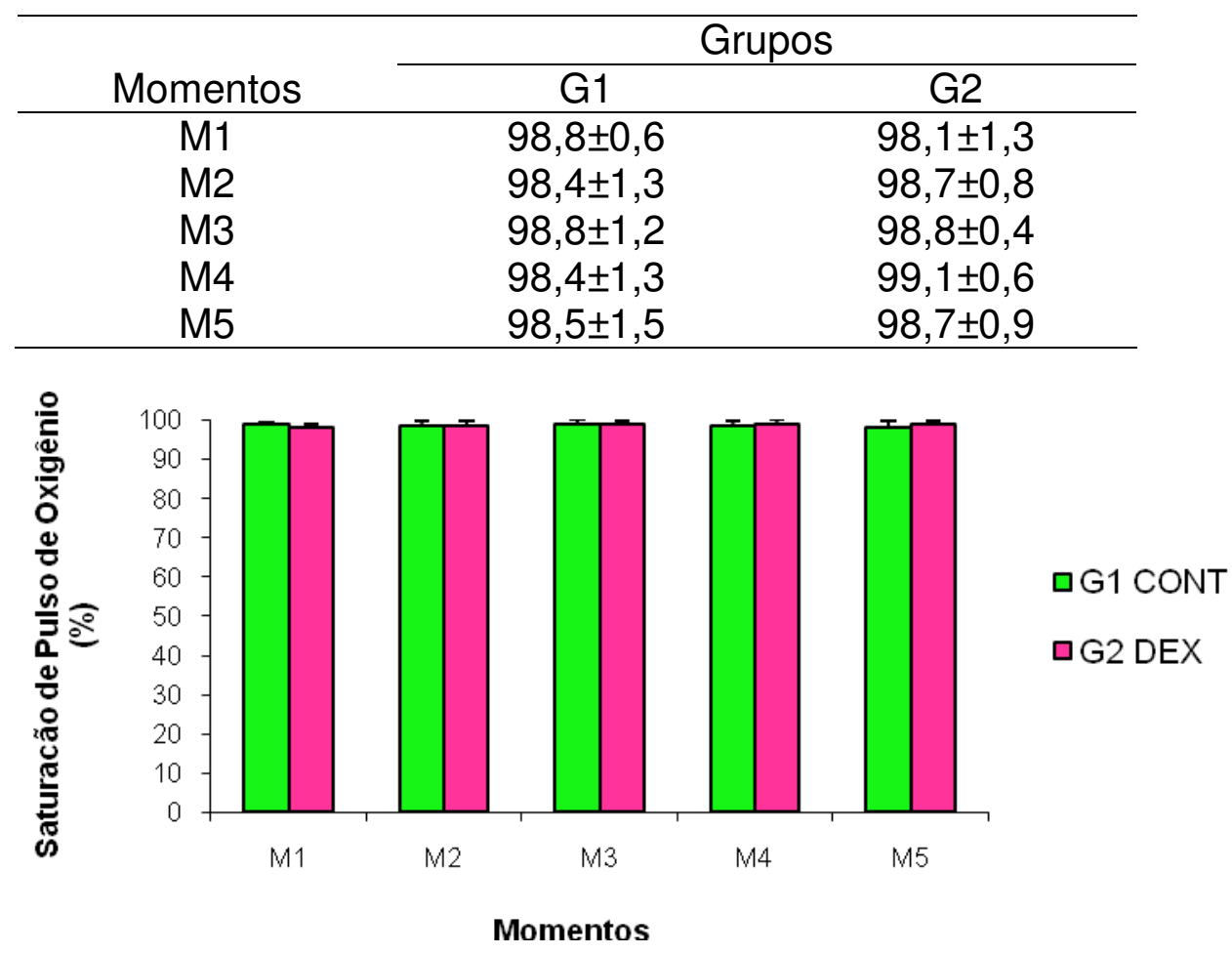

Figura 7. Saturação de pulso oxigênio. Média e desvio padrão dos valores obtidos nos dois grupos estudados.

Quadro 6. Saturação de pulso de oxigênio. Hipótese testada e comentários

\begin{tabular}{l|ll|l}
\hline Hipótese & \multicolumn{2}{|l|}{ Estatística } & Comentários \\
$\begin{array}{l}\text { H01- Interação entre os grupos e } \\
\text { momentos }\end{array}$ & $F=0,34$ & $p>0,05$ & Perfis similares \\
$\begin{array}{l}\text { H02- Efeito entre grupos no } \\
\text { conjunto dos momentos }\end{array}$ & $F=1,41$ & $p>0,05$ & Perfis iguais \\
$\begin{array}{l}\text { H03- Diferença entre momentos } \\
\text { no conjunto dos grupos }\end{array}$ & $F=1,84$ & $p>0,05$ & Momentos não diferem \\
\hline
\end{tabular}

Comentários gerais: na tabela 6 e figura 7 houve distribuição normal. Portanto, foram utilizados média e desvio padrão, como parâmetros estatísticos. Os testes das hipóteses, previamente estabelecidas, demonstraram que não houve alteração significativa da saturação de pulso de oxigênio em nenhum momento ou grupo estudado durante todo experimento. 


\subsection{Pressão Expiratória Final de $\mathrm{CO}_{2}$}

Tabela 6. Pressão Expiratória Final de $\mathrm{CO}_{2}(\mathrm{mmHg})$. Média e desvio padrão dos valores obtidos em cada momento nos dois grupos experimentais

\begin{tabular}{ccc}
\hline & \multicolumn{2}{c}{ Grupos } \\
\cline { 2 - 3 } Momentos & G1 & G2 \\
\hline M1 & $41,5 \pm 6,5$ & $39,6 \pm 9,5$ \\
M2 & $42,1 \pm 8,3$ & $38,1 \pm 9,3$ \\
M3 & $42,5 \pm 8,8$ & $36,1 \pm 9,8$ \\
M4 & $42,0 \pm 8,9$ & $35,1 \pm 9,1$ \\
M5 & $41,5 \pm 9,2$ & $34.5 \pm 7,4$ \\
\hline
\end{tabular}

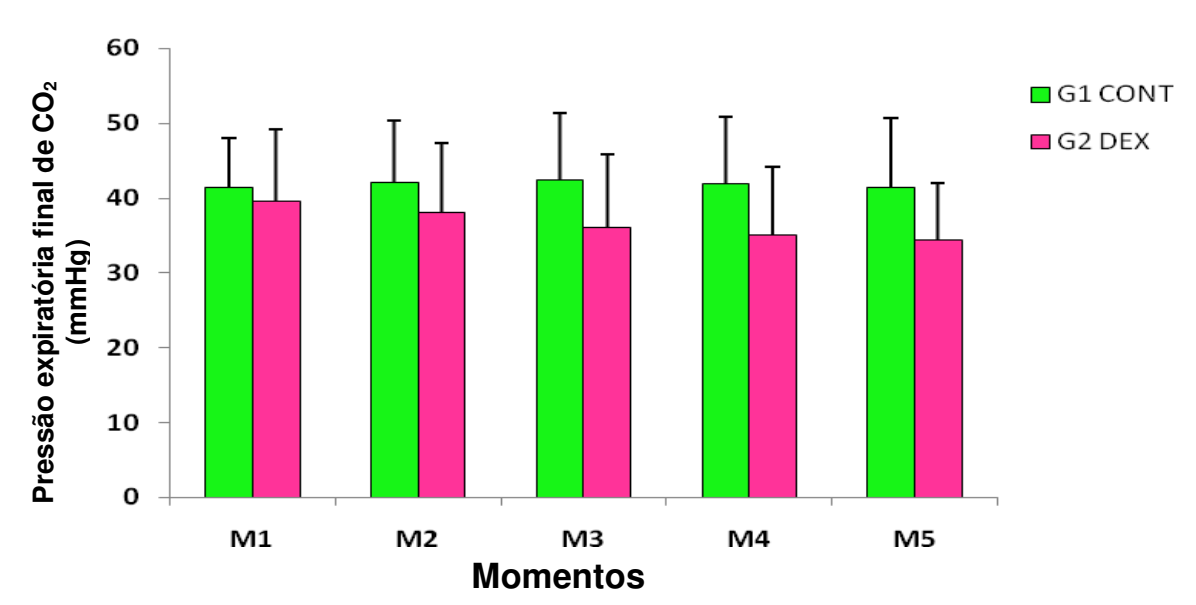

Figura 8. Pressão Expiratória Final de $\mathrm{CO}_{2}$. Média e desvio padrão dos valores obtidos nos dois grupos estudados.

Quadro 7. Pressão Expiratória Final de $\mathrm{CO}_{2}$. Hipótese testada e comentários

\begin{tabular}{l|l|l}
\hline Hipótese & Estatística & Comentários \\
H01- Interação entre os grupos & $\mathrm{F}=5,72$ & Perfis não similares \\
e momentos & $\mathrm{p}>0,05$ & \\
H02- Efeito entre grupos no & $\mathrm{F}=1,73$ & $\mathrm{M} 2, \mathrm{M} 3, \mathrm{M} 4, \mathrm{M} 5: \mathrm{G} 1>\mathrm{G} 2$ \\
conjunto dos momentos & $\mathrm{p}>0,05$ & $\mathrm{M} 1: \mathrm{G} 1=\mathrm{G} 2$ \\
H03- Diferença entre momentos & $\mathrm{F}=4,95$ & $\mathrm{G} 1: \mathrm{M} 1=\mathrm{M} 2=\mathrm{M} 3=\mathrm{M} 4=\mathrm{M} 5 ; \mathrm{G} 2:$ \\
no conjunto dos grupos & $\mathrm{p}>0,05$ & $\mathrm{M} 1>\mathrm{M} 2>\mathrm{M} 3=\mathrm{M} 4=\mathrm{M} 5 ; \mathrm{M} 1=\mathrm{M} 2$ \\
\hline
\end{tabular}

Comentários gerais: na tabela 7 e figura 8 houve distribuição normal. Portanto, foram utilizados média e desvio padrão, como parâmetros estatísticos. Os testes das hipóteses, previamente estabelecidas, demonstraram que a pressão expiratória final de CO2 ficou entre 35 e 45 mmhg na na anáslise dos dois grupos, ou seja, dentro dos limites estabelecidos para a realização da pesquisa. 


\subsection{Temperatura esofágica}

Tabela 8. Temperatura esofágica $\left({ }^{\circ} \mathrm{C}\right)$. Média e desvio padrão dos valores obtidos em cada momento nos dois grupos experimentais

\begin{tabular}{lcc}
\hline & \multicolumn{2}{c}{ Grupos } \\
\cline { 2 - 3 } Momentos & G1 & G2 \\
\hline M1 & $36,5 \pm 0,7$ & $36,7 \pm 0,8$ \\
M2 & $36,4 \pm 0,7$ & $36,3 \pm 0,7$ \\
M3 & $36,0 \pm 1,0$ & $35,7 \pm 0,8$ \\
M4 & $35,8 \pm 1,0$ & $35,5 \pm 0,8$ \\
M5 & $35,7 \pm 1,1$ & $35,4 \pm 0,8$ \\
\hline
\end{tabular}

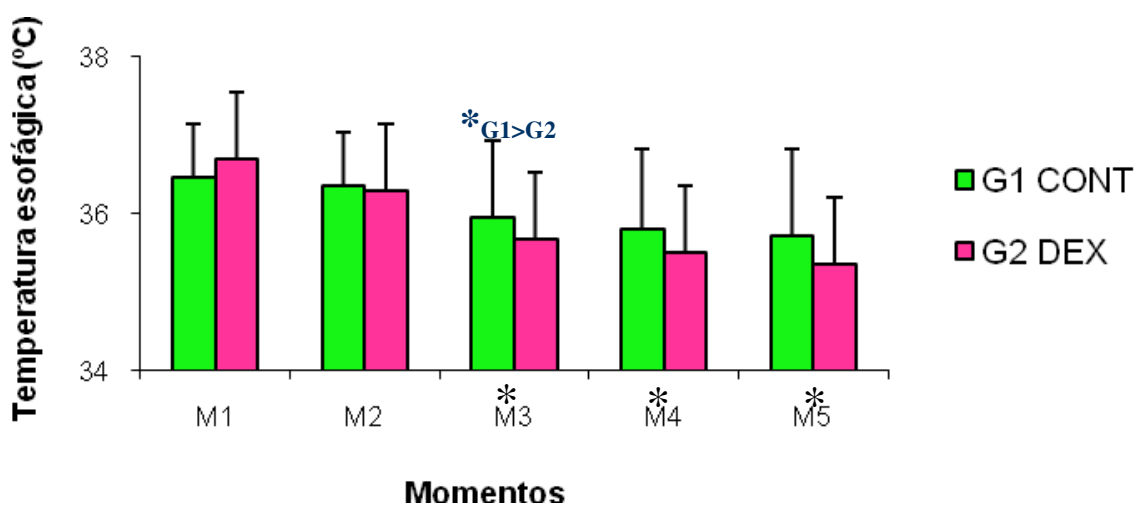

Figura 9. Temperatura esofágica. Média e desvio padrão dos valores obtidos em cada momento nos dois grupos experimentais.

Quadro 8. Temperatura esofágica. Hipótese testada e comentários

\begin{tabular}{l|l|l}
\hline Hipótese & Estatística & Comentários \\
H01- Interação entre os grupos & $\mathrm{F}=4,33$ & Perfis não similares \\
e momentos & $\mathrm{p}<0,05$ & \\
H02- Efeito entre grupos no & $\mathrm{F}=0,06$ & $\mathrm{M} 2, \mathrm{M} 3, \mathrm{M} 4, \mathrm{M} 5: \mathrm{G} 1>\mathrm{G} 2$ \\
conjunto dos momentos & $\mathrm{p}>0,05$ & $\mathrm{M} 1: \mathrm{G} 1<\mathrm{G} 2$ \\
H03- Diferença entre momentos & $\mathrm{F}=81,12$ & $\mathrm{G} 1: \mathrm{M} 1=\mathrm{M} 2>\mathrm{M} 3=\mathrm{M} 4=\mathrm{M} 5 ;$ \\
no conjunto dos grupos & $\mathrm{p}<0,05$ & $\mathrm{G} 2: \mathrm{M} 1=\mathrm{M} 2>\mathrm{M} 3=\mathrm{M} 4=\mathrm{M} 5$ \\
\hline
\end{tabular}

Comentários gerais: na tabela 8 e figura 9 houve distribuição normal. Portanto, foram utilizados média e desvio padrão, como parâmetros estatísticos. Os testes das hipóteses, previamente estabelecidas, demonstraram que em M3 G1>G2. Entre momentos de cada grupo M3, M4 e M5 são menores que M1 e M2. 


\subsection{Freqüência Cardíaca}

Tabela 9. Freqüência Cardíaca (bat.min ${ }^{-1}$ ). Média e desvio padrão dos valores obtidos em cada grupo experimental

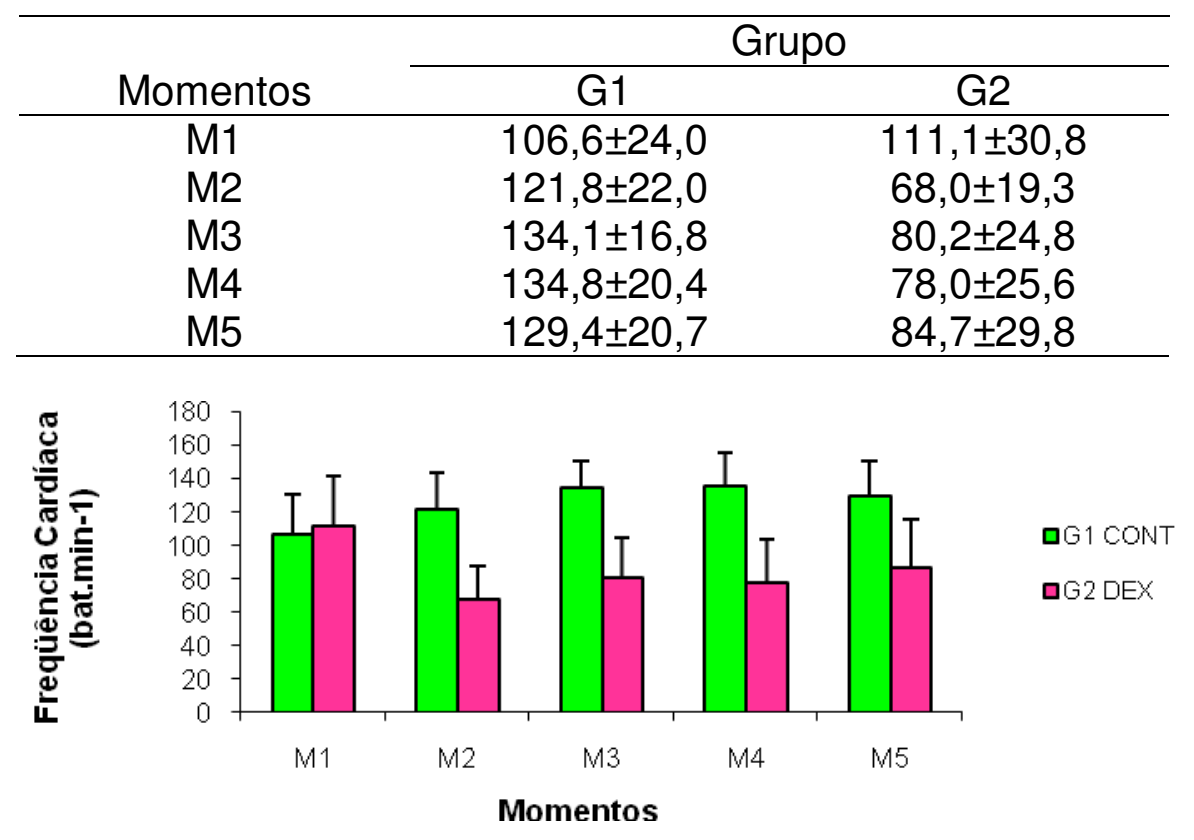

Figura 10. Freqüência cardíaca. Média e desvio padrão dos valores obtidos nos dois grupos estudados.

Quadro 9. Freqüência cardíaca. Hipótese testada e comentários

\begin{tabular}{l|l|l}
\hline Hipótese & Estatística & Comentários \\
H01- Interação entre os grupos e & $\mathrm{F}=10,47$ & Perfis não similares \\
momentos & $\mathrm{p}<0,05$ & \\
H02- Efeito entre grupos no & $\mathrm{F}=7,14$ & $\mathrm{M} 2, \mathrm{M} 3, \mathrm{M} 4, \mathrm{M} 5: \mathrm{G} 1>\mathrm{G} 2$ \\
conjunto dos momentos & $\mathrm{p}<0,05$ & $\mathrm{M} 1: \mathrm{G} 1<\mathrm{G} 2$ \\
H03- Diferença entre momentos no & $\mathrm{F}=2,37$ & $\mathrm{G} 1: \mathrm{M} 1<\mathrm{M} 2=\mathrm{M} 3=\mathrm{M} 4=\mathrm{M} 5$ \\
conjunto dos grupos & $\mathrm{p}>0,05$ & $\mathrm{G} 2: \mathrm{M} 1>\mathrm{M} 2=\mathrm{M} 3=\mathrm{M} 4=\mathrm{M} 5$ \\
\hline
\end{tabular}

Comentários gerais: na tabela 9 e figura 10 houve distribuição normal. Portanto, foram utilizados média e desvio padrão, como parâmetros estatísticos. Os testes das hipóteses, previamente estabelecidas, demonstraram que a freqüência cardíaca foi menor no momento 1 do G1, nos demais momentos a freqüência cardíaca foi maior no grupo 1 em relação ao grupo 2. Nos grupos, em G1 a freqüência cardíaca foi menor no M1, e no G2 houve diminuição significativa no M2, M3, M4 e M5 em relação ao M1. 


\subsection{Pressão Arterial Média}

Tabela 10. Pressão Arterial Média $(\mathrm{mmHg})$. Média e desvio padrão dos valores obtidos em cada grupo experimental

\begin{tabular}{ccc}
\hline & \multicolumn{2}{c}{ Grupo } \\
\cline { 2 - 3 } Momentos & G1 & G2 \\
\hline M1 & $111,2 \pm 18,3$ & $114,6 \pm 12,7$ \\
M2 & $118,7 \pm 22,7$ & $109,0 \pm 6,3$ \\
M3 & $119,7 \pm 23,0$ & $118,8 \pm 17,7$ \\
M4 & $121,6 \pm 19,1$ & $119,5 \pm 17,2$ \\
M5 & $119,6 \pm 19,9$ & $116,2 \pm 14,2$ \\
\hline
\end{tabular}

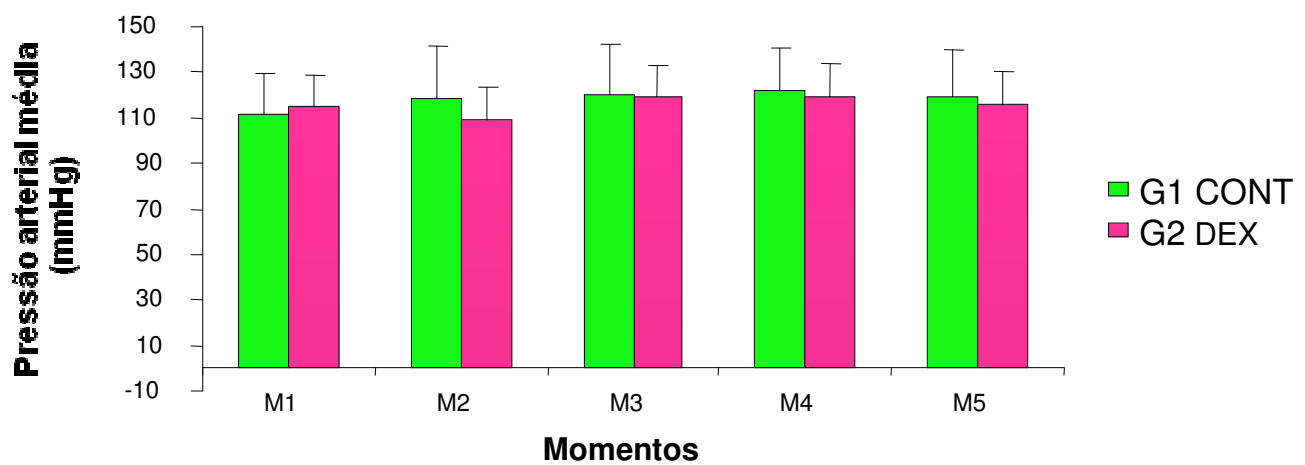

Figura 11. Pressão arterial média. Média e desvio padrão dos valores obtidos nos dois grupos estudados.

Quadro 10. Pressão arterial média. Hipótese testada e comentários

\begin{tabular}{l|l|l}
\hline Hipótese & Estatística \\
H01- Interação entre os grupos & $\mathrm{F}=0,81 \mathrm{p}>0,05$ & $\begin{array}{l}\text { Comentários } \\
\text { Perfis similares }\end{array}$ \\
$\begin{array}{l}\text { H02- Efeito entre grupos no } \\
\text { conjunto dos momentos }\end{array}$ & $\mathrm{F}=0,09 \mathrm{p}>0,05$ & Perfis iguais \\
$\begin{array}{l}\text { H03- Diferença entre momentos } \\
\text { no conjunto dos grupos }\end{array}$ & $\mathrm{F}=3,18 \mathrm{p}>0,05$ & $\begin{array}{l}\text { Momentos não } \\
\text { diferem }\end{array}$ \\
\hline
\end{tabular}

Comentários gerais: na tabela 10 e figura 11 houve distribuição normal. Portanto, foram utilizados média e desvio padrão, como parâmetros estatísticos. Os testes das hipóteses, previamente estabelecidas, demonstraram que não houve alteração significativa da pressão arterial média em nenhum momento ou grupo estudado durante todo experimento. 


\subsection{Pressão Média do Átrio Direito}

Tabela 11. Pressão Média do Átrio Direito $(\mathrm{mmHg})$. Média e desvio padrão dos valores obtidos em cada momento nos dois grupos experimentais

\begin{tabular}{ccc}
\hline & \multicolumn{2}{c}{ Grupos } \\
\cline { 2 - 3 } Momentos & G1 & G2 \\
\hline M1 & $3,6 \pm 1,3$ & $3,6 \pm 1,6$ \\
M2 & $3,6 \pm 1,3$ & $4,5 \pm 1,0$ \\
M3 & $3,4 \pm 1,3$ & $3,8 \pm 1,5$ \\
M4 & $3,7 \pm 1,5$ & $3,9 \pm 1,8$ \\
M5 & $3,2 \pm 1,6$ & $4,0 \pm 1,6$ \\
\hline
\end{tabular}

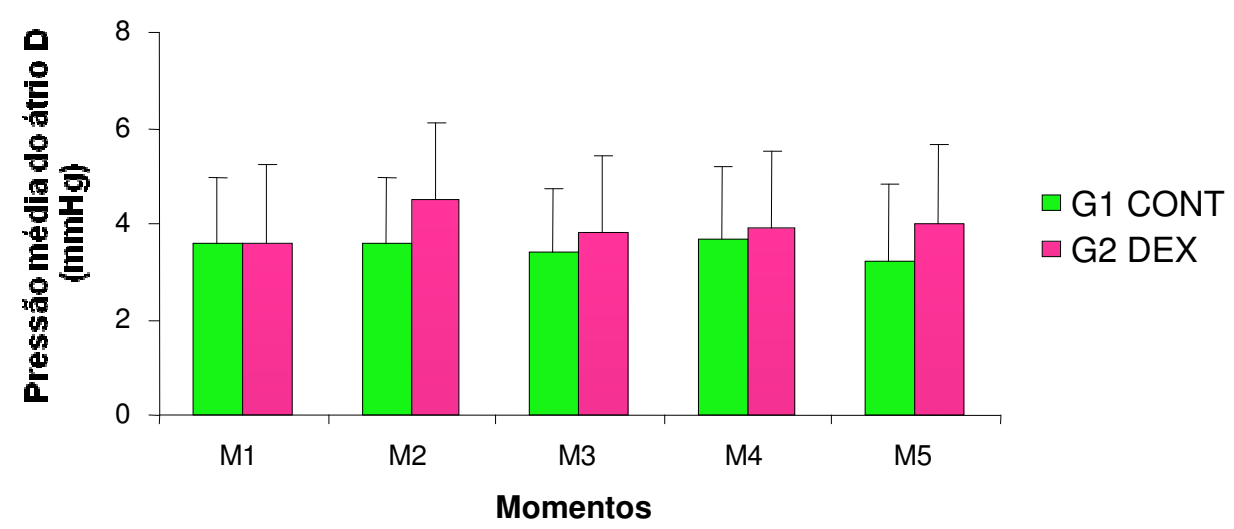

Figura 12. Pressão média do átrio direito. Média e desvio padrão dos valores obtidos nos dois grupos estudados.

Quadro 11. Pressão média do átrio direito. Hipótese testada e comentários

\begin{tabular}{l|l|l}
\hline Hipótese & Estatística \\
H01- Interação entre os grupos & $\mathrm{F}=0,62 \mathrm{p}>0,05$ & $\begin{array}{l}\text { Comentários } \\
\text { e momentos }\end{array}$ \\
$\begin{array}{l}\text { H02- Efeito entre grupos no } \\
\text { conjunto dos momentos }\end{array}$ & $\mathrm{F}=0,02 \mathrm{p}>0,05$ & Perfis iguais \\
$\begin{array}{l}\text { H03- Diferença entre momentos } \\
\text { no conjunto dos grupos }\end{array}$ & $\mathrm{F}=0,82 \mathrm{p}>0,05$ & $\begin{array}{l}\text { Momentos não } \\
\text { diferem }\end{array}$ \\
\hline
\end{tabular}

Comentários gerais: na tabela 11 e figura 12 houve distribuição normal. Portanto, foram utilizados média e desvio padrão, como parâmetros estatísticos. Os testes das hipóteses, previamente estabelecidas, demonstraram que não houve alteração significativa da pressão arterial média em nenhum momento ou grupo estudado durante todo experimento. 


\subsection{Pressão Média da Artéria Pulmonar}

Tabela 12. Pressão média da artéria pulmonar $(\mathrm{mmHg})$. Média e desvio padrão dos valores obtidos em cada momento nos dois grupos experimentais

\begin{tabular}{lcc}
\hline & \multicolumn{2}{c}{ Grupos } \\
\cline { 2 - 3 } Momentos & G1 & G2 \\
\hline M1 & $14,5 \pm 2,4$ & $13,8 \pm 2,9$ \\
M2 & $15,2 \pm 2,7$ & $14,1 \pm 1,4$ \\
M3 & $14,1 \pm 2,8$ & $13,8 \pm 2,5$ \\
M4 & $13,8 \pm 3,5$ & $13,5 \pm 2,9$ \\
M5 & $13,8 \pm 3,2$ & $13,4 \pm 3,1$ \\
\hline
\end{tabular}

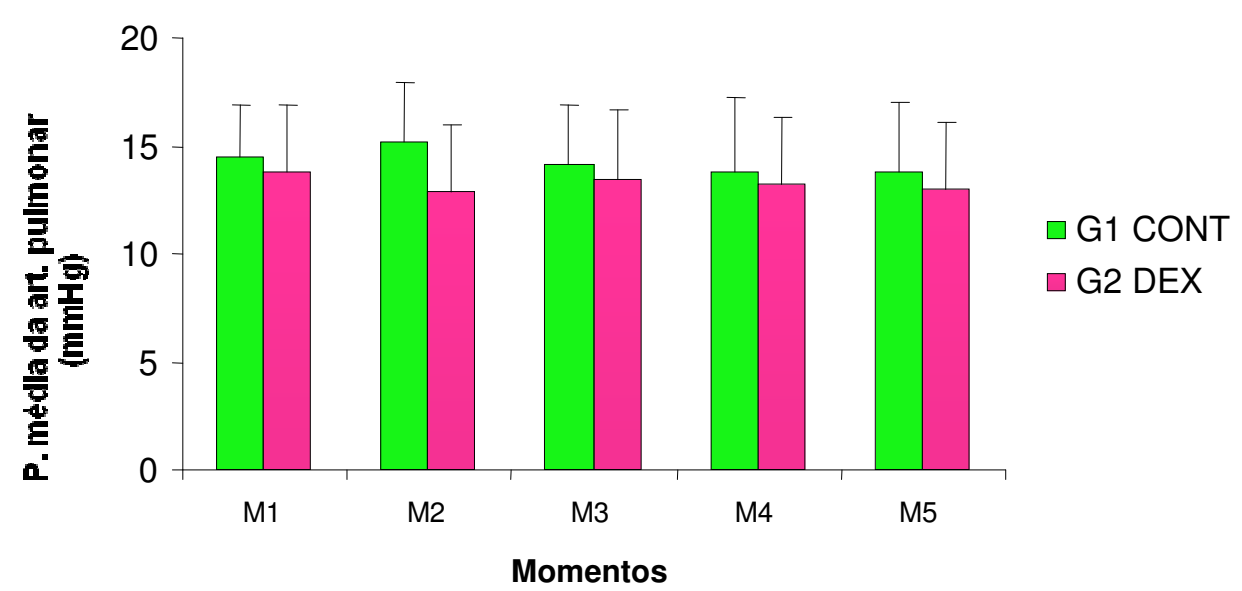

Figura 13. Pressão média da artéria pullmonar. Média e desvio padrão dos valores obtidos nos dois grupos estudados.

Quadro 12. Pressão média da artéria pulmonar. Hipótese testada e comentários

\begin{tabular}{l|l|l}
\hline $\begin{array}{l}\text { Hipótese } \\
\text { H01- Interação entre os grupos } \\
\text { e momentos }\end{array}$ & $\begin{array}{l}\text { Estatística } \\
\mathrm{F}=1,13 \mathrm{p}>0,05\end{array}$ & $\begin{array}{l}\text { Comentários } \\
\text { Perfis similares }\end{array}$ \\
$\begin{array}{l}\text { H02- Efeito entre grupos no } \\
\text { conjunto dos momentos }\end{array}$ & $\mathrm{F}=1,02 \mathrm{p}>0,05$ \\
$\begin{array}{l}\text { H03- Diferença entre momentos } \\
\text { no conjunto dos grupos }\end{array}$ & $\mathrm{F}=1,13 \mathrm{p}>0,05$ & $\begin{array}{l}\text { Momentos não } \\
\text { diferem }\end{array}$ \\
\hline
\end{tabular}

Comentários gerais: na tabela 12 e figura 13 houve distribuição normal. Portanto, foram utilizados média e desvio padrão, como parâmetros estatísticos. Os testes das hipóteses, previamente estabelecidas, demonstraram que não houve alteração significativa da pressão arterial média da artéria pulmonar em nenhum momento ou grupo estudado durante todo experimento. 


\subsection{Pressão de Oclusão da Artéria Pulmonar}

Tabela 13. Pressão de oclusão da artéria pulmonar $(\mathrm{mmHg})$. Média e desvio padrão dos valores obtidos em cada momento nos dois grupos experimentais

\begin{tabular}{lcc}
\hline & \multicolumn{2}{c}{ Grupos } \\
\cline { 2 - 3 } Momentos & G1 & G2 \\
\hline M1 & $5,0 \pm 2,1$ & $5,1 \pm 1,4$ \\
M2 & $5,2 \pm 2,6$ & $5,5 \pm 1,2$ \\
M3 & $4,7 \pm 2,1$ & $5,4 \pm 1,4$ \\
M4 & $4,9 \pm 2,3$ & $5,1 \pm 1,3$ \\
M5 & $4,5 \pm 2,1$ & $4,7 \pm 1,9$ \\
\hline
\end{tabular}

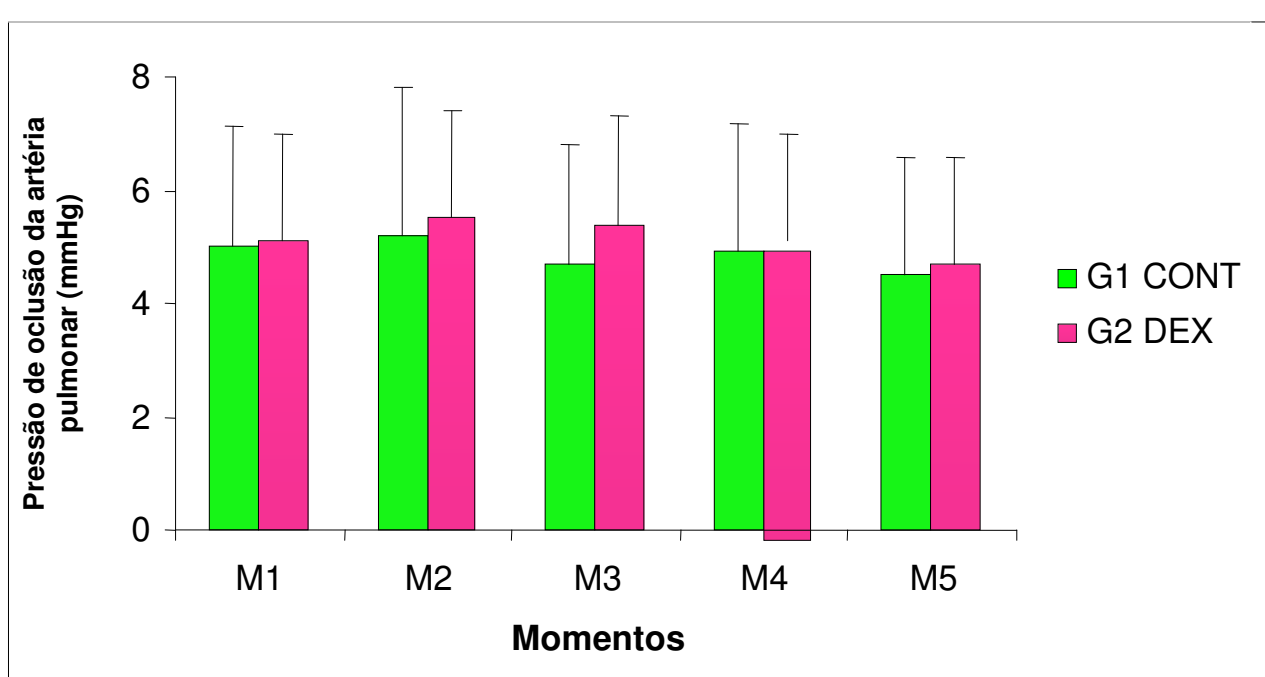

Figura 14. Pressão de oclusão da artéria pulmonar. Média e desvio padrão dos valores obtidos nos dois grupos estudados.

Quadro 13. Pressão de oclusão da art. pulmonar. Hipótese testada e comentários

\begin{tabular}{l|l|l}
\hline $\begin{array}{l}\text { Hipótese } \\
\text { H01- Interação entre os grupos } \\
\text { e momentos }\end{array}$ & $\begin{array}{l}\text { Estatística } \\
\text { H02- Efeito entre grupos no }\end{array}$ & $\begin{array}{l}\text { Comentários } \\
\text { Perfis similares }\end{array}$ \\
$\begin{array}{l}\text { conjunto dos momentos } \\
\text { H03- Diferença entre momentos } \\
\text { no conjunto dos grupos }\end{array}$ & $\mathrm{F}=0,42 \mathrm{p}=0,0,05 \mathrm{p}>0,05$ & $\begin{array}{l}\text { Momentos não } \\
\text { diferem }\end{array}$ \\
\hline
\end{tabular}

Comentários gerais: na tabela 13 e figura 14 houve distribuição normal. Portanto, foram utilizados média e desvio padrão, como parâmetros estatísticos. Os testes das hipóteses, previamente estabelecidas, demonstraram que não houve alteração significativa da pressão de oclusão da artéria pulmonar em nenhum momento ou grupo estudado durante todo experimento. 


\subsection{4 Índice Cardíaco}

Tabela 14. Índice Cardíaco $\left(\mathrm{L} \cdot \mathrm{min}^{-1} \cdot \mathrm{m}^{-2}\right)$. Média e desvio padrão dos valores obtidos em cada momento nos dois grupos experimentais

\begin{tabular}{lcc}
\hline & \multicolumn{2}{c}{ Grupos } \\
\cline { 2 - 3 } Momentos & G1 & G2 \\
\hline M1 & $4,2 \pm 0,9$ & $4,5 \pm 1,2$ \\
M2 & $4,6 \pm 1,2$ & $3,5 \pm 0,7$ \\
M3 & $4,3 \pm 1,4$ & $3,6 \pm 1,3$ \\
M4 & $4,0 \pm 1,4$ & $3,4 \pm 1,4$ \\
M5 & $4,0 \pm 1,4$ & $3,5 \pm 1,0$ \\
\hline
\end{tabular}

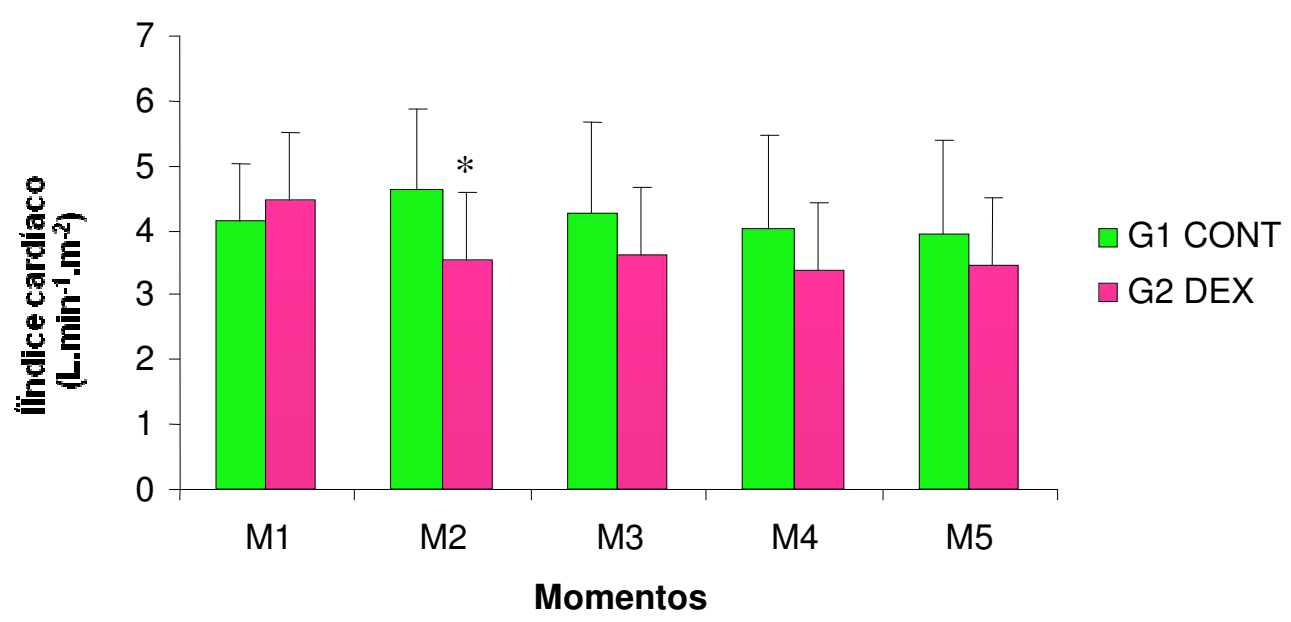

Figura 15. Índice Cardíaco. Média e desvio padrão dos valores obtidos nos dois grupos estudados.

Quadro 14. Índice Cardíaco. Hipótese testada e comentários

\begin{tabular}{l|l|l}
\hline Hipótese & Estatística \\
$\begin{array}{l}\text { H01- Interação entre os } \\
\text { grupos e momentos }\end{array}$ & $\mathrm{F}=2,28 \mathrm{p}>0,05$ & $\begin{array}{l}\text { Comentários } \\
\text { Perfis similares }\end{array}$ \\
$\begin{array}{l}\text { conjunto dos momentos } \\
\text { H03- Diferença entre } \\
\text { momentos no conjunto dos } \\
\text { grupos }\end{array}$ & $\mathrm{F}=2,47 \mathrm{p}>0,05$ & Perfis iguais \\
\hline
\end{tabular}

Comentários gerais: na tabela 14 e figura 15 houve distribuição normal. Portanto, foram utilizados média e desvio padrão, como parâmetros estatísticos. Os testes das hipóteses, previamente estabelecidas, demonstraram que houve diminuição significativa do índice cardíaco no M2 do G2 (DEX) em relação ao momento inicial, permanecendo até o final do experimento. 


\subsection{5 Índice de Resistência Vascular Sistêmica}

Tabela 15. Índice de resistência vascular sistêmica (dinas.s. $\mathrm{cm}^{-5} \cdot \mathrm{m}^{-2}$ ). Média e desvio padrão dos valores obtidos em cada momento nos dois grupos experimentais

\begin{tabular}{lcc}
\hline & \multicolumn{2}{c}{ Grupos } \\
\cline { 2 - 3 } Momentos & G1 & G2 \\
\hline M1 & $2702,8 \pm 524,3$ & $2112,4 \pm 545,6$ \\
M2 & $1994,6 \pm 618,6$ & $2643,9 \pm 664,1$ \\
M3 & $2346,1 \pm 1195,8$ & $3082,1 \pm 1053,4$ \\
M4 & $2728,1 \pm 1834,1$ & $3333,4 \pm 1200,5$ \\
M5 & $2611,4 \pm 1405,9$ & $2997,1 \pm 936,0$ \\
\hline
\end{tabular}

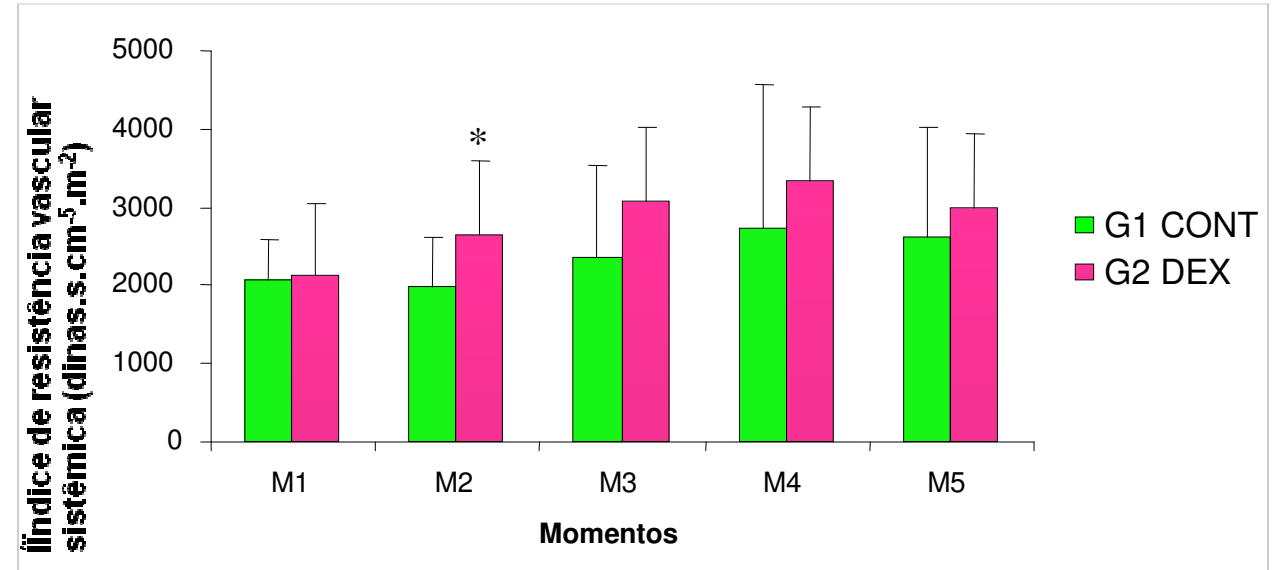

Figura 16. Índice de resistência vascular sistêmica. Média e desvio padrão dos valores obtidos nos dois grupos estudados.

Quadro 15. Índice de res. vascular sistêmica. Hipótese testada e comentários

\begin{tabular}{|c|c|c|}
\hline $\begin{array}{l}\text { Hipótese } \\
\text { H01- Interação entre os } \\
\text { grupos e momentos } \\
\text { H02- Efeito entre grupos no } \\
\text { conjunto dos momentos } \\
\text { H03- Diferença entre } \\
\text { momentos no conjunto dos } \\
\text { grupos }\end{array}$ & $\begin{array}{l}\text { Estatística } \\
F=0,53 p>0,05 \\
F=0,72 p>0,05 \\
F=7,63 p<0,05\end{array}$ & $\begin{array}{l}\text { Comentários } \\
\text { Perfis similares } \\
\text { Perfis iguais } \\
\text { G1:M1=M2=M3=M4=M5 } \\
\text { G2:M1 }<M 2=M 3=M 4=M 5\end{array}$ \\
\hline
\end{tabular}

Comentários gerais: na tabela 15 e figura 16 houve distribuição normal. Portanto, foram utilizados média e desvio padrão, como parâmetros estatísticos. Os testes das hipóteses, previamente estabelecidas, demonstraram que houve aumento significativo do índice de resistência vascular sistêmica no M2 do G2 em relação ao momento inicial, permanecendo até o final do experimento. 


\subsection{Vasopressina}

Tabela 16. Vasopressina $\left(\mathrm{pg} \cdot \mathrm{mL}^{-1}\right)$. Média e desvio-padrão dos valores observados em cada momento nos dois grupos experimentais

\begin{tabular}{lcc}
\hline & \multicolumn{2}{c}{ Grupos } \\
\cline { 2 - 3 } Momentos & G1 & G2 \\
\hline M1 & $6,0 \pm 1,9$ & $6,9 \pm 1,5$ \\
M2 & $5,6 \pm 2,3$ & $5,0 \pm 1,1$ \\
M4 & $6,4 \pm 3,0$ & $6,2 \pm 1,1$ \\
M5 & $7,0 \pm 3,0$ & $6,4 \pm 2,4$ \\
\hline
\end{tabular}

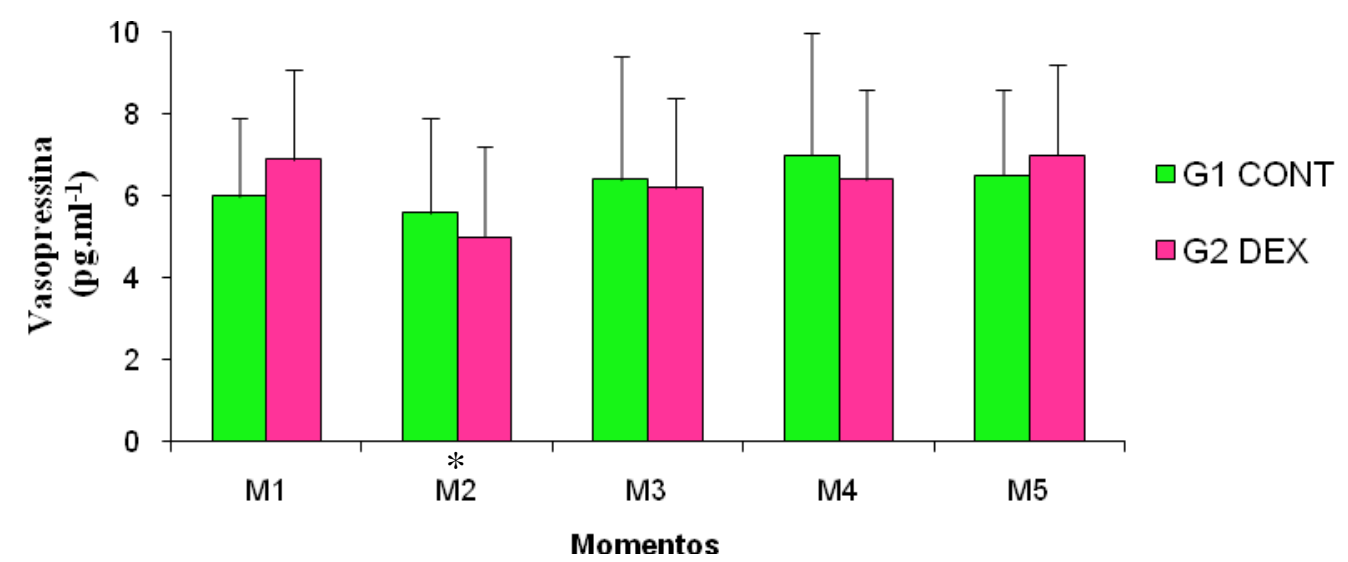

Figura 17. Dosagem de vasopressina. Média e desvio padrão dos valores observados em cada momento nos dois grupos estudados.

Quadro 16. Vasopressina plasmática. Hipótese testada e comentários

\begin{tabular}{l|l|l}
\hline Hipóteses & Estatísticas & Comentários \\
\hline H01. Interação entre os grupos e & $\mathrm{F}=1,08$ & Perfis similares \\
momentos & $p>0,05$ & \\
H02. Efeito entre grupos no & $\mathrm{F}=2,00$ & Perfis iguais \\
conjunto dos momentos & $\mathrm{p}>0,05$ & \\
H03. Diferença entre momentos no & $\mathrm{F}=2,00$ & No conjunto dos grupos: \\
conjunto dos grupos & $\mathrm{p}<0,05$ & (M1=M3=M4=M5)>M2 \\
\hline
\end{tabular}

Comentários gerais: na tabela 16 e figura 17 houve distribuição normal. Portanto, foram utilizados média e desvio padrão, como parâmetros estatísticos. Os testes das hipóteses, previamente estabelecidas, demonstram que a vasopressina plasmática diminuiu significativamente apenas no momento 2 em relação aos outros momentos em todos os grupos estudados. 


\subsection{Resistência Vascular Renal}

Tabela 17. Resistência vascular renal (RVR). Mediana, $1^{\circ}$ e $3^{\circ}$ quartis dos valores observados em cada momento nos dois grupos experimentais

\begin{tabular}{ccc}
\hline & \multicolumn{2}{c}{ Grupos } \\
\cline { 2 - 3 } Momentos & G1 & G2 \\
\hline M1 & $1,01[0,36 ; 2,10]$ & $0,86[0,67 ; 1,60]$ \\
M2 & $0,71[0,37 ; 1,54]$ & $1,02[0,63 ; 1,87]$ \\
M3 & $4,04[1,09 ; 10,35]$ & $2,70[1,40 ; 5,49]$ \\
M4 & $1,59[0,87 ; 4,16]$ & $1,98[1,46 ; 5,44]$ \\
M5 & $1,50[0,67 ; 3,05]$ & $1,88[1,26 ; 2,83]$ \\
\hline
\end{tabular}

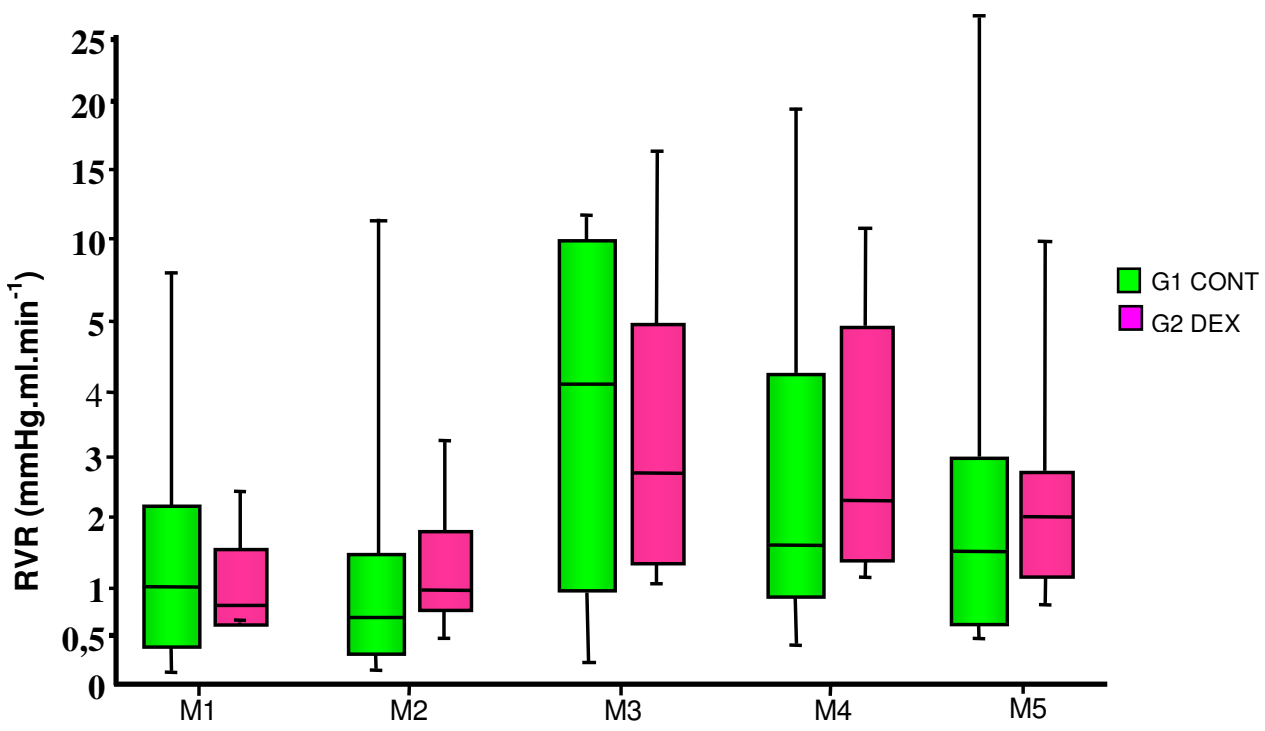

Figura 18. Mediana dos valores observados em cada momento nos dois grupos experimentais estudados.

Quadro 17. Resistência vascular renal. Hipótese testada e comentários

\begin{tabular}{|c|c|c|}
\hline Hipótese & Estatística & Comentário \\
\hline $\begin{array}{l}\text { H01. Interação entre os grupos e } \\
\text { momentos } \\
\text { H02. Efeito de grupo em cada } \\
\text { momento } \\
\text { H03. Efeito de momento em cada } \\
\text { grupo }\end{array}$ & $\begin{array}{l}P<0,05 \\
P>0,05 \\
P<0,05\end{array}$ & $\begin{array}{l}\text { Perfis não similares } \\
M 1, \quad M 2, \quad M 3, \quad M 4 \quad \& \quad M 5: \\
G 1=G 2 \\
G 1: M 1=M 2<M 4=M 5<M 3 \\
G 2: M 1=M 2<M 3=M 4=M 5\end{array}$ \\
\hline
\end{tabular}

Comentários gerais: na tabela 17 e figura 18 demonstraram que não houve distribuição normal. Portanto, foi utilizada a mediana como variável estatística. Para melhor representação gráfica, optou-se pelo "bloxplot". Os testes das hipóteses, previamente estabelecidas, demonstram que a RVR aumentou significativamente no grupo $1 \mathrm{em} \mathrm{M3}$, diminuindo posteriormente nos M4 e M5. Observa-se, também, aumento significativo da RVR nos momentos 3,4 e 5 no grupo 2 em relação ao início do experimento (M1 e M2). 


\subsection{Fluxo Sangüíneo Renal}

Tabela 18. Média do Fluxo Sanguíneo Renal $\left(\mathrm{mL} \cdot \mathrm{min}^{-1} \cdot \mathrm{kg}^{-1}\right)$. Média e desvio padrão dos valores obtidos em cada momento nos dois grupos experimentais

\begin{tabular}{ccc}
\hline & \multicolumn{2}{c}{ Grupos } \\
\cline { 2 - 3 } Momentos & G1 & G2 \\
\hline M1 & $7,124 \pm 6,109$ & $7,560 \pm 3,831$ \\
M2 & $9,266 \pm 6,520$ & $6,791 \pm 4,156$ \\
M3 & $3,849 \pm 5,257$ & $2,874 \pm 2,011$ \\
M4 & $3,990 \pm 3,716$ & $3,369 \pm 2,186$ \\
M5 & $4,992 \pm 3,784$ & $3,902 \pm 2,427$ \\
\hline
\end{tabular}

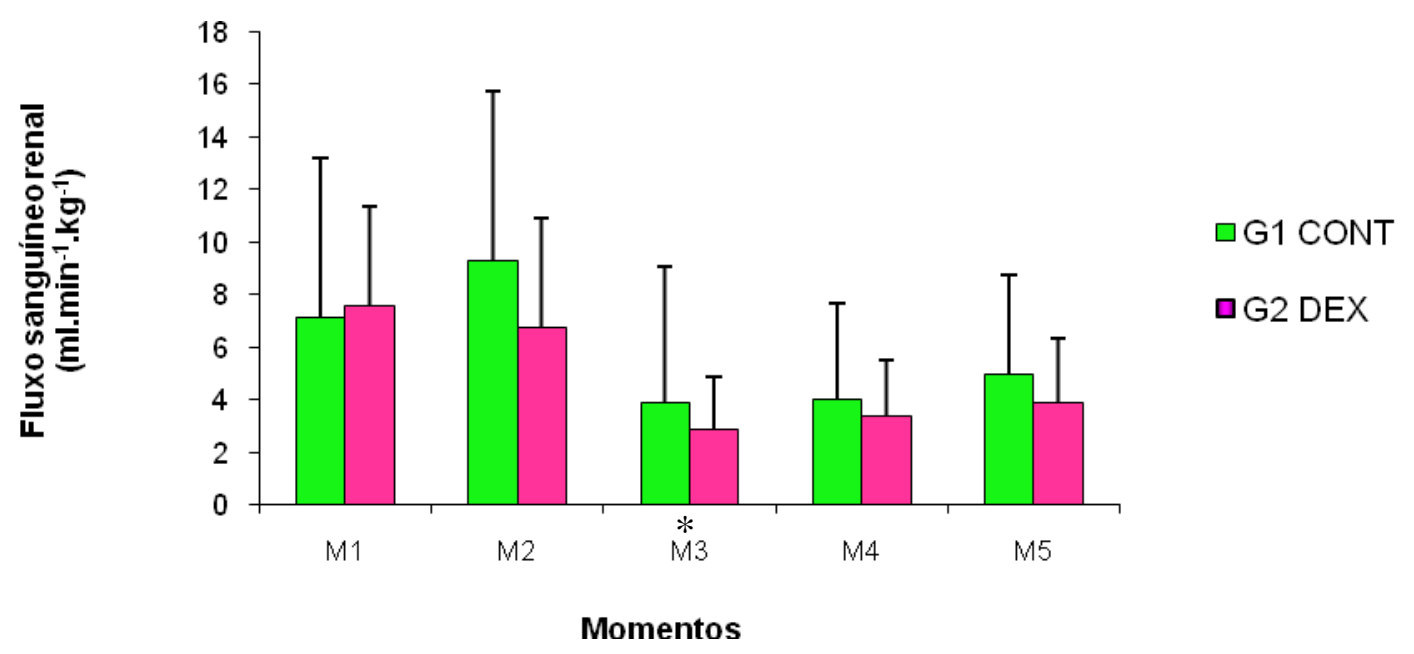

Figura 19. Fluxo sanguíneo renal. Média e desvio padrão dos valores obtidos em cada momento nos dois grupos estudados.

Quadro 18. Fluxo sanguíneo renal (FSR). Hipótese testada e comentários

\begin{tabular}{l|l|l}
\hline Hipóteses & Estatísticas & Comentários \\
\hline H01. Interação entre os grupos & $\mathrm{F}=1,05$ & Perfis similares \\
e momentos & $\mathrm{p}>0,05$ & \\
H02. Efeito entre grupos no & $\mathrm{F}=0,32$ & Perfis iguais \\
conjunto dos momentos & $\mathrm{p}>0,05$ & \\
H03. Diferença entre momentos & $\mathrm{F}=17,93$ & No conjunto dos grupos: \\
no conjunto dos grupos & $\mathrm{p}<0,05$ & $\mathrm{M} 1=\mathrm{M} 2<\mathrm{M} 3=\mathrm{M} 4=\mathrm{M} 5$ \\
\hline
\end{tabular}

Comentários gerais: na tabela 18 e figura 19 houve distribuição normal. Portanto, foram utilizados média e desvio padrão, como parâmetros estatísticos. Os testes das hipóteses, previamente estabelecidas, demonstram que houve redução significativa do FSR a partir do momento 3, mantendo esta redução até o final do experimento (M4 \& M5) em todos os grupos estudados. 


\subsection{Depuração de Para-Aminohipurato de Sódio}

Tabela 19. Depuração de para-aminohipurato de sódio $\left(\mathrm{mL} \cdot \mathrm{min}^{-1} \cdot \mathrm{kg}^{-1}\right)$. Média e desvio padrão dos valores obtidos em cada momento nos dois grupos experimentais

\begin{tabular}{ccc}
\hline & \multicolumn{2}{c}{ Grupos } \\
\cline { 2 - 3 } Momentos & G1 & G2 \\
\hline M1 & $3,629 \pm 2,675$ & $3,880 \pm 2,479$ \\
M2 & $4,223 \pm 2,954$ & $3,425 \pm 2,391$ \\
M3 & $2,130 \pm 2,595$ & $1,623 \pm 1,205$ \\
M4 & $2,224 \pm 2,024$ & $1,821 \pm 1,346$ \\
M5 & $2,719 \pm 1,994$ & $1,965 \pm 1,306$ \\
\hline
\end{tabular}

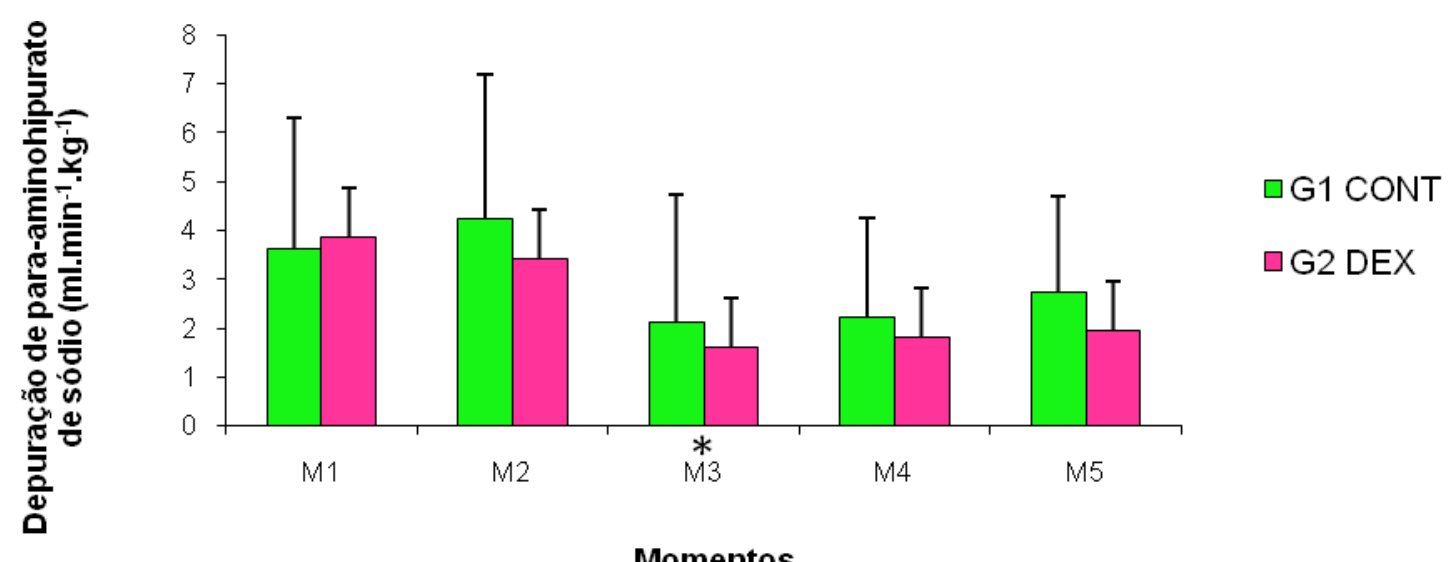

Figura 20. Depuração de para-aminohipurato. Média e desvio padrão dos valores obtidos nos dois grupos estudados.

Quadro 19. Depuração de para-aminohipurato. Hipótese testada e comentários

\begin{tabular}{l|l|l}
\hline Hipóteses & Estatísticas & Comentários \\
\hline H01. Interação entre os grupos e & $F=0,63$ & Perfis similares \\
momentos & $p>0,05$ & \\
H02. Efeito entre grupos no conjunto & $F=0,27$ & Perfis iguais \\
dos momentos & $p>0,05$ & \\
H03. Diferença entre momentos no & $F=12,77$ & No conjunto dos grupos: \\
conjunto dos grupos & $p<0,05$ & $M 1=M 2>M 3=M 4=M 5$ \\
\hline
\end{tabular}

Comentários gerais: na tabela 19 e figura 20 houve distribuição normal. Portanto, foram utilizados média e desvio padrão, como parâmetros estatísticos. Os testes das hipóteses, previamente estabelecidas, demonstram que houve redução significativa da depuração de para-aminohipurato a partir do momento 3, mantendo esta redução até o final do experimento (M4 \& M5) em todos os grupos estudados. 


\subsection{Depuração de Creatinina}

Tabela 20. Depuração de creatinina $\left(\mathrm{mL} \cdot \mathrm{min}^{-1} \cdot \mathrm{kg}^{-1}\right)$. Média e desvio padrão dos valores obtidos em cada momento nos dois grupos experimentais

\begin{tabular}{ccc}
\hline & \multicolumn{2}{c}{ Grupos } \\
\cline { 2 - 3 } Momentos & G1 & G2 \\
\hline M1 & $1,152 \pm 0,734$ & $1,346 \pm 0,508$ \\
M2 & $1,345 \pm 0,675$ & $1,331 \pm 0,778$ \\
M3 & $0,393 \pm 0,352$ & $0,446 \pm 0,322$ \\
M4 & $0,818 \pm 0,618$ & $0,837 \pm 0,762$ \\
M5 & $0,827 \pm 0,482$ & $0,986 \pm 0,595$ \\
\hline
\end{tabular}

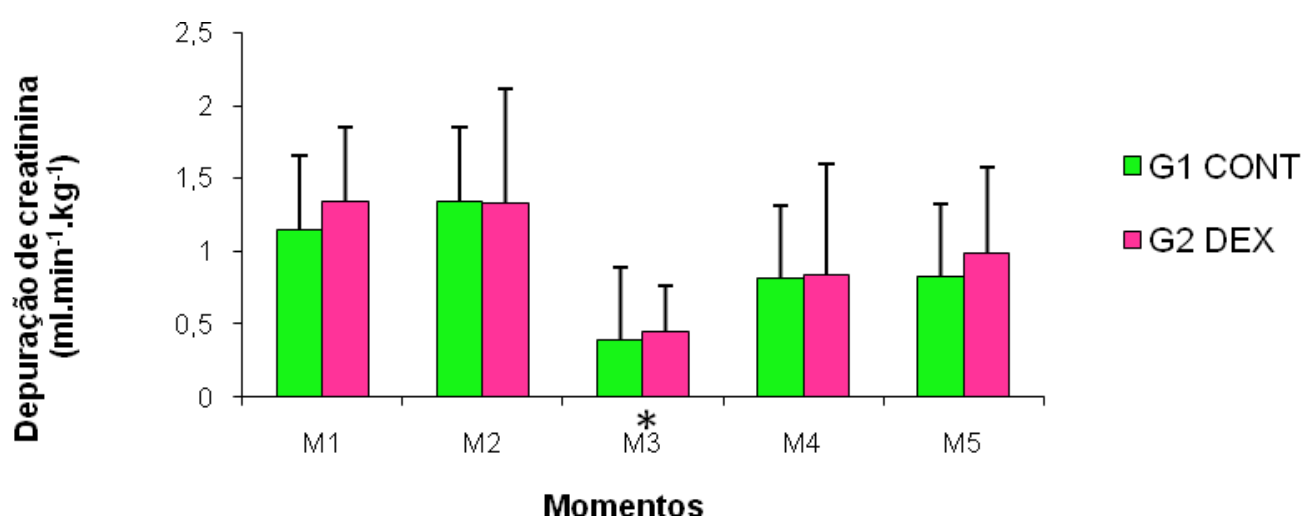

Figura 21. Depuração de creatinina. Média e desvio padrão dos valores obtidos nos dois grupos estudados.

Quadro 20. Depuração de creatinina. Hipótese testada e comentários

\begin{tabular}{l|l|l}
\hline Hipóteses & Estatísticas & Comentários \\
\hline H01. Interação entre os grupos e momentos & $F=0,25$ & Perfis similares \\
& $p>0,05$ & \\
H02. Efeito entre grupos no conjunto dos & $F=0,15$ & Perfis iguais \\
momentos & $p>0,05$ & \\
H03. Diferença entre momentos no conjunto & $F=16,34$ & No conjunto dos \\
dos grupos & $p<0,05$ & grupos:M1=M2>M3; \\
& & M3<M4=M5 \\
\hline
\end{tabular}

Comentários gerais: na tabela 20 e figura 21 houve distribuição normal. Portanto, foram utilizados média e desvio padrão, como parâmetros estatísticos. Os testes das hipóteses, previamente estabelecidas, demonstram que houve diminuição significativa da depuração de creatinina no momento 3 em relação ao início (M1 \& M2) e aumentando novamente até o final do experimento (M4 \& M5) em todos os grupos estudados. 


\subsection{Fração de Filtração}

Tabela 21. Fração de Filtração. Média e desvio padrão dos valores observados em cada momento nos dois grupos experimentais

\begin{tabular}{lcc}
\hline & \multicolumn{2}{c}{ Grupos } \\
\cline { 2 - 3 } Momentos & G1 & G2 \\
\hline M1 & $0,438 \pm 0,281$ & $0,368 \pm 0,183$ \\
M2 & $0,480 \pm 0,479$ & $0,424 \pm 0,215$ \\
M3 & $0,358 \pm 0,167$ & $0,381 \pm 0,267$ \\
M4 & $0,497 \pm 0,413$ & $0,479 \pm 0,287$ \\
M5 & $0,382 \pm 0,329$ & $0,490 \pm 0,241$ \\
\hline
\end{tabular}

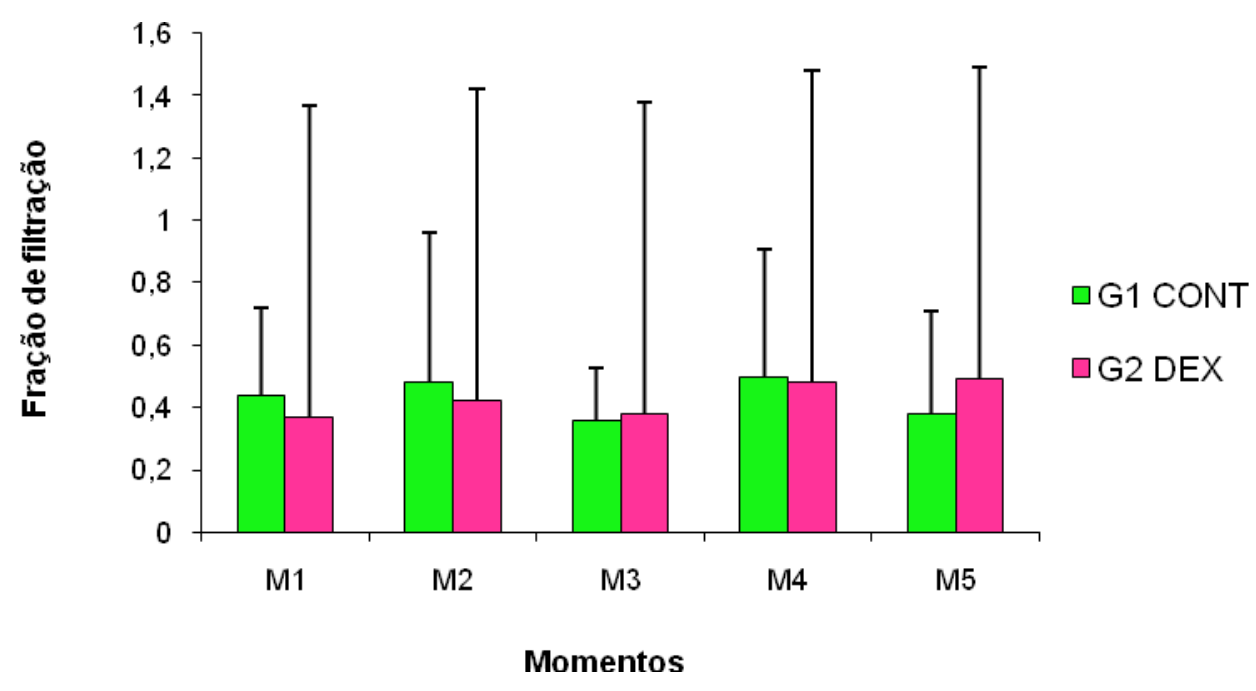

Figura 22. Fração de Filtração. Média e desvio padrão dos valores observados em cada momento nos dois grupos estudados.

Quadro 21. Fração de Filtração (FF). Hipótese testada e comentários

\begin{tabular}{l|l|l}
\hline Hipóteses & Estatísticas & Comentários \\
\hline H01. Interação entre os grupos e momentos & $F=0,41$ & Perfis similares \\
H02. Efeito entre grupos no conjunto dos & $p>0,05$ & \\
momentos & $\mathrm{F}=0,00$ & Perfis iguais \\
H03. Diferença entre momentos no conjunto dos & $\mathrm{F}=0,05$ & \\
grupos & $\mathrm{p}>0,05$ & $\begin{array}{l}\text { Momentos não } \\
\text { diferem }\end{array}$ \\
\hline
\end{tabular}

Comentários gerais: na tabela 21 e figura 22 houve distribuição normal. Portanto, utilizados média e desvio padrão, como parâmetros estatísticos. Os testes das hipóteses, previamente estabelecidas, demonstram que não houve alteração significativa da FF em nenhum momento ou grupo estudado durante todo experimento. 


\subsection{Débito Urinário}

Tabela 22. Débito urinário $\left(\mathrm{mL} \cdot \mathrm{min}^{-1} \cdot \mathrm{kg}^{-1}\right)$. Média e desvio padrão dos valores observados em cada momento nos dois grupos experimentais

\begin{tabular}{ccc}
\hline & \multicolumn{2}{c}{ Grupos } \\
\cline { 2 - 3 } Momentos & G1 & G2 \\
\hline M1 & $0,023 \pm 0,021$ & $0,026 \pm 0,021$ \\
M2 & $0,031 \pm 0,032$ & $0,026 \pm 0,019$ \\
M3 & $0,011 \pm 0,009$ & $0,025 \pm 0,018$ \\
M4 & $0,018 \pm 0,015$ & $0,038 \pm 0,027$ \\
M5 & $0,025 \pm 0,021$ & $0,052 \pm 0,039$ \\
\hline
\end{tabular}

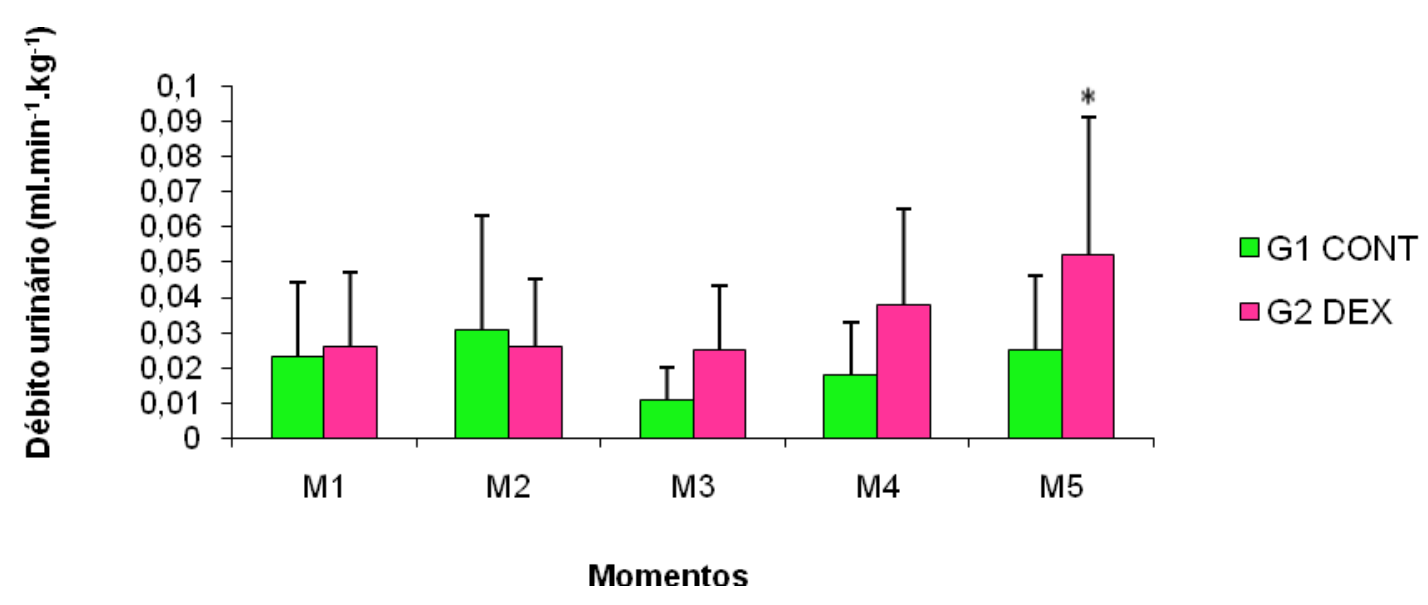

Figura 23. Média e desvio padrão dos valores do débito urinário obtidos nos grupos e momentos estudados.

Quadro 22. Débito urinário. Hipótese testada e comentários

\begin{tabular}{l|l|l}
\hline Hipóteses & Estatísticas & Comentários \\
\hline H01. Interação entre os grupos e & $F=2,80$ & Perfis não similares \\
momentos & $p<0,05$ & \\
H02. Efeito de grupo em cada & $F=2,09$ & $M 1, M 2, M 3, M 4: G 1=G 2$ \\
momento & $p<0,05$ & $M 5: G 1<G 2$ \\
H03. Efeito de momento em cada & $F=3,86$ & $\mathrm{G} 1: \mathrm{M} 1=\mathrm{M} 2>\mathrm{M} 3<\mathrm{M} 4=\mathrm{M} 5$ \\
grupo & $\mathrm{p}<0,05$ & $\mathrm{G} 2: \mathrm{M} 1=\mathrm{M} 2=\mathrm{M} 3=\mathrm{M} 4<\mathrm{M} 5$ \\
\hline
\end{tabular}

Comentários gerais: na tabela 22 e figura 23 houve distribuição normal. Portanto, foram utilizados média e desvio padrão, como parâmetros estatísticos. Os testes das hipóteses, previamente estabelecidas, demonstram que o débito urinário teve alteração no momento 5, onde o grupo 2 obteve diurese significante maior que grupo 1. No grupo 1, houve redução significativa no $M 3$, retornando aos valores iniciais no final do experimento. Observa-se, também, elevação significativa da diurese somente no grupo 2 no final do experimento (M5>M4). 


\subsection{Sódio Plasmático}

Tabela 23. Sódio plasmático $\left(\mu\right.$ Eq. $\left.\min ^{-1}\right)$. Média e desvio padrão dos valores obtidos em cada momento nos dois grupos experimentais

\begin{tabular}{|c|c|c|}
\hline \multirow[b]{2}{*}{ Momentos } & \multicolumn{2}{|c|}{ Grupos } \\
\hline & G1 & G2 \\
\hline M1 & $142,70 \pm 10,07$ & $146,90 \pm 3,03$ \\
\hline M2 & $143,50 \pm 8,29$ & $146,80 \pm 3,68$ \\
\hline M3 & $140,00 \pm 12,70$ & $144,80 \pm 3,26$ \\
\hline M4 & $138,80 \pm 7,93$ & $144,40 \pm 4,50$ \\
\hline M5 & $136,40 \pm 11,73$ & $145,50 \pm 3,81$ \\
\hline
\end{tabular}

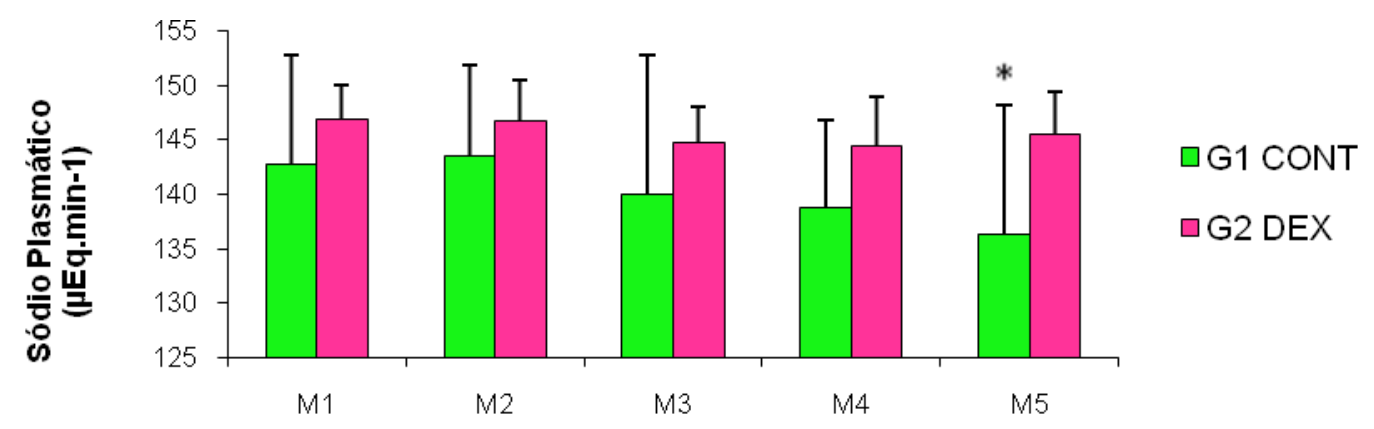

Momentos

Figura 24. Sódio plasmático. Média e desvio padrão dos valores obtidos em cada momento nos dois grupos estudados.

Quadro 23. Sódio plasmático. Hipótese testada e comentários

\begin{tabular}{l|l|l}
\hline Hipóteses & Estatísticas & Comentários \\
\hline H01. Interação entre os grupos e & $\mathrm{F}=1,30$ & Perfis similares \\
momentos & $p>0,05$ & \\
H02. Efeito entre grupos no & $\mathrm{F}=3,26$ & Perfis iguais \\
conjunto dos momentos & $\mathrm{p}>0,05$ & \\
H03. Diferença entre momentos & $\mathrm{F}=3,76$ & No conjunto dos grupos: G2: \\
no conjunto dos grupos & $\mathrm{p}<0,05$ & iguais; $\mathrm{G} 1$ :(M1=M2=M3=M4)>M5 \\
\hline
\end{tabular}

Comentários gerais: na tabela 23 e figura 24 houve distribuição normal. Portanto, foram utilizados média e desvio padrão, como parâmetros estatísticos. Os testes das hipóteses, previamente estabelecidas, demonstram que houve redução significativa da concentração de sódio plasmático apenas do momento 5 em relação aos outros momentos no grupo controle $\mathrm{G} 1$. 


\subsection{Potássio Plasmático}

Tabela 24. Potássio plasmático $\left(\mu \mathrm{Eq} \cdot \mathrm{min}^{-1}\right)$. Média e desvio padrão dos valores obtidos em cada momento nos dois grupos experimentais

\begin{tabular}{ccc}
\hline & \multicolumn{2}{c}{ Grupos } \\
\cline { 2 - 3 } Momentos & G1 & G2 \\
\hline M1 & $3,18 \pm 0,49$ & $3,41 \pm 0,40$ \\
M2 & $3,15 \pm 0,31$ & $3,52 \pm 0,30$ \\
M3 & $3,23 \pm 0,32$ & $3,75 \pm 0,39$ \\
M4 & $3,30 \pm 0,37$ & $3,66 \pm 0,43$ \\
M5 & $3,18 \pm 0,35$ & $3,68 \pm 0,40$ \\
\hline
\end{tabular}

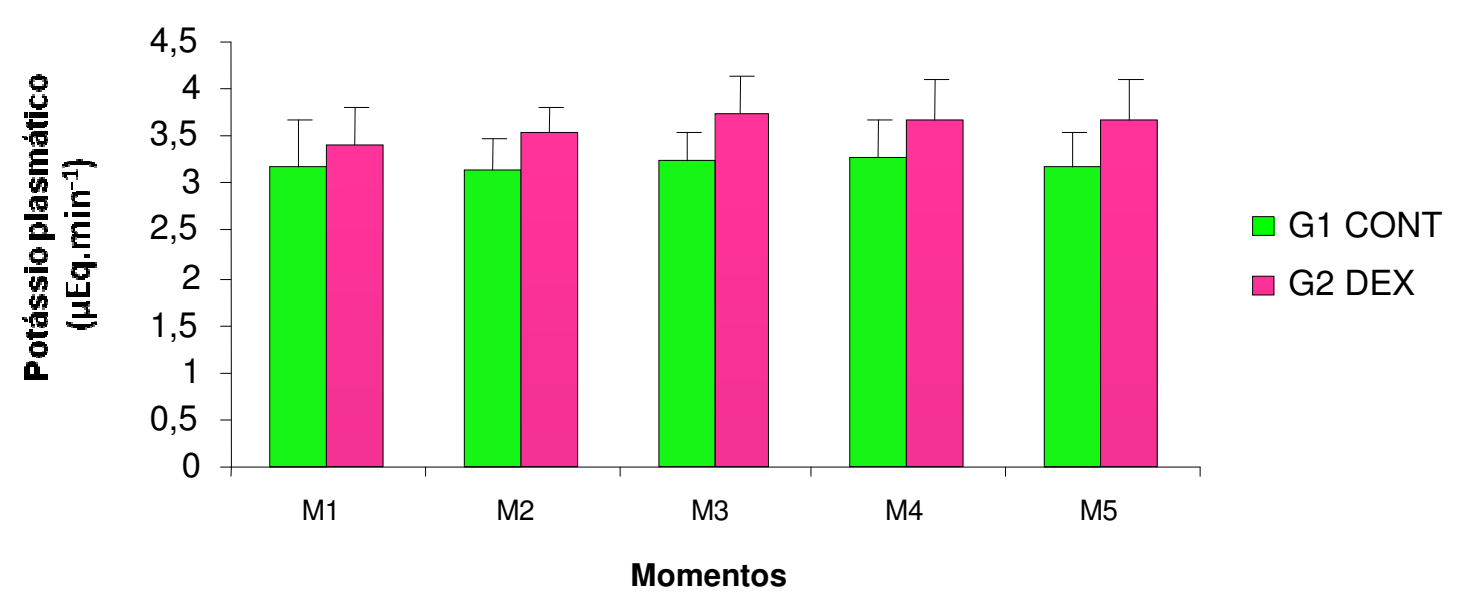

Figura 25. Potássio plasmático. Média e desvio padrão dos valores obtidos em cada momento nos dois grupos estudados.

Quadro 24. Potássio plasmático. Hipótese testada e comentários

\begin{tabular}{l|l|l}
\hline Hipóteses & Estatísticas & Comentários \\
\hline H01. Interação entre os grupos e momentos & $\mathrm{F}=1,32$ & Perfis similares \\
H02. Efeito entre grupos no conjunto dos & $\mathrm{p}>0,05$ & \\
momentos & $\mathrm{p}>0,85$ & Perfis iguais \\
H03. Diferença entre momentos no conjunto & $\mathrm{F}=2,79$ & Momentos não \\
dos grupos & $\mathrm{p}>0,05$ & diferem \\
\hline
\end{tabular}

Comentários gerais: na tabela 24 e figura 25 houve distribuição normal. Portanto, foram utilizados média e desvio padrão, como parâmetros estatísticos. Os testes das hipóteses, previamente estabelecidas, demonstram que não houve alteração significativa do potássio plasmático em nenhum momento ou grupo estudado durante todo experimento. 


\subsection{Osmolalidade Plasmática}

Tabela 25. Osmolalidade plasmática $\left(\mathrm{mOsm} \cdot \mathrm{kg}^{-1} \cdot \mathrm{H}_{2} \mathrm{O}^{-1}\right)$. Média e desvio padrão dos valores observados em cada momento nos dois grupos experimentais

\begin{tabular}{ccc}
\hline & \multicolumn{3}{c}{ Grupos } \\
\cline { 2 - 3 } Momentos & G1 & G2 \\
\hline M1 & $291,00 \pm 14,44$ & $281,10 \pm 12,85$ \\
M2 & $288,40 \pm 21,11$ & $275,20 \pm 18,22$ \\
M3 & $284,60 \pm 20,69$ & $278,00 \pm 18,48$ \\
M4 & $296,30 \pm 32,24$ & $278,20 \pm 14,36$ \\
M5 & $284,10 \pm 17,52$ & $278,30 \pm 14,91$ \\
\hline
\end{tabular}

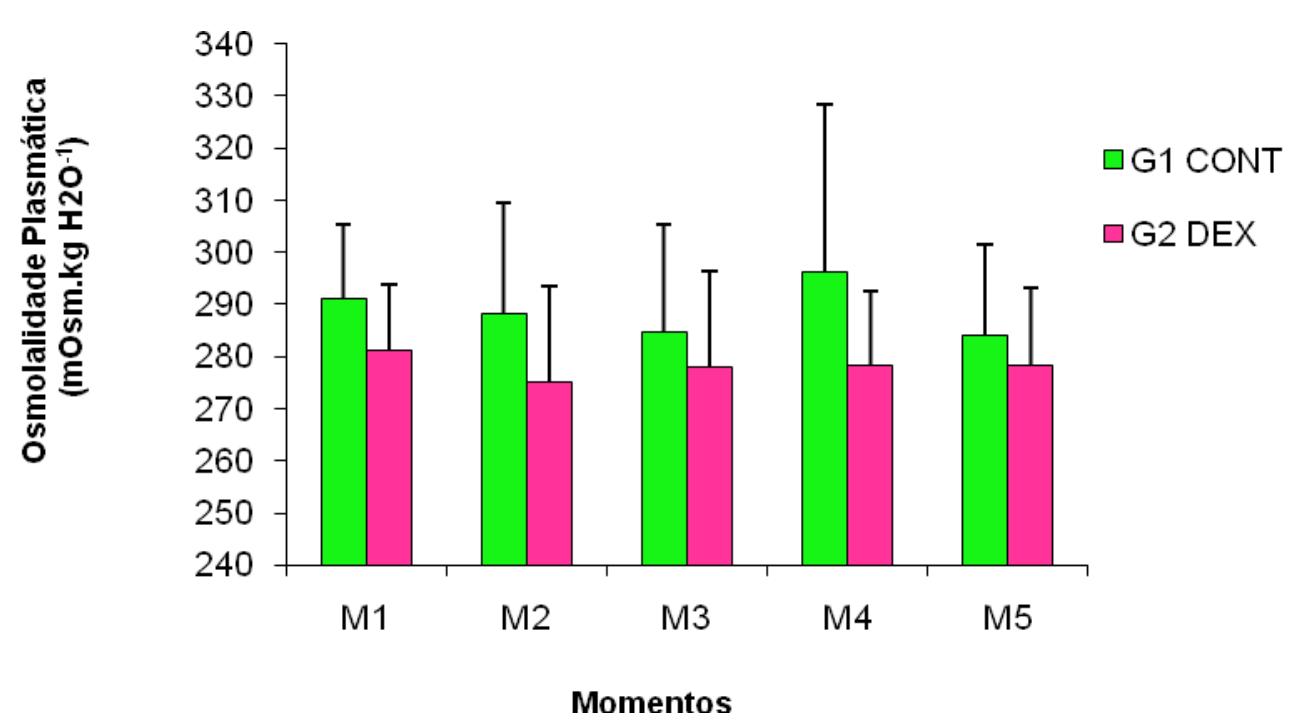

Figura 26. Osmolalidade plasmática. Média e desvio padrão dos valores observados em cada momento nos dois grupos estudados.

Quadro 25. Osmolalidade plasmática. Hipótese testada e comentários

\begin{tabular}{l|l|l}
\hline Hipóteses & Estatísticas & Comentários \\
\hline H01. Interação entre os grupos e momentos & $F=1,16$ & Perfis \\
H02. Efeito entre grupos no conjunto dos & $p>0,05$ & similares \\
momentos & $\mathrm{F}=2,04$ & Perfis iguais \\
H03. Diferença entre momentos no conjunto & $\mathrm{F}=1,05$ & \\
dos grupos & $\mathrm{p}>0,05$ & Momentos \\
\hline
\end{tabular}

Comentários gerais: na tabela 25 e figura 26 houve distribuição normal. Portanto, foram utilizados média e desvio padrão, como parâmetros estatísticos. Os testes das hipóteses, previamente estabelecidas, demonstram que não houve alteração significativa da osmolalidade plasmática em nenhum momento ou grupo estudado durante todo experimento. 


\subsection{Osmolalidade Urinária}

Tabela 26. Osmolalidade urinária $\left(\mathrm{mOsm} \cdot \mathrm{kg}^{-1} \cdot \mathrm{H}_{2} \mathrm{O}^{-1}\right)$. Média e desvio padrão dos valores observados em cada momento nos dois grupos experimentais

\begin{tabular}{ccc}
\hline & \multicolumn{2}{c}{ Grupos } \\
\cline { 2 - 3 } Momentos & G1 & G2 \\
\hline M1 & $720,00 \pm 295,16$ & $606,40 \pm 253,92$ \\
M2 & $720,20 \pm 351,48$ & $619,70 \pm 399,65$ \\
M3 & $538,30 \pm 155,60$ & $420,20 \pm 144,19$ \\
M4 & $470,20 \pm 114,42$ & $405,80 \pm 143,00$ \\
M5 & $421,50 \pm 137,22$ & $373,30 \pm 151,14$ \\
\hline
\end{tabular}

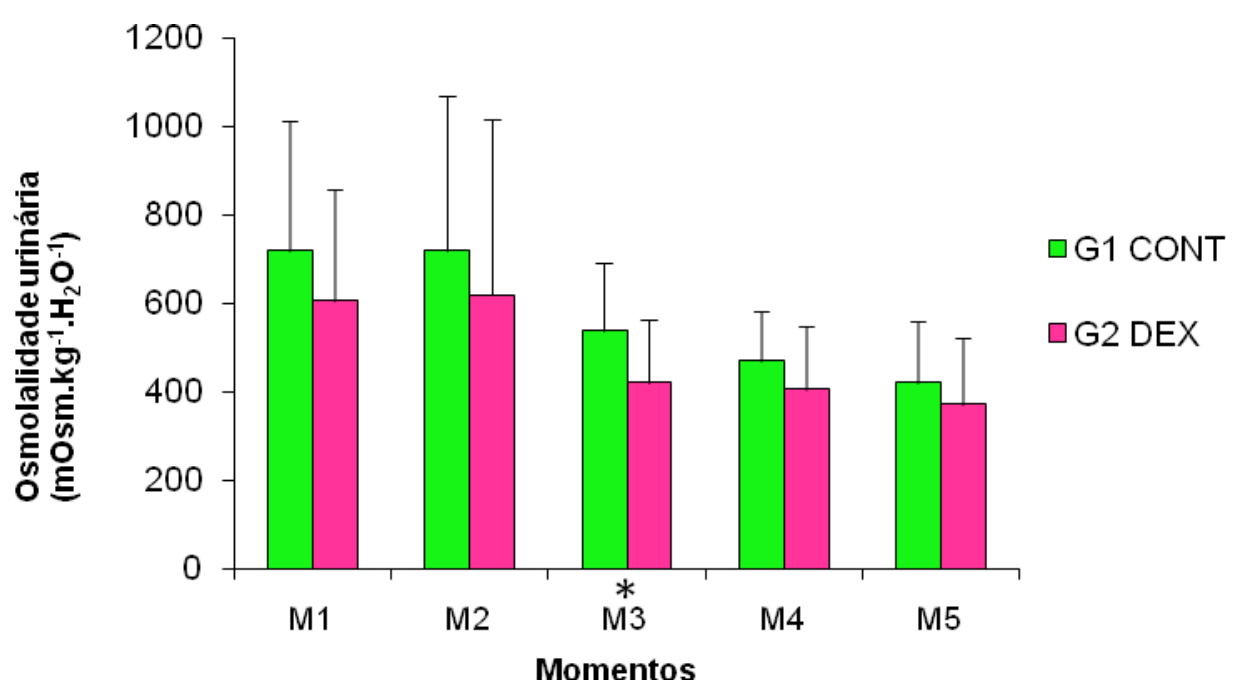

Figura 27. Osmolalidade urinária. Média e desvio padrão dos valores observados em cada momento nos dois grupos estudados.

Quadro 26. Osmolalidade urinária. Hipótese testada e comentários

\begin{tabular}{l|l|l}
\hline Hipóteses & Estatísticas & Comentários \\
\hline H01. Interação entre os grupos e momentos & $F=0,24$ & Perfis similares \\
H02. Efeito entre grupos no conjunto dos & $p>0,05$ & \\
momentos & $p>0,01$ & Perfis iguais \\
H03. Diferença entre momentos no conjunto & $F=16,30$ & No conjunto dos \\
dos grupos & $p<0,05$ & grupos: M1=M2 \\
& & M2>M3=M4=M5 \\
\hline
\end{tabular}

Comentários gerais: na tabela 26 e figura 27 houve distribuição normal. Portanto, foram utilizados média e desvio padrão, como parâmetros estatísticos. Os testes das hipóteses, previamente estabelecidas, demonstram que houve diminuição significativa da osmolalidade urinária a partir do momento 3 , mantendo esta redução até o final do experimento (M4 \& M5) em todos os grupos estudados. 


\subsection{Depuração Osmolar}

Tabela 27. Depuração osmolar $\left(\mathrm{mL} \cdot \mathrm{min}^{-1}\right)$. Média e desvio padrão dos valores observados em cada momento nos dois grupos experimentais.

\begin{tabular}{lcc}
\hline & \multicolumn{2}{c}{ Grupos } \\
\cline { 2 - 3 } Momentos & G1 & G2 \\
\hline M1 & $1,010 \pm 0,610$ & $0,903 \pm 0,486$ \\
M2 & $1,292 \pm 0,612$ & $0,899 \pm 0,422$ \\
M3 & $0,534 \pm 0,371$ & $0,618 \pm 0,394$ \\
M4 & $0,816 \pm 0,504$ & $0,905 \pm 0,533$ \\
M5 & $0,977 \pm 0,572$ & $1,055 \pm 0,578$ \\
\hline
\end{tabular}

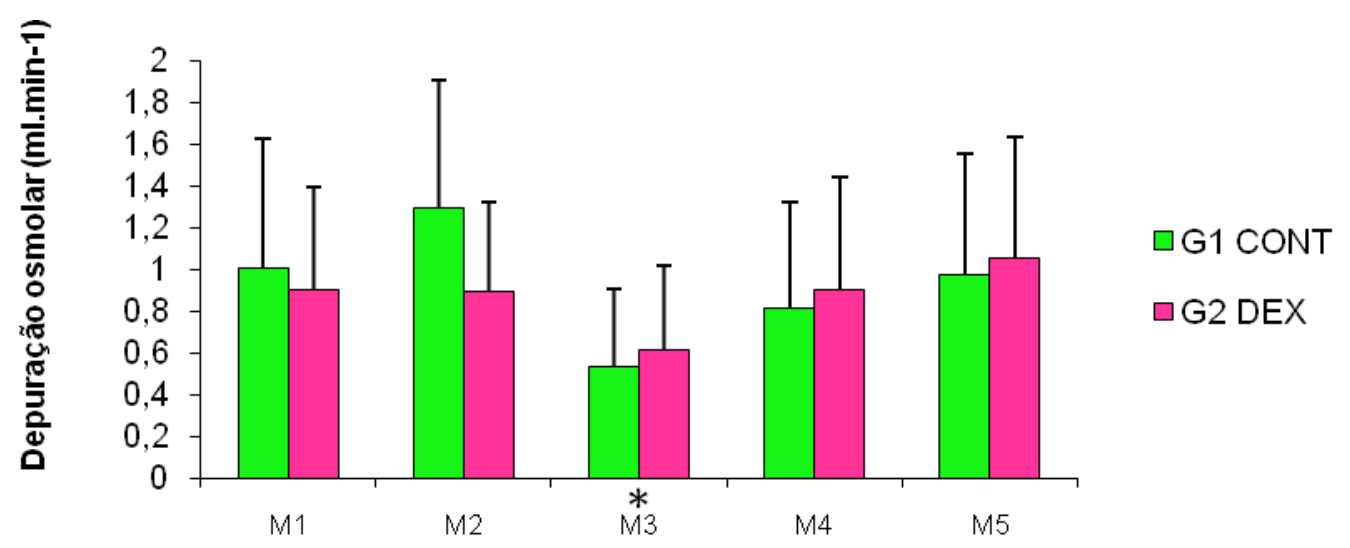

Momentos

Figura 28. Depuração osmolar. Média e desvio padrão dos valores observados em cada momento nos dois grupos experimentais.

Quadro 27. Depuração osmolar. Hipótese testada e comentários

\begin{tabular}{ll|l|l}
\hline \multicolumn{2}{c|}{ Hipóteses } & Estatísticas & Comentários \\
\hline H01. Interação entre os grupos e & $F=2,05$ & Perfis similares \\
momentos & $p>0,05$ & \\
H02. Efeito entre grupos no conjunto dos & $F=0,07$ & Perfis iguais \\
momentos & $p>0,05$ & \\
H03. Diferença entre momentos no & $F=7,60$ & No conjunto dos \\
conjunto dos grupos & & $p<0,05$ & grupos:M1=M2>M3 \\
& & M3=M4=M5;M3<M5 \\
\hline
\end{tabular}

Comentários gerais: na tabela 27 e figura 28 houve distribuição normal. Portanto, foram utilizados média e desvio padrão, como parâmetros estatísticos. Os testes das hipóteses, previamente estabelecidas, demonstram que houve diminuição significativa da depuração osmolar no momento 3 em relação ao início (M1 \& M2). A partir deste momento, a depuração osmolar foi aumentando gradativamente até o final do experimento (M4 \& M5) em todos os grupos estudados. 


\subsection{Depuração de Água Livre}

Tabela 28. Depuração de água livre $\left(\mathrm{mL} \cdot \mathrm{min}^{-1}\right)$. Média e desvio padrão dos valores observados em cada momento nos dois grupos experimentais.

\begin{tabular}{lcc}
\hline & \multicolumn{3}{c}{ Grupos } \\
\cline { 2 - 3 } Momentos & G1 & G2 \\
\hline M1 & $-0,415 \pm 0,249$ & $-0,449 \pm 0,211$ \\
M2 & $-0,416 \pm 0,415$ & $-0,432 \pm 0,384$ \\
M3 & $-0,105 \pm 0,197$ & $-0,175 \pm 0,259$ \\
M4 & $-0,160 \pm 0,277$ & $-0,225 \pm 0,326$ \\
M5 & $-0,134 \pm 0,424$ & $-0,143 \pm 0,344$ \\
\hline
\end{tabular}

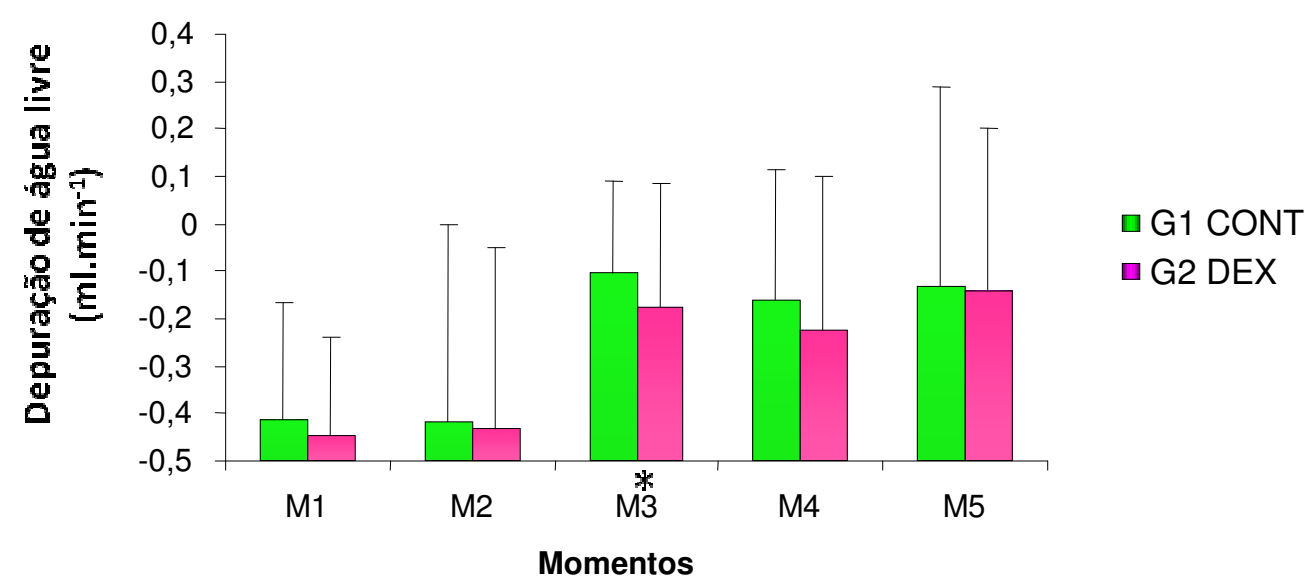

Figura 29. Depuração de água livre. Média e desvio padrão dos valores observados em cada momento nos dois grupos estudados.

Quadro 28. Depuração de água livre. Hipótese testada e comentários

\begin{tabular}{l|l|l}
\hline Hipóteses & Estatísticas & Comentários \\
\hline H01. Interação entre os grupos e momentos & $\mathrm{F}=0,11$ & Perfis similares \\
H02. Efeito entre grupos no conjunto dos & $p>0,05$ & \\
$\begin{array}{l}\text { momentos } \\
\text { H03. Diferença entre momentos no conjunto }\end{array}$ & $p>0,05$ & Perfis iguais \\
dos grupos & $\mathrm{F}=13,30$ & No conjunto dos \\
& $p<0,05$ & grupos:M1=M2 \\
& $\mathrm{M} 2<\mathrm{M} 3=\mathrm{M} 4=\mathrm{M} 5$ \\
\hline
\end{tabular}

Comentários gerais: na tabela 28 e figura 29 houve distribuição normal. Portanto, foram utilizados média e desvio padrão, como parâmetros estatísticos. Os testes das hipóteses, previamente estabelecidas, demonstram que houve aumento significativo da depuração água livre a partir do momento 3 , mantendo este aumento até o final do experimento (M4 \& M5) em todos os grupos estudados. 


\subsection{Depuração de Sódio}

Tabela 29. Depuração de Sódio $\left(\mathrm{mL} \cdot \mathrm{min}^{-1}\right)$. Média e desvio padrão dos valores obtidos em cada momento nos dois grupos experimentais

\begin{tabular}{ccc}
\hline & \multicolumn{2}{c}{ Grupos } \\
\cline { 2 - 3 } Momentos & G1 & G2 \\
\hline M1 & $0,498 \pm 0,540$ & $0,524 \pm 0,561$ \\
M2 & $0,640 \pm 0,630$ & $0,485 \pm 0,431$ \\
M3 & $0,269 \pm 0,275$ & $0,500 \pm 0,429$ \\
M4 & $0,424 \pm 0,377$ & $0,706 \pm 0,577$ \\
M5 & $0,541 \pm 0,443$ & $0,885 \pm 0,753$ \\
\hline
\end{tabular}

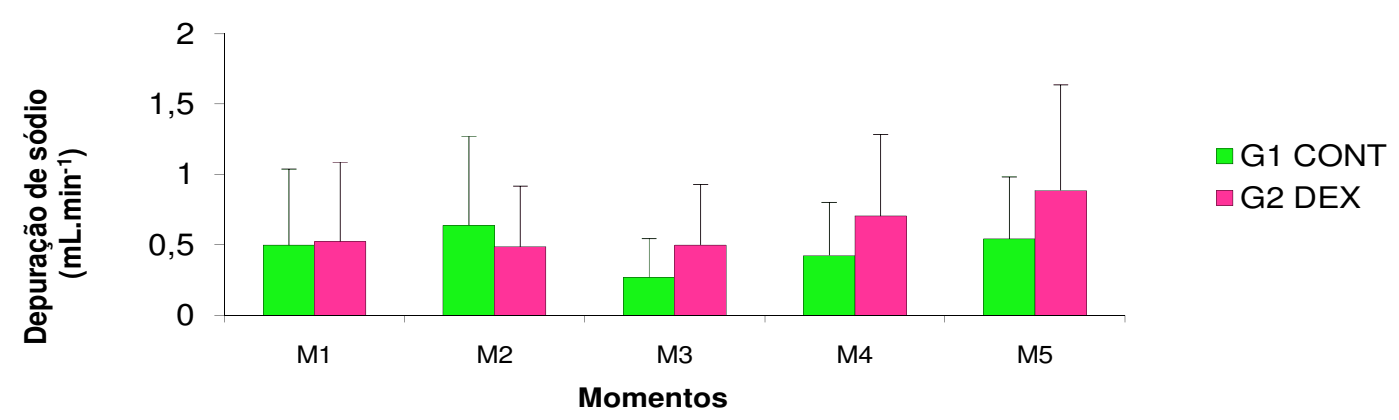

Figura 30. Depuração de Sódio. Média e desvio padrão dos valores observados em cada momento nos dois grupos estudados.

Quadro 29. Depuração de Sódio. Hipótese testada e comentários

\begin{tabular}{l|l|l}
\hline \multicolumn{1}{c|}{ Hipóteses } & Estatísticas & Comentários \\
\hline H01. Interação entre os grupos e momentos & $F=1,65$ & Perfis similares \\
H02. Efeito entre grupos no conjunto dos & $p>0,05$ & \\
momentos & $p>0,64$ & Perfis iguais \\
H03. Diferença entre momentos no conjunto & $F=2,17$ & Momentos não \\
dos grupos & $p>0,05$ & diferem \\
\hline
\end{tabular}

Comentários gerais: na tabela 29 e figura 30 houve distribuição normal. Portanto, utilizados média e desvio padrão, como parâmetros estatísticos. Os testes das hipóteses, previamente estabelecidas, demonstram que não houve alteração significativa da depuração de sódio em nenhum momento ou grupo estudado durante todo experimento. 


\subsection{Excreção Fracionária de Sódio}

Tabela 30. Excreção fracionária de sódio $\left(\mu \mathrm{Eq} \cdot \mathrm{min}^{-1}\right)$. Médias e desvio padrào dos valores observados em cada momento nos dois grupos experimentais

\begin{tabular}{ccc}
\hline & \multicolumn{2}{c}{ Grupos } \\
\cline { 2 - 3 } Momentos & G1 & G2 \\
\hline M1 & $1,919 \pm 1,735$ & $2,178 \pm 2,400$ \\
M2 & $2,177 \pm 2,224$ & $2,142 \pm 1,924$ \\
M3 & $2,989 \pm 2,150$ & $6,702 \pm 4,914$ \\
M4 & $6,480 \pm 13,482$ & $6,062 \pm 4,740$ \\
M5 & $8,276 \pm 16,970$ & $5,486 \pm 4,410$ \\
\hline
\end{tabular}

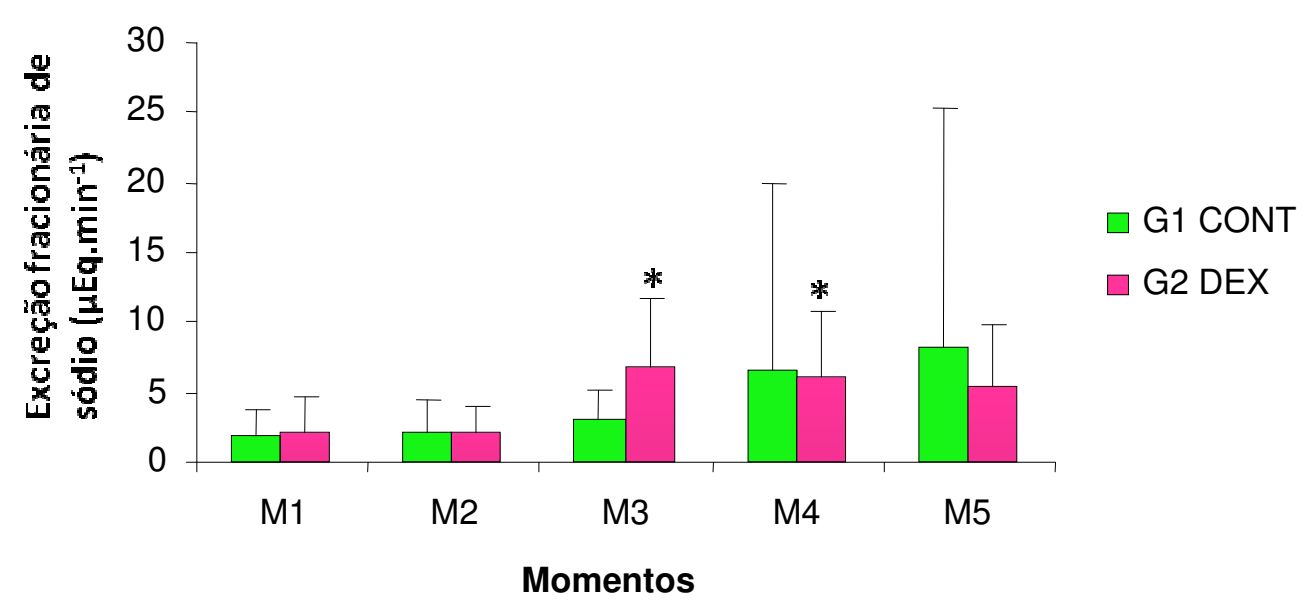

Figura 31. Excreção fracionária de sódio. Média e desvio padrão dos valores observados em cada momento nos dois grupos estudados.

Quadro 30. Excreção fracionária de sódio. Hipótese testada e comentários

\begin{tabular}{|c|c|c|}
\hline Hipóteses & Estatísticas & Comentários \\
\hline $\begin{array}{l}\text { H01. Interação entre os grupos e } \\
\text { momentos } \\
\text { H02. Efeito de grupo em cada } \\
\text { momento } \\
\text { H03. Efeito de momento em cada } \\
\text { grupo }\end{array}$ & $\begin{array}{l}p<0,05 \\
p>0,05 \\
p<0,05\end{array}$ & $\begin{array}{l}\text { Perfis não similares } \\
M 1, M 2, M 3, M 4 \text { e M5: } \\
\text { G1=G2 } \\
\text { G1: M1=M2=M3=M4=M5 } \\
\text { G2: } M 1=M 2<M 5<M 3=M 4\end{array}$ \\
\hline
\end{tabular}

Comentários gerais: na tabela 30 e figura 31 houve distribuição normal. Portanto, média e desvio padrão, como parâmetros estatísticos. Os testes das hipóteses, previamente estabelecidas, demonstram que a excreção fracionária de sódio aumentou significativamente no grupo 2 nos momentos 3 e 4 em relação ao início do experimento. 


\subsection{Excreção Urinária de Sódio}

Tabela 31. Excreção urinária de sódio $\left(\mu E q \cdot \mathrm{min}^{-1}\right)$. Médias e desvio padrào dos valores observados em cada momento nos dois grupos experimentais

\begin{tabular}{lcc}
\hline & \multicolumn{2}{c}{ Grupos } \\
\cline { 2 - 3 } Momentos & G1 & G2 \\
\hline M1 & $69,828 \pm 74,655$ & $77,836 \pm 84,640$ \\
M2 & $89,996 \pm 89,086$ & $71,414 \pm 63,250$ \\
M3 & $36,109 \pm 35,441$ & $72,104 \pm 61,570$ \\
M4 & $57,656 \pm 50,176$ & $101,94 \pm 84,720$ \\
M5 & $71,361 \pm 57,968$ & $129,29 \pm 111,29$ \\
\hline
\end{tabular}

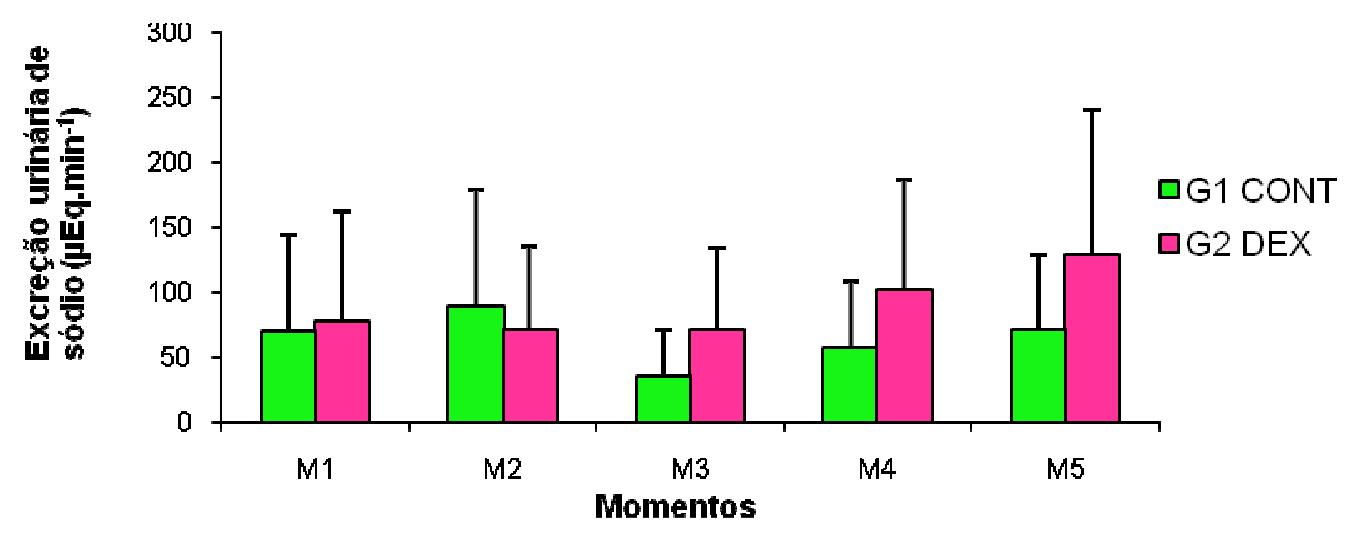

Figura 32. Excreção urinária de sódio. Média e desvio padrão dos valores observados em cada momento nos dois grupos estudados.

Quadro 31. Excreção urinária de sódio. Hipótese testada e comentários

\begin{tabular}{l|l|l}
\hline Hipóteses & Estatísticas & Comentários \\
\hline H01. Interação entre os grupos e momentos & $F=0,42$ & Perfis similares \\
H02. Efeito entre grupos no conjunto dos & $p>0,05$ & \\
momentos & $p>0,39$ & Perfis iguais \\
H03. Diferença entre momentos no conjunto dos & $F=7,09$ & Momentos não \\
grupos & $p>0,05$ & diferem \\
\hline
\end{tabular}

Comentários gerais: na tabela 31 e figura 32 não houve distribuição normal. Portanto, utilizados mediana como variável estatística. Os testes das hipóteses, previamente estabelecidas, demonstram que não houve alteração significativa da excreção urinária de sódio em nenhum momento ou grupo estudado durante todo experimento. 


\subsection{Excreção Urinária de Potássio}

Tabela 32. Excreção urinária de potássio $\left(\mu E q \cdot \min ^{-1}\right)$. Média e desvio padrão dos valores observados em cada momento nos dois grupos experimentais

\begin{tabular}{ccc}
\hline & & Grupos \\
\cline { 2 - 3 } Momentos & G1 & G2 \\
\hline M1 & $31,86 \pm 19,79$ & $44,34 \pm 15,16$ \\
M2 & $34,83 \pm 24,62$ & $40,95 \pm 12,77$ \\
M3 & $14,57 \pm 11,51$ & $31,05 \pm 24,36$ \\
M4 & $36,60 \pm 29,02$ & $51.92 \pm 32,90$ \\
M5 & $36,70 \pm 27,63$ & $52,81 \pm 25,80$ \\
\hline
\end{tabular}

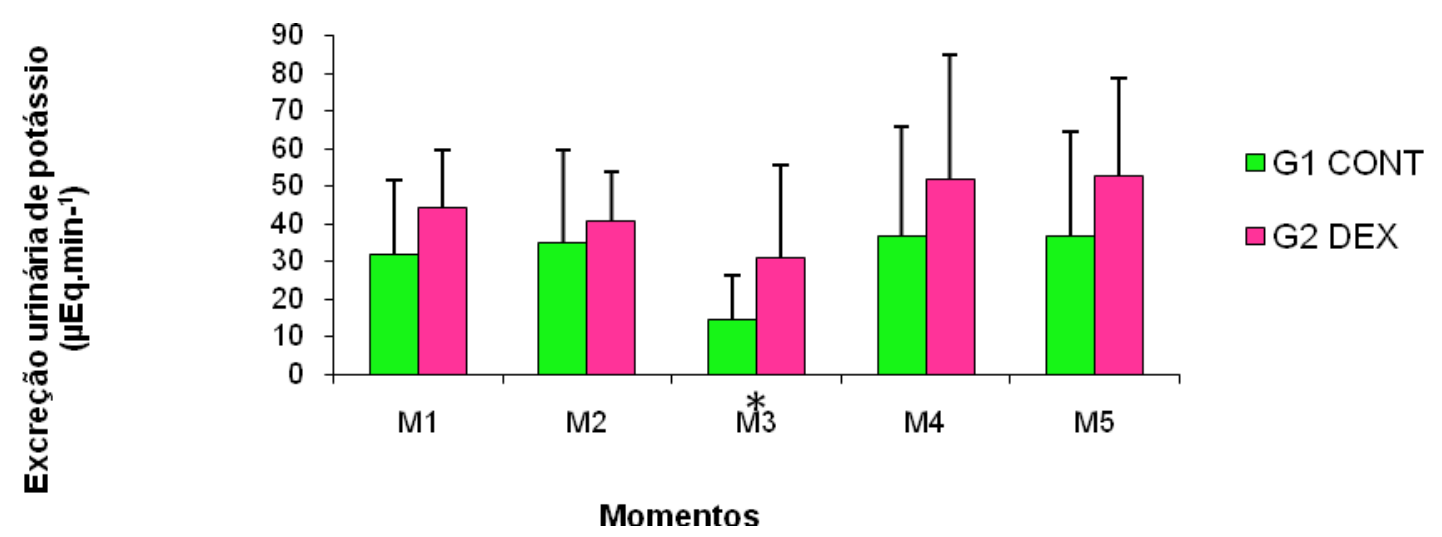

Figura 33. Excreção urinária de potássio. Média e desvio padrão dos valores observados em cada momento nos dois grupos estudados.

Quadro 32. Excreção urinária de potássio. Hipótese testada e comentários

\begin{tabular}{l|l|l}
\hline Hipóteses & Estatísticas & Comentários \\
\hline H01. Interação entre os grupos e & $\mathrm{F}=0,42$ & Perfis similares \\
momentos & $p>0,05$ & \\
H02. Efeito entre grupos no & $\mathrm{F}=2,39$ & Perfis iguais \\
conjunto dos momentos & $\mathrm{p}>0,05$ & \\
H03. Diferença entre momentos & $\mathrm{F}=7,09$ & No conjunto dos grupos: \\
no conjunto dos grupos & $\mathrm{p}<0,05$ & $\mathrm{M} 1=\mathrm{M} 2>\mathrm{M} 3 ; \mathrm{M} 1=\mathrm{M} 4=\mathrm{M} 5$ \\
\hline
\end{tabular}

Comentários gerais: na tabela 32 e figura 33 houve distribuição normal. Portanto, foram utilizados média e desvio padrão, como parâmetros estatísticos. Os testes das hipóteses, previamente estabelecidas, demonstram que houve diminuição significativa da excreção urinária de potássio apenas no momento 3 em relação aos momentos iniciais (M1 \& M2), voltando aos valores iniciais até o final do experimento (M4 \& M5) em todos os grupos estudados 


\subsection{Depuração de Potássio}

Tabela 33. Depuração de potássio $\left(\mathrm{mL} \cdot \mathrm{min}^{-1}\right)$. Média e desvio padrão dos valores observados em cada momento nos dois grupos experimentais

\begin{tabular}{lcc}
\hline & \multicolumn{2}{c}{ Grupos } \\
\cline { 2 - 3 } Momentos & G1 & G2 \\
\hline M1 & $9,86 \pm 5,45$ & $13,04 \pm 4,14$ \\
M2 & $11,01 \pm 7,45$ & $11,70 \pm 3,91$ \\
M3 & $4,43 \pm 3,29$ & $8,41 \pm 6,74$ \\
M4 & $11,02 \pm 8,15$ & $14,40 \pm 9,26$ \\
M5 & $11,32 \pm 7,75$ & $14,55 \pm 7,15$ \\
\hline
\end{tabular}

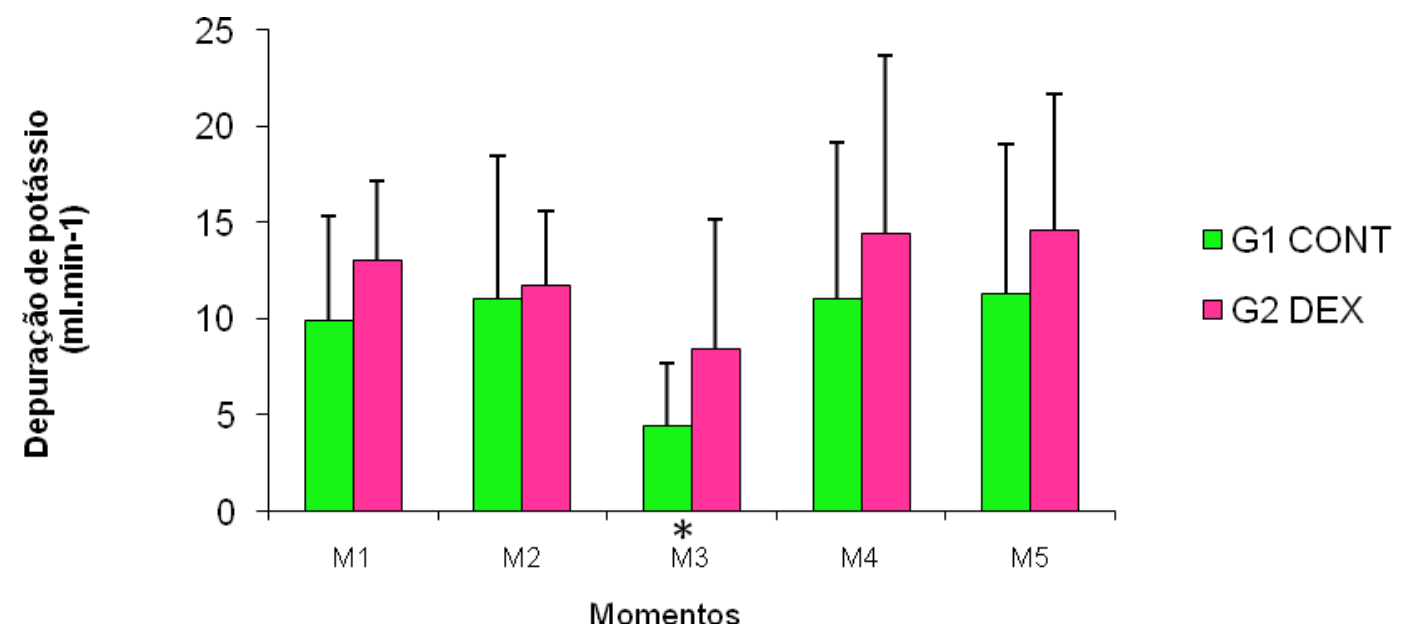

Figura 34. Depuração de potássio. Média e desvio padrão dos valores observados em cada momento nos dois grupos estudados.

Quadro 33. Depuração de potássio Hipótese testada e comentários

\begin{tabular}{|c|c|c|}
\hline Hipóteses & Estatísticas & Comentários \\
\hline $\begin{array}{l}\text { H01. Interação entre os grupos e } \\
\text { momentos }\end{array}$ & $\begin{array}{l}F=0,45 \\
p>0,05\end{array}$ & Perfis similares \\
\hline $\begin{array}{l}\text { H02. Efeito entre grupos no } \\
\text { conjunto dos momentos }\end{array}$ & $\begin{array}{l}F=1,43 \\
p>0,05\end{array}$ & Perfis iguais \\
\hline $\begin{array}{l}\text { H03. Diferença entre momentos no } \\
\text { conjunto dos grupos }\end{array}$ & $\begin{array}{l}F=7,70 \\
p<0,05\end{array}$ & $\begin{array}{l}\text { No conjunto dos grupos: } \\
\mathrm{M} 1=\mathrm{M} 2>\mathrm{M} 3 ; \mathrm{M} 1=\mathrm{M} 4=\mathrm{M} 5\end{array}$ \\
\hline
\end{tabular}

Comentários gerais: na tabela 33 e figura 34 houve distribuição normal. Portanto, foram utilizados média e desvio padrão, como parâmetros estatísticos. Os testes das hipóteses, previamente estabelecidas, demonstram que houve diminuição significativa da excreção urinária de potássio apenas no momento 3 em relação aos momentos iniciais (M1 \& M2), voltando aos valores iniciais até 0 final do experimento (M4 \& M5) em todos os grupos estudados. 


\subsection{Excreção Fracionária de Potássio}

Tabela 34. Excreção fracionária de potássio (\%). Média e desvio padrão dos valores observados em cada momento nos dois grupos experimentais

\begin{tabular}{ccc}
\hline & & Grupos \\
\cline { 2 - 3 } Momentos & G1 & G2 \\
\hline M1 & $51,97 \pm 31,04$ & $59,14 \pm 26,00$ \\
M2 & $42,98 \pm 26,40$ & $57,05 \pm 19,90$ \\
M3 & $63,80 \pm 48,49$ & $107,46 \pm 27,36$ \\
M4 & $66,48 \pm 33,89$ & $124,07 \pm 58,85$ \\
M5 & $70,27 \pm 39,70$ & $98,15 \pm 39,44$ \\
\hline
\end{tabular}

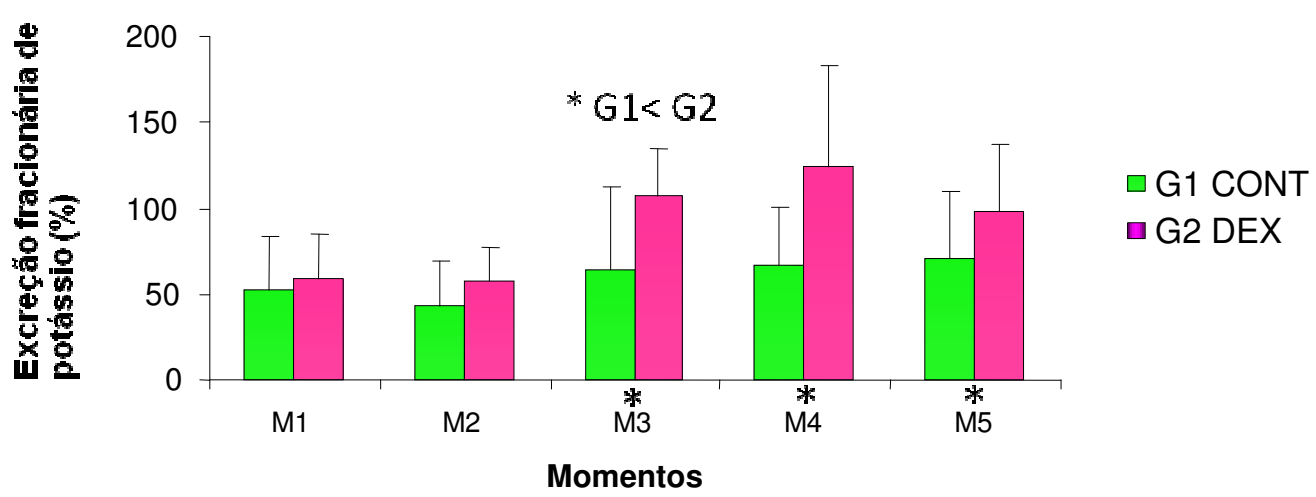

Figura 35. Excreção fracionária de potássio. Média e desvio padrão dos valores observados em cada momento nos dois grupos estudados.

Quadro 34. Excreção fracionária de potássio. Hipótese testada e comentários

\begin{tabular}{l|l|l}
\hline \multicolumn{1}{c|}{ Hipótese } & Estatística & Comentário \\
\hline H01. Interação entre os grupos e & $F=3,29$ & Perfis não similares \\
momentos & $p<0,05$ & \\
H02. Efeito de grupo em cada & $F=5,43$ & $M 1, M 2 \& M 5: G 1=G 2$ \\
momento & $p<0,05$ & $M 3$ \& M: G1<G2 \\
H03. Efeito de momento em cada & $F=12,26$ & $G 1: M 1=M 2=M 3=M 4=M 5$ \\
grupo & $p<0,05$ & $G 2: M 1=M 2<M 3=M 4=M 5$ \\
\hline
\end{tabular}

Comentários gerais: na tabela 34 e figura 35 houve distribuição normal. Portanto, foram utilizados média e desvio padrão, como parâmetros estatísticos. Os testes das hipóteses, previamente estabelecidas, demonstram perfis não similares entre grupos/momentos e entre momentos no grupo 2. Entre os grupos, nos momentos 3 e 4 , a excreção fracionária de potássio foi significativamente maior no G2 (DEX) em relação ao G1 (CONT). Somente no grupo 2 houve aumento significativo da excreção fracionária de potássio nos momentos 3 e 4 em relação aos momentos iniciais. 


\subsection{Microscopia de Luz dos Rins}

Tabela 35. Resultado da microscopia de luz do grupo controle - G1

\begin{tabular}{c|c|c|c|c}
\hline Cães & $\begin{array}{l}\text { Dilatação } \\
\text { tubular }\end{array}$ & $\begin{array}{l}\text { Degeneração } \\
\text { Tubular }\end{array}$ & Necrose & Inflamação \\
\hline 1 & $2+$ & $1+$ & $1+$ & $3+$ \\
2 & $1+$ & $2+$ & 0 & $1+$ \\
3 & $3+$ & $2+$ & $3+$ & $3+$ \\
4 & $1+$ & $2+$ & 0 & $3+$ \\
5 & $3+$ & $3+$ & $2+$ & $2+$ \\
6 & $2+$ & $2+$ & 0 & $3+$ \\
7 & $1+$ & $1+$ & $1+$ & $1+$ \\
8 & $1+$ & $1+$ & 0 & 0 \\
9 & $1+$ & $3+$ & 0 & 0 \\
10 & $2+$ & $2+$ & $2+$ & $3+$ \\
\hline
\end{tabular}

Tabela 36. Resultado da microscopia de luz do grupo dexmedetomidina - G2

\begin{tabular}{c|c|c|c|c}
\hline Cães & $\begin{array}{l}\text { Dilatação } \\
\text { tubular }\end{array}$ & $\begin{array}{l}\text { Degeneração } \\
\text { Tubular }\end{array}$ & Necrose & Inflamação \\
\hline 1 & $1+$ & 0 & 0 & 0 \\
2 & $2+$ & $2+$ & $2+$ & $3+$ \\
3 & $1+$ & $2+$ & 0 & $3+$ \\
4 & $2+$ & $2+$ & 0 & $1+$ \\
5 & $2+$ & $2+$ & 0 & $3+$ \\
6 & $3+$ & $3+$ & $2+$ & $3+$ \\
7 & $3+$ & $3+$ & $2+$ & $3+$ \\
8 & $3+$ & $3+$ & $1+$ & $2+$ \\
9 & $3+$ & $2+$ & $1+$ & $1+$ \\
10 & $3+$ & $2+$ & $2+$ & $2+$ \\
\hline
\end{tabular}




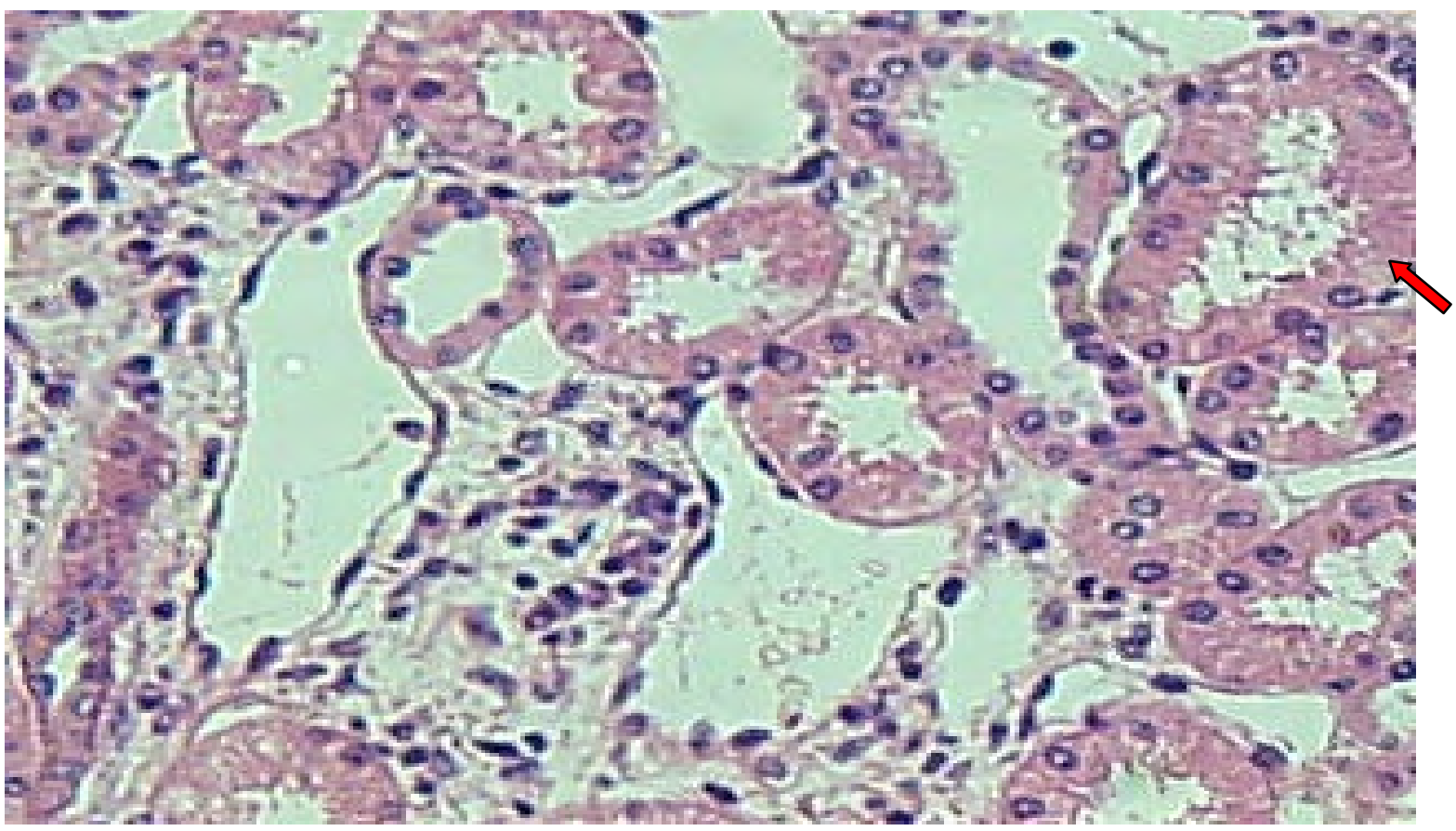

Figura 36. Rim esquerdo do cão no 3 , do G1 (CONT), apresentando necrose. Ácido periódico de Schiff (PAS) 420X.

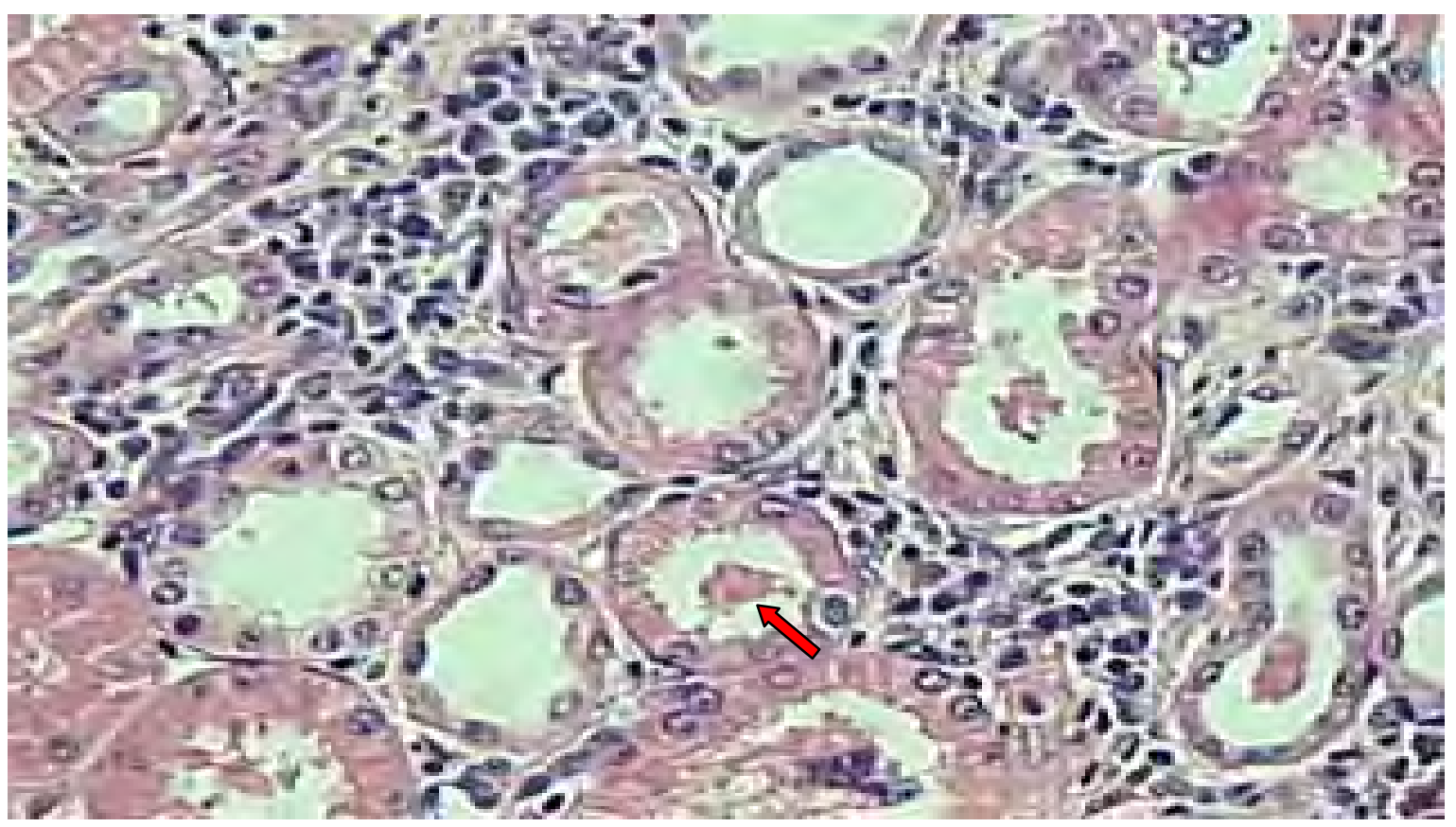

Figura 37. Rim esquerdo do cão $n^{\circ}$ 3, do G2 (DEX), apresentando dilataçào tubular com restos celulares. Ácido periódico de Schiff (PAS) 420X. 


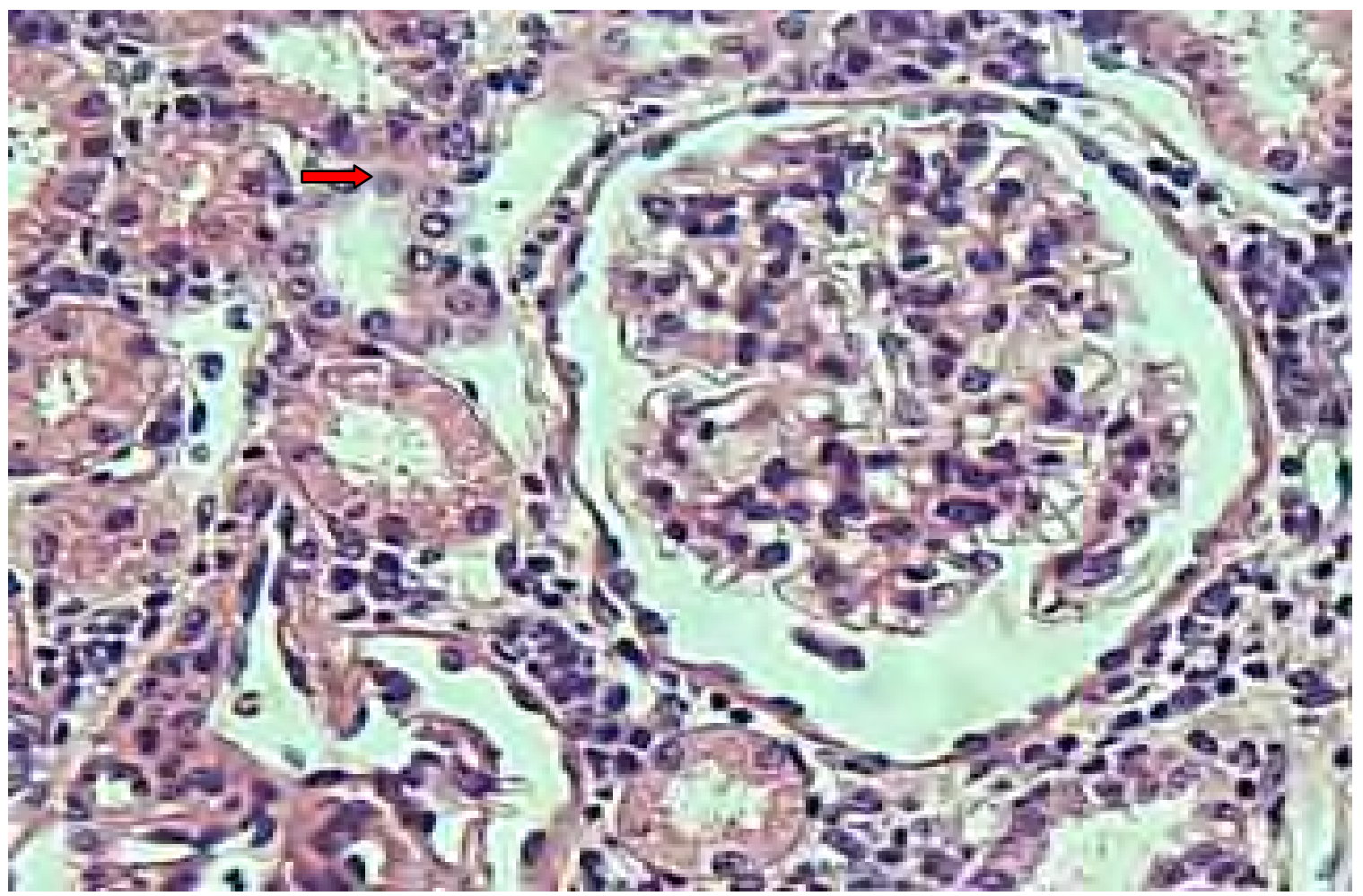

Figura 38. Rim esquerdo do cão $n^{\circ}$ 7, do G2 (DEX), apresentando células inflamatórias (roxeadas). Ácido periódico de Schiff (PAS) 420X.

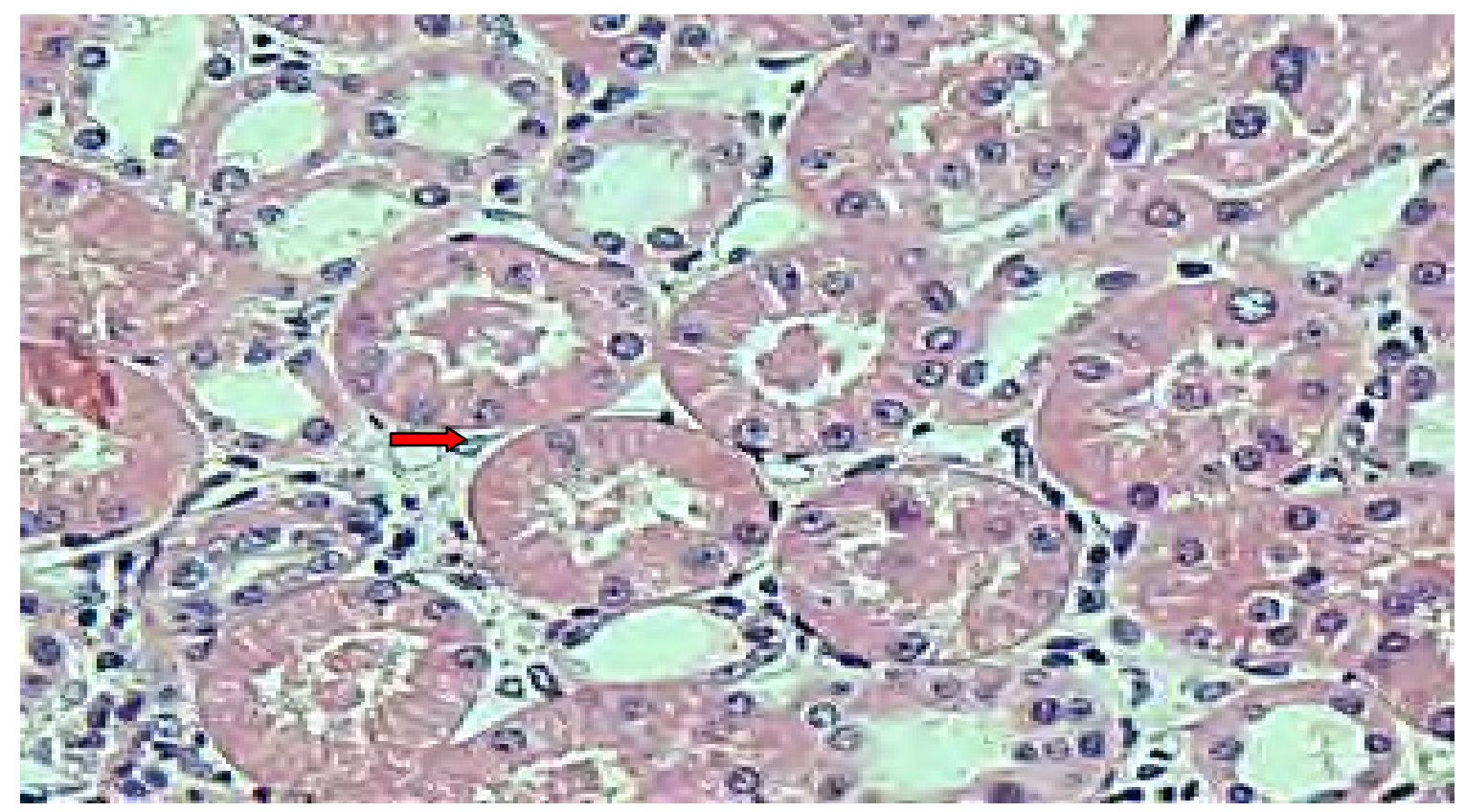

Figura 39. Rim esquerdo do cão $\mathrm{n}^{\circ}$ 2, do G2 (DEX), apresentando vacuolização tubular. Ácido periódico de Schiff (PAS) 420X. 


\section{DISCUSSÃO}

\subsection{Da Metodologia}

\subsubsection{Grupos Experimentais}

A pesquisa foi realizada em cães de ambos os sexos, aspecto sadio, porém sem raça definida por se tratar de cães de rua. O cão foi escolhido para modelo experimental por ser de médio ou grande porte, fato que facilita desde o seu manuseio e coleta de material biológico em quantidade adequada para exames laboratoriais, até a monitorização hemodinâmica, renal e ventilatória, que apresentam padrões semelhantes aos dos seres humanos durante a anestesia, o que torna os procedimentos bastante similares. Devido à forma peculiar de obtenção deste animal, que permite grande variação de raça e tamanhos, cada cão teve seu próprio controle no momento inicial.

Um dos objetivos desta pesquisa foi estabelecer a maior estabilidade hemodinâmica possível durante a indução e manutenção da anestesia, para que houvesse o mínimo de interferência das variáveis nos estudos renais, portanto os hipnoanalgésicos selecionados para a realização da indução anestésica foram propofol e fentanil, que nas doses utilizadas provocam pouca alteração hemodinâmica (Flacke et al., 1985; Nascimento et al., 1994; Reves et al., 2000). A dose utilizada (6 mg. $\left.\mathrm{Kg}^{-1}\right)$ foi similar à utilizada por Wouters et al. (1993) (7 mg. $\left.\mathrm{Kg}^{-1}\right)$. A manutenção da anestesia foi realizada com isoflurano na concentração expiratória de 1,7 CAM durante a fase de preparação cirúrgica e, reduzida para 1,0 CAM durante a fase de manutenção, permanecendo até o 
final do experimento. Tal redução se fez necessária para evitar também que houvesse alterações importantes nos parâmetros hemodinâmicos, uma vez que, nessa fase, havia diminuição do estímulo doloroso.

O bloqueio neuromuscular foi realizado com o brometo de rocurônio, que nas doses utilizadas não provoca alterações hemodinâmicas significativas (Roberston \& Hull, 1994), tampouco promove liberação de histamina (Levy e Davis, 1944), portanto é muito provável que este medicamento não tenha interferido nas variáveis estudadas.

\subsubsection{Hidratação}

A hidratação dos animais nos dois grupos,foi realizada com solução de Ringer com lactado na dose de $18 \mathrm{~mL} \cdot \mathrm{kg}^{-1} \cdot \mathrm{h}^{-1}$ durante os primeiros 30 minutos. Ao iniciar-se o período de estabilização hemodinâmica, a dose foi diminuída para $6 \mathrm{~mL} \cdot \mathrm{kg}^{-1} \cdot \mathrm{h}^{-1}$. A hidratação teve como finalidade repor as perdas que acontecem devido à manipulação cirúrgica e minimizar alterações hemodinâmicas, principalmente em cães que chegaram à mesa cirúrgica sem uma hidratação adequada. A expansão do fluido extracelular tem ainda como objetivos a obtenção de clearence com maior fidelidade e manter um adequado débito urinário, otimizando o estudo da função renal.

\subsubsection{Ventilação}

Todos os animais foram submetidos à respiração com pressão positiva intermitente, oxigênio, modo controlado a volume com freqüência respiratória entre 12 e 16 movimentos por minuto e volume corrente determinado em função do peso corporal do cão, $20 \mathrm{~mL} \cdot \mathrm{kg}^{-1}$. Os ajustes na 
ventilação foram determinados pelos valores da pressão expiratória final do dióxido de carbono $\left(\mathrm{ETCO}_{2}\right)$, a fim de mantê-los dentro dos limites de 35 a 45 $\mathrm{mmHg}$ (tabela 6, figura 7 e quadro 6), já que esta apresenta uma boa correlação entre os níveis de $\mathrm{PaCO}_{2}$ (Braz et al., 1995). Na tabela 5, figura 6 e quadro 5 , houve distribuição normal dos resultados da saturação periférica de oxigênio. Portanto, foram utilizados média e desvio padrão como parâmetros estatísticos. Os testes das hipóteses, previamente estabelecidas, demonstraram que não houve alteração significativa da saturação de pulso de oxigênio em nenhum momento ou grupo estudado durante todo o experimento.

\subsection{Dos Resultados}

\subsubsection{Frequência Cardíaca}

A freqüência cardíaca apresentou diferença significativa entre os grupos a partir de M2 (tabela e quadro 9, figura 10), marcado pelo início da infusão de dexmedetomidina até o final do experimento, onde houve diminuição da frequência cardíaca nos momentos 2, 3, 4 e 5 em relação ao grupo controle. Nos grupos, observamos que no G2 a frequência cardíaca foi menor nos M2, M3, M4 e M5 em relação ao momento inicial, enquanto no G1 a freqüência cardíaca aumentou progressivamente durante o experimento em relação aos momentos iniciais. Esse aumento ocorrido no G1 era esperado, já que a manutenção da anestesia com 0,6 CAM de isoflurano por tempo prolongado tenderia a aumentá-la, provavelmente por ativação do barorreflexo (Kotrly et al, 1984; Saeki, 1996), em decorrência da diminuição da pós-carga (Eger, 1981).

Entre os agentes indutores anestésicos utilizados neste experimento, o fentanil seria a medicação que tenderia a diminuir a frequência 
cardíaca, já que o propofol promove efeitos mínimos sobre o cronotropismo cardíaco (Twerky, 1993, Reves et al., 2000). Segundo Laubie (1977) e Reitan, o efeito bradicardizante do fentanil está relacionado ao aumento do tônus parassimpático. Castiglia et al. (1997), em estudo experimental, utilizaram doses elevadas de citrato de fentanil $\left(20 \mu \mathrm{g} \cdot \mathrm{kg}^{-1}\right)$ associado a propofol na indução anestésica e observaram queda na freqüência cardíaca. Neste experimento, ao contrário observado por Castiglia, o grupo controle apresentou discreto aumento da freqüência cardíaca a partir do M2, porém foram utilizadas doses clínicas de opióide $\left(5 \mu \mathrm{g} \cdot \mathrm{kg}^{-1}\right)$.

O experimento de isquemia renal realizado por Módolo et al (2000) não mostrou aumento significativo na freqüência cardíaca após episódio isquêmico. Este fato indica que provavelmente neste experimento, a isquemia renal na qual foram submetidos os cães, não interferiu na freqüência cardíaca, similarmente ao estudo de Módolo.

Administração de $1 \mu \mathrm{g} \cdot \mathrm{kg}^{-1}$ de dexmedetomidina em bolus, resulta em diminuição da freqüência cardíaca, especialmente em voluntários jovens e saudáveis (Bloor et al., 1992) e este efeito parece não ter relação com ação direta da droga sobre o coração (Housmans, 1990). Este experimento corroborou com Bloor, ao ser observada diminuição significativa da freqüência cardíaca no G2, após o início do segundo momento. Em voluntários saudáveis, dexmedetomidina diminuiu em até $90 \%$ os níveis de catecolaminas circulantes (Scheinin et al., 1992; Kauppila, 1991), podendo ser esta a justificativa para a queda da freqüência cardíaca observada neste experimento. 
Outro mecanismo que pode explicar a diminuição da freqüência cardíaca ocorrido no grupo dexmedetomidina, seria a ativação do barorreflexo em relação ao aumento da pressão arterial média, como concluíram (Kirchheim, 1976; Ketch et al., 2002). Dyck et al., (1993) observaram que a injeção de dexmedetomidina em voluntários, na dose de $2 \mu \mathrm{gg} \cdot \mathrm{kg}^{-1} \mathrm{em}$ intervalo de 5 minutos, promoveu, em relação aos valores basais, aumento de $22 \%$ na pressão arterial média e diminuição de $27 \%$ na freqüência cardíaca, corroborando com a hipótese de Kirchheim e Ketch.

Neste estudo, não se observou redução da freqüência cardíaca precedida do aumento da pressão arterial média (tabela e quadro 10, figura 11). Tal redução pode ter sido consequência da diminuição das catecolaminas circulantes, do tônus simpático ou do aumento da atividade do sistema nervoso parassimpático, pois não observamos alteração da pressão arterial média que justificasse a ativação do barorreflexo.

\subsubsection{Pressão Arterial Média}

A pressão arterial média não apresentou diferença estatisticamente significativa entre os grupos durante o experimento. Nos momentos de cada grupo também não houve diferença (tabela e quadro 10, figura 11).

O propofol é um depressor do sistema cardiovascular. Independente da presença de doença cardiovascular, doses de 2 a 2,5 mg.kg-1 podem reduzir de 25 a 40\% as pressões arteriais sistólica, diastólica e média (Beheiry et al., 1995, Claeys et al., 1983). A hipotensão verificada após o uso de propofol resulta de depressão miocárdica, inibição simpática, alteração na resposta do 
barorreflexo e vasodilatação periférica (Ebert et al., 1992). O efeito vasodilatador do propofol deve-se à redução da atividade simpática (Ebert et al., 1992) e o efeito direto sobre a mobilização intracelular de íons cálcio no músculo liso vascular, causando diminuição da resistência vascular periférica, pré e pós-carga (Xuan et al., 1992; Chang 1993). Tanto depressão miocárdica quanto redução da resistência vascular sistêmica são dose dependentes (Pagel \& Warltier, 1993). Quando propofol é utilizado em dose única na indução, seus níveis plasmáticos caem rapidamente pela distribuição e eliminação do fármaco (Reves, 2000). A recuperação da hipotensão ocorre com a queda da concentração plasmática do propofol. Neste experimento, é possível afirmar que seja pouco provável a interferência do propofol de forma significativa na pressão arterial, pois houve um intervalo de 60 minutos entre a indução com propofol e início do primeiro momento de estudo.

A associação de fentanil com agentes hipnóticos na indução da anestesia, como propofol (Smith et al., 1996) e midazolam (Babazono, Braz e Curi, 1998), tende a reduzir a pressão arterial. A utilização de macro-doses de fentanil em cães demonstrou queda significativa da pressão arterial média (Castiglia et al., 1997), entretanto, quando utilizado em pequenas doses, 5 a 20 $\mu \mathrm{g} \cdot \mathrm{kg}^{-1}$, o fentanil não determina alterações cardiovasculares importantes (Ostheimer et al., 1975; Braz et al, 1978). A dose utilizada neste experimento produz pouca alteração sobre a pressão arterial média, corroborando com os estudos de Flacke et al. (1985), onde pacientes receberam fentanil na indução anestésica $\left(7 \mu \mathrm{g} \cdot \mathrm{kg}^{-1}\right)$ e não sofreram alterações importantes deste atributo. 
Neste experimento, a isquemia realizada e a subseqüente ausência de perfusão renal por um período de 30 minutos, poderia ter ativado o eixo renina-angiotensina aldosterona, e, sendo a angiotensina potente vasoconstritor renal e periférico, haveria desta forma, aumento na resistência periférica total, com maiores valores de pressão arterial média. Por outro lado, é possível que o isoflurano tenha atenuado este efeito, uma vez que, de forma dose dependente, diminui a pós-carga do ventrículo esquerdo (Stevens et al., 1971; Eger, 1981; Pagel et al., 1988).

A ação da dexmedetomidina no sistema cardiovascular pode ser periférica e central. No sistema nervoso central alguns locais são muito importantes na ativação dos receptores agonistas $\alpha_{2}$, como o trato solitário, que é o principal, mas também o locus coeruleus, o núcleo motor dorsal do vago e o núcleo reticular lateral (Kubo e Misu, 1981). Nesta área, quando $\alpha_{2^{-}}$ adrenorreceptores pré-sinápticos são ativados, ocorre inibição da exocitose da norepinefrina nas terminações nervosas periféricas, o que explica de certo modo, a ocorrência de hipotensão arterial (Jonge et al., 1981). A estimulação dos receptores $\alpha_{2}$ do centro vasomotor, provoca diminuição progressiva das catecolaminas circulantes, potencializando, com isto, o tônus parassimpático e conseqüentemente causando queda da pressão arterial (Ruffolo et al., 1985; Kubo et al., 1981). Diferentemente, a estimulação dos $\alpha_{2}$-adrenorreceptores no endotélio provoca vasoconstrição, podendo ocorrer, muitas vezes, hipertensão arterial transitória no inicio da infusão venosa de dexmedetomidina.

O efeito hipotensor é causado provavelmente pela ação simpaticolítica do SNC, principalmente pela ação do fármaco sobre receptores 
$\alpha_{2} b$ pós-sinápticos e também sobre receptores $\alpha_{1}$, embora a dexmedetomidina apresente alta seletividade para os receptores $\alpha_{2}$ (Talke et al., 2000; Gertler et al., 2001).

A infusão de $1 \mu \mathrm{g} \cdot \mathrm{kg}^{-1}$ em bolus de dexmedetomidina resulta em aumento passageiro da pressão arterial e queda da freqüência cardíaca reflexa, como observaram Bloor et al. (1992). O aumento da pressão arterial iniciou-se um minuto após o bolus e foi atribuído aos efeitos excitatórios diretos sobre os $\alpha_{2}$-adrenorreceptores no músculo liso vascular. Depois deste aumento inicial da pressão arterial ocorreu a sua diminuição, provavelmente causada por inibição do sistema nervoso simpático, que anulou os efeitos diretos da dexmedetomidina sobre o músculo liso vascular. Schmeling et al. (1991) observaram que a injeção de dexmedetomidina nas doses crescentes de 1,25, 2,5 e 5,0 $\mu \mathrm{g} \cdot \mathrm{kg}-1$ em cães acordados, produziu alteração bifásica da pressão arterial média, havendo aumento inicial significativo e após 60 minutos, uma pequena redução. Em estudo feito com cães acordados que receberam doses de $10 \mu \mathrm{g} \cdot \mathrm{kg}^{-1}$ e $20 \mu \mathrm{g} \cdot \mathrm{kg}^{-1}$, Kuusela et al. (2000) relataram comportamento semelhante da pressão arterial média, havendo aumento inicial significativo com posterior redução de pequena intensidade. Scheinin et al. (1998) utilizando dexmedetomidina intramuscular em voluntários saudáveis, na dose $2 \mu \mathrm{g} \cdot \mathrm{kg}^{-1}$, não demonstraram esta resposta bifásica da pressão arterial, sendo observada apenas queda da pressão arterial de até $13 \%$. Nesta dose, a dexmedetomidina apresenta biodisponibilidade de $73 \%$, atingindo um pico de concentração plasmática de 0,8 ng. $\mathrm{mL}^{-1}$ em 15 min (Hayashi e Maze, 1993; Talke, 2000). 
Kallio (1989), Bloor, (1992) e Ebert (2000), observaram que concentrações plasmáticas altas (acima de 1,9 ng. $\mathrm{mL}^{-1}$ ) tendem a elevar a pressão arterial média, enquanto que concentrações plasmáticas baixas de dexmedetomidina $\left(0,7\right.$ a $\left.1,2 \mathrm{ng} \cdot \mathrm{mL}^{-1}\right)$ tendem a reduzi-las.

Neste experimento não foi observada alteração bifásica da pressão arterial média, provavelmente por ter sido administrada a dose inicial em 10 min, e não em bolus. Outro fator, é que a dose de infusão utilizada $\left(2 \mu \mathrm{g} \cdot \mathrm{kg}^{-1}\right)$, provavelmente manteve a concentração plasmática de dexmedetomidina perto de $0,8 \mathrm{ng} \cdot \mathrm{mL}^{-1}$, níveis improváveis de causar hipertensão. Como também não ocorreu diminuição da pressão arterial média, é pouco provável que tenha havido interferência destes parâmetros nos valores da resistência vascular renal e fluxo sanguíneo renal. A hidratação vigorosa e técnica anestésica empregadas previamente ao início da infusão podem explicar a não queda da pressão arterial descrita pela literatura após o uso de dexmedetomidina.

\subsubsection{Pressão Média do Átrio D, Pressão da Artéria Pulmonar, Pressão de Oclusão da Artéria Pulmonar, Índice Cardíaco e Índice de Resistência Vascular Sistêmica}

Neste experimento não foram observadas alterações estatisticamente significativas da pressão média do átrio direito (tabela e quadro 11, figura 12), pressão da artéria pulmonar (tabela e quadro 12, figura 13) e pressão de oclusão da artéria pulmonar (tabela e quadro 13, figura 14) entre os grupos, nem nos diferentes momentos de cada grupo estudado. 
A análise dos resultados do índice cardíaco (tabela e quadro 14, figura 15) demonstra que houve diminuição estastisticamente significativa do índice cardíaco no M2 (início da infusão em estudo) do G2 (DEX) em relação ao momento inicial, permanecendo até o final do experimento.

Em relação à resistência vascular sistêmica (tabela e quadro 15, figura 16), houve aumento estatisticamente no $M 2$ no grupo da dexmedetomidina quando comparado com o momento inicial, permanecendo até o final do experimento.

Schmeling et al. (1991) relataram diminuição de débito cardíaco dose dependente em cães que receberam dexmedetomidina via intravenosa em doses progressivas $(1,25,2,5$ e $5 \mu \mathrm{g} . \mathrm{kg}-1)$. Prinzem et al. (1996) observaram diminuição de débito cardíaco em cães que receberam dose 10 $\mu \mathrm{g} . \mathrm{kg}^{-1}$ via intravenosa. Ebert et al. (2000) descreveram diminuição importante do índice cardíaco em voluntários que receberam dexmedetomidina. Esse fato ocorreu, segundo os autores, por elevação na resistência vascular sistêmica e redução na freqüência cardíaca. Villela (2003) observou pouca alteração do índice cardíaco em cães que receberam dexmedetomidina.

Aho (1992), Aantaa (1997) e Talke (2000) concluíram que as alterações promovidas pela dexmedetomidina sobre o sistema cardiovascular são doses dependentes, e, quando esta droga é utilizada em concentrações plasmáticas abaixo de $0,9 \mathrm{ng} \cdot \mathrm{mL}^{-1}$, não ocorre alterarações dos parâmetros hemodinâmicos de forma importante. Em estudos que empregaram doses elevadas de dexmedetomidina (Flacke et al., 1990; Ebert et al., 2000; Hamasaki et al., 2002) acima de 1,9 ng. $\mathrm{mL}^{-1}$ de concentração plasmática, as 
alterações hemodinâmicas costumaram ser mais exacerbadas, pois houveram predominância dos efeitos decorrentes da ativação dos receptores $\alpha_{2}$-agonistas periféricos, promovendo constrição arterial e venosa, aumentando o retorno venoso, pós-carga do ventrículo esquerdo, resistência vascular pulmonar e pressão média do átrio direito. Outro fator que pode ser importante na diminuição do débito cardíaco com o uso de altas doses de dexmedetomidina é a vasoconstrição coronariana e conseqüente diminução da contratilidade miocárdica (Indolfi et al., 1992; Baumgart et al., 1999; Flacke et al., 1993; Jones et al., 2005). Deussen (1985) observou que a injeção intracoronária de um $\alpha_{2^{-}}$ agonista, provocou aumento da resistência vascular coronariana de $32 \%$ e diminuição do fluxo coronariano de $43 \%$.

Em nossa pesquisa, embora o índice cardíaco tenha demonstrado redução significativa, não foram observadas alterações relevantes das pressões de átrio direito, artéria pulmonar e oclusão da artéria pulmonar, provavelmente por serem utilizadas doses de dexmedetomidina semelhantes às administradas na prática clínica ou também, devido ao aumento da resistência vascular sistêmica, que pode ter minimizado a queda de seus valores. Estes fatos nos levam a crer, que provavelmente não houve interferência significativa nos resultados renais pelas variáveis hemodinâmicas observadas neste estudo.

\subsubsection{Temperatura}

A temperatura esofágica normal para o cão varia entre 38,5 a $39{ }^{\circ} \mathrm{C}$ (Massone, 1999). Neste experimento a temperatura apresentou redução 
significativa do momento $3 \mathrm{em}$ diante, sendo que estes momentos foram menores que os primeiros em ambos os grupos (tabela e quadro 8, figura 9). A hipotermia é observada com freqüência durante 0 ato anestésico, sendo resultado da combinação da diminuição dos mecanismos termorreguladores com a exposição ao ambiente frio da sala cirúrgica (Sessler, 2005). A dexmedetomidina, em ambientes de baixa temperatura pode levar a hipotermia, isto ocorre pela diminuição do limiar de vasoconstricção e tremores, em resposta à diminuição da temperatura corporal. Neste experimento foi utilizado o sistema de aquecimento de fluidos Hotline e a sala cirúrgica foi mantida aquecida por aparelho de ar condicionado, com objetivo de prevenir ou ao menos amenizar a hipotermia dos cães. Devido à exposição do rim esquerdo para estudo da isquemia e reperfusão, foi impossibilitada a utilização de manta térmica; sistema de aquecimento externo por insuflação de ar quente, contribuindo para queda da temperatura dos animais observada durante 0 experimento.

\subsubsection{Vasopressina}

Analisando os resultados (tabela e quadro 16, figura 17), foi observado que a vasopressina plasmática aumentou nos momentos 3,4 e 5, em relação ao M2 nos dois grupos estudados. O efeito entre grupos no conjunto dos momentos apresentou perfis similares.

Villela (2005), realizou estudo com duas doses de dexmedetomidina em infusão contínua (1 e $2 \mu \mathrm{g} \cdot \mathrm{kg}^{-1}$ ) e observou diminuição de forma dose dependente da secreção do hormônio anti-diurético (HAD). Neste experimento, 
diferente do esperado e do que Villela observou, houve aumento da concentração plasmática de HAD imediatamente após o período de isquemia e término da infusão de dexmedetomidina em ambos os grupos estudados. A hipótese mais provável deste evento é decorrente da resposta endócrina metabólica ao trauma anestésico-cirúrgico a que foram submetidos os cães. Outros pesquisadores observaram valores sanguíneos bastante elevados do HAD após procedimentos anestésico-cirúrgicos em cães (Reid et al., 1984).

A vasopressina (VP), também conhecida como hormônio antidiurético (HAD), é um hormônio hipotalâmico com ação nas células renais, hepatócitos e células vasculares, produzindo antidiurese, aumentando a gliconeogênese e atuando como um importante vasoconstritor (Sashs et al., 1969). É encontrada nas espécies vertebradas e invertebradas e sua estrutura de aminoácidos é altamente conservada entre os mamíferos (Landry et al., 1997).

A vasopressina é sintetizada na forma de um precursor comum, que é clivado por proteólise para tornar-se um peptídeo funcionalmente ativo (Sashs et al., 1969). Este peptídeo é primeiramente sintetizado nos núcleos supraótico e paraventricular do hipotálamo (pré-pro-vasopressina-neurofisina que tem 164 aminoácidos em sua cadeia), depois é transportado e estocado nas vesículas secretoras da glândula pituitária posterior na sua forma madura (Cowley, 1988). Mais recentemente foi encontrada a expressão da vasopressina em coração e pâncreas de ratos por análise por transcriptase reversa (RT-PCR) (Hupf, 1999). Os núcleos supraótico e paraventricular funcionam como osmorreceptores, porém, o supraótico tem um papel mais 
importante nesse processo. Um aumento na osmolaridade plasmática estimula as células deste núcleo a sintetizarem a vasopressina, que circula no plasma sem uma ligação significante com proteínas do soro (Brook \& Share, 1966). A neurosecreção (exocitose) da vasopressina ocorre em quantidades substanciais para compensar sua diluição e é liberada diretamente na corrente sanguínea para poder agir em seus órgãos alvo.

A vasopressina possui três tipos de receptores $\mathrm{V} 1 \mathrm{a}, \mathrm{V} 1 \mathrm{~b}$ e V2 (Girolmo, 1997) que se distinguem baseados em estudos funcionais e farmacológicos (Hara et al., 1990) e pelas diferentes afinidades de ligação para estruturas análogas da VP (Barberis et al., 1998). O V1a é expresso no fígado, células endoteliais e vários outros tecidos periféricos (Lolait et al., 1992) e é provavelmente o receptor mais comum no cérebro (Ostrowsky, 1993). A ativação deste receptor estimula a fosfolipase C, D e A2 aumentando o cálcio intracelular e a acidificação celular pela estimulação das trocas de íons sódio e hidrogênio (Briley et al., 1994). O receptor V1b estimula a fosfolipase C e induz um aumento no cálcio intracelular. É expresso em sua maioria nas células corticotróficas da pituitária anterior, em múltiplas regiões do cérebro e em alguns tecidos periféricos incluindo rim, timo, coração, pulmão, baço e útero (Lolait et al., 1995).

Nos rins, a ação da vasopressina ocorre, principalmente, por sua ação sobre receptores V2. O efeito mais importante da vasopressina é sobre 0 túbulo coletor, onde aumenta a permeabilidade desse segmento do rim à água e à uréia, evento provavelmente secundário ao aumento do AMPc intracelular (Aires, 1999). A vasopressina também induz reposta contrátil nas células 
mesangiais glomerulares, diminuindo o coeficiente de filtração glomerular (Sighal et al., 1986) e reduzindo o fluxo sanguíneo da medula renal (Thurau et al., 1960). Tais alterações são decorrentes da ação da vasopressina nos receptores V1 (Thibonnier et al., 1988).

Em animais com hemorragia, as concentrações plasmáticas da vasopressina aumentam em níveis suficientes para causar vasoconstrição, deste modo, atenuando a resposta hipotensiva (Scherier, 1985) como também acontece na insuficiência cardíaca (principalmente na insuficiência cardíaca crônica), cirrose, prenhez e em resposta às alterações na integridade vascular (Sachs et al., 1969). O efeito vasopressor é mediado pelos receptores V1 (Liard, 1986). Essas influências hemodinânicas são mediadas por aferentes neurogênicos que se iniciam com receptores sensíveis às diferenças de pressão em conjunto com o átrio cardíaco e artéria aorta chegando ao tronco cerebral via nervo vago e glossofaríngeo. Pequenas diminuições no volume dos fluidos têm pouco efeito na secreção da VP, mas qualquer redução superior a $10 \%$ do fluido extracelular causa uma marcante secreção deste hormônio, que não só conserva a água, mas também pode ter um papel importante na manutenção da pressão sangüínea (Ransay, 1983).

A regulação da liberação da vasopressina é um processo complexo que envolve estimulação osmótica e não osmótica. Os principais e mais potentes estímulos de liberação da vasopressina são o aumento da osmolaridade plasmática (regulação osmótica), hipovolemia e hipertensão (regulação não osmótica) (Scherier, 1979). Além destes estímulos, dor, náusea, hipóxia, estímulo faringeano, acidose, hormônios, drogas endógenas e 
exógenas também aumentam a liberação da vasopressinas na circulação (Kovacs \& Robertson, 1992; Wood \& Chen, 1989). Dentre as substâncias que estimulam a secreção da vasopressina estão: acetilcolina, morfina, epinefrina, histamina, prostaglandinas, vincristina e insulina. Algumas drogas agem sobre a vasopressina inibindo sua secreção como a norepinefrina, haloperidol, prometazina e glicocorticóides (Moller \& Moses, 1976). Podem ainda estimular a secreção da VP: estresse causado por fatores como emoção, exercício físico (Ryden \& Verney, 1988) e resposta endócrino metabólica ao trauma anestésico-ciirúrgico (Reide et al., 1984), hipoglicemia (Baylis \& Heath, 1977) e o sistema renina-angiotensina (Shrier et al., 1985). Embora o núcleo magnocelular seja osmosensitivo (Bourque, 1989; Mason, 1980), ele pode integrar este estímulo com sinais endócrinos gerados por hormônios circulantes como a angiotensina II, relaxina e peptídeo atrial natriurético (ANP) (Mendelsohn et al., 1984; Osheroff \& Phillips, 1991). Enquanto a angiotensina II e a relaxina estimulam a liberação da VP, o ANP inibe (Fitasimmons et al., 1994; Standaert et al., 1987).

Os agonistas a2-adrenérgicos podem causar inibição da secreção de vasopressina. Reid et al. (1979) descreveram diminuição da concentração plasmática da vasopressina em cães anestesiados após injeção de altas doses de clonidina $\left(30 \mu \mathrm{g} \cdot \mathrm{kg}^{-1}\right)$. Kimura et al. (1981) demonstraram redução da concentração plasmática da vasopressina após injeção de $0,1 \mu \mathrm{g} \cdot \mathrm{kg}^{-1}$ de clonidina no ventrículo lateral dos cães. Kulka et al. (1996), entretanto, não observaram alteração da concentração plasmática de vasopressina em pacientes que receberam clonidina $4 \mu \mathrm{g} \cdot \mathrm{kg}^{-1}$ e submetidos a cirurgia vascular. 
Vários mecanismos podem explicar a inibição da vasopressina pelo agonistas a2-adrenérgicos. Humpreys \& Reid (1975) associaram essa diminuição com o aumento inicial da pressão arterial média em resposta à injeção intravenosa de clonidina. Roman et al. (1979), entretanto, observaram que a clonidina bloqueou a liberação deste hormônio em ratos, mesmo quando foram utilizadas pequenas doses que não provocaram alterações hemodinâmicas. Nolan \& Reid (1978) atribuíram como mecanismo possível à supressão desse hormônio, a diminuição plasmática de angiotensina II, secundária ao bloqueio da liberação de renina.

Neste experimento a dexmedetomidina não promoveu alteração na concentração da vasopressina, onde não foi observada diferença estatística entre os momentos em relação ao grupo controle. A concentração de HAD no plasma não foi diferente em G1 \& G2, tendo aumentado após reperfusão, nos momentos seguintes ao desclampeamento nos dois grupos, demonstrando que o aumento do débito urinário não envolveu mecanismos de inibição plasmática do HAD pela dexmedetomidina, podendo este efeito ser atribuído à inibição tubular do HAD (Smyth et. al., 1985) e/ou liberação do peptídio natriurético (Chen et.al., 1989), uma vez que as alterações hemodinâmicas não foram significativas.

Os receptores a2-adrenérgicos já foram identificados em várias áreas do rim de diferentes animais (Schmitz et al., 1981; Evans \& Haynes, 1994). Em ratos, a ativação desses receptores promove inibição do AMPc intracelular (Chabardes et al., 1984; Umemura 1985), sendo esse um dos mecanismos responsáveis pela inibição da ação do HAD no túbulo coletor. Em 
outros animais, como no cão, alguns pesquisadores não detectaram tal inibição do AMPc intracelular (Brooks, 1991), sugerindo outro mecanismo envolvido na inibição da absorção de água no túbulo coletor pelos agonistas a2adrenérgicos, hipótese também afirmada por Rouch et al. (1997), que em modelo experimental de túbulo coletor isolado de rato, observaram inibição da absorção de água com o uso da dexmedetomidina, mesmo na presença do hormônio anti-diurético. A hipótese sustentada por esses autores, é que a proteína C kinase na presença de seu inibidor staurosporina, aumenta a permeabilidade à água no túbulo coletor renal, apresentando-se como um possível mediador celular na regulação do débito urinário. Esta hipótese corrobora com os resultados obtidos neste experimento, uma vez que, houve aumento do débito urinário na presença do HAD.

\subsubsection{Fluxo Sangüíneo Renal, Clearance de PAH, Clearance de Creatinina, Resistência Vascular Renal, Fração de Filtração e Débito Urinário}

Os resultados obtidos do fluxo sangüíneo renal e do Clearance de PAH que traduz o fluxo plasmático renal, efetivamente, apresentaram curvas similares, derivando comentários estatísticos idênticos (tabelas, figuras e quadros 18,19 e 20). A interação entre os grupos e momentos estudados, apresentou perfis similares. No conjunto dos grupos, houve diferença estatisticamente significativa entre os momentos, ocorrendo redução do fluxo 
sanguíneo renal e depuração de para-aminopurato a partir de M3, sendo esta, mantida até o final do experimento.

O estudo estatístico dos valores da resistência vascular renal demonstrou em relação aos momentos iniciais, aumento significativo no momento 3 de ambos os grupos, que coincidiu com o início do desclampeamento da artéria renal. Esses valores foram reduzidos no final do experimento (tabela e quadro 17, figura 18).

A provável causa dessas variáveis (FSR e RVR) é a vasoconstrição renal controlada por mediadores neurais, humorais ou por fatores físicos intrarenais liberados após evento de isquemia e repefusão (McDougal, 1988; Brady et al., 2000).

O clearance de creatinina tem como tradução clínica o ritmo de filtração glomerular, que demonstrou haver interação significativa entre grupos e momentos estudados (tabela e quadro 20, figura 21), onde ocorreu redução significativa do M3 em ambos os grupos em relação aos momentos iniciais. O resultado não foi o que se esperava, demonstrando que provavelmente, a dexmedetomidina não causou proteção renal.

Outro parâmetro estudado, a fração de filtração, que mede a relação do plasma filtrado pelos capilares glomerulares com o volume total do plasma que circula pelo rim, não exibiu resultados com alterações significativas. Os perfis são similares e iguais, não existindo diferença entre momentos no conjunto dos grupos.

A análise estatística dos resultados referentes ao volume urinário mostrou perfis não similares (tabela e quadro 22, figura 23), havendo diferença 
entre os grupos em M3, sendo o grupo dexmedetomidina, significativamente maior que o grupo controle. Esse resultado demonstra que a dexmedetomidina pode aumentar a diurese.

A filtração glomerular é determinada pela soma algébrica das pressões hidrostática e osmótica coloidal que atuam sobre a membrana glomerular, resultando na pressão efetiva de filtração, e pelo coeficiente de filtração capilar. As variações na pressão hidrostática glomerular constituem o principal mecanismo para a regulação fisiológica da filtração glomerular, isto é, aumentos na pressão hidrostática glomerular elevam-na, enquanto que diminuições reduzem-na. A pressão hidrostática glomerular é determinada pela pressão arterial sistêmica, pela resistência das arteríolas aferentes e pela resistência das arteríolas eferentes. Mediada por fatores neurais, humorais ou intra-renais, a regulação da circulação renal depende de mudanças na resistência resultante da constrição e relaxamento do músculo vascular liso (Maddox e Bernner, 2000).

No rim, os agentes vasoconstritores não somente causam vasoconstrição, mas, também, liberam substâncias e/ou fatores vasodilatadores, os quais modulam os efeitos vasoconstritores, e, vice-versa, para as substâncias vasodilatadoras. Entretanto, em surtos isquêmicos, pode haver quebra deste equilíbrio com predomínio dos efeitos vasoconstritores, que causam elevação da resistência vascular renal, diminuição do ritmo de filtração glomerular, do fluxo sangüíneo renal e do volume urinário (Maddox e Bernner, 2000). 
O sistema renina-angiotensina-aldosterona é um fator de extrema importância para o rim, influenciando na modulação do fluxo sangüíneo glomerular e na taxa de filtração glomerular.

A renina é uma enzima sintetizada pelas células justaglomerulares do córtex renal e sua secreção é controlada pela pressão sangüínea renal e concentração de sódio do fluido tubular sentida pela mácula densa e atividade nervosa simpática. A renina cliva seu substrato, o angiotensinogênio, que é sintetizado no fígado para produzir um decapeptídeo, angiotensina I. A angiotensina I é rapidamente convertida a angiotensina II pela enzima conversora da angiotensina (ECA) nos pulmões, endotélio vascular e outros tecidos para formar o octapeptídeo ativo. Outra enzima, chamada angiotensinase, pode ainda clivar o resíduo Asp da porção $\mathrm{N}$-terminal da angiotensina II para formar um heptapeptídeo, a angiotensina III. As angiotensina II e III estimulam a secreção de aldosterona e atuam como potentes vasoconstritores. A angiotensina II é um vasoconstritor mais potente do que a angiotensina III. Os altos níveis de angiotensina II também estimulam a produção e a liberação de pelo menos duas prostaglandinas vasodilatadoras renais, a prostaglandina E2 e a prostaglandina 12 (prostaciclina). Este é um importante regulador do sistema renina-angiotensina-aldosterona. A produção intra-renal destes vasodilatadores neutraliza o efeito constritor da angiotensina II sobre a vascularização intra-renal e ajuda a manter a resistência vascular renal em níveis normais ou quase normais.

Os fatores constritores derivados do endotélio renal incluem 0 potente vasoconstritor endotelina, o tromboxano A2 e a angiotensina II. Os 
fatores relaxantes derivados do endotélio incluem o óxido nítrico, a protaglandina 12 e a prostaglandina E2. Em condições normais, a produção de óxido nítrico, fator relaxante do endotélio, contrabalança continuamente o efeito dos agentes, como a angiotensina II, na superfície de filtração, e a inibição da produção do fator relaxante do endotélio produz diminuição acentuada da superfície de filtração. Tem-se postulado, que durante a isquemia, a produção de óxido nítrico está comprometida e a produção de endotelina, um potente vasoconstritor, aumentada (Radermacher, Fosttermann e Frolich, 1990; Lieberthal, 1997; Brady et al., 2000; Dworkin, Sun e Bernner, 2000).

Além dos fatores excercidos pelo rim, fatores sistêmicos podem contribuir para alterações no ritmo de filtração glomerular. Esses fatores incluem o controle sistêmico do volume sanguineo e do tônus vascular. $O$ volume sanguíneo é regulado por inúmeros hormônios. A secreção de aldosterona e vasopressina (hormônio antidiurético) aumenta a reabsorção de água e soluto pelo rim, aumentando o volume sanguíneo. O peptídeo natriurético atrial, um hormônio produzido nos átrios cardíacos, demonstrou causar natriurese (eliminação de sódio) e diurese (eliminação de água), reduzindo o volume sanguíneo.

Lieberthal et al., em 1989, estudaram a resposta hemodinâmica em rins de ratos submetidos à isquemia de 25 min e posterior reperfusão. Os autores encontraram aumento na resistência vascular renal e diminuição de $37 \%$ no ritmo de filtração glomerular.

Nesta pesquisa, houve aumento de resistência vascular renal (tabela e quadro17, figura 18), diminuição do fluxo sanguíneo renal (tabela e quadro 
18, figura 19), do clearance de para-aminohipurato de sódio (tabela e quadro 19, figura 20) e no clearance de creatinina (tabela e quadro 20, figura 21) após o desclampeamento (efeitos provavelmente ocasionados pelo fenômeno de isquemia-reperfusão), porém o volume urinário foi maior no grupo que recebeu infusão de dexmedetomidina (tabela e quadro 22, figura 23). Pode-se atribuir, a princípio, que o débito urinário elevou-se por ação da dexmedetomidina, porque os a2-agonistas podem elevar a diurese (Maze \& Tranquilli, 1991; Hamaya et al., 1994; Cabral et al., 1998) por alterações hemodinâmicas (Brooks et al., 1991), por inibição da secreção do HAD (Reid et al., 1979) ou redução de sua ação tubular (Rouch et al., 1997) e liberação do peptídeo natriurético (Chen et al., 1989).

Neste estudo verificou-se elevação da diurese principalmente em M4 e M5 e sendo significativamente maior em G2. Tal fato não foi causado pelo aumento do ritmo de filtração glomerular (RFG), que é a tradução clínica da depuração de creatinina, que não apresentou alterações entre grupos, mas somente entre os momentos de ambos. Por conseguinte, em razão da clonidina ser capaz de prevenir ou diminuir as lesões renais secundárias aos eventos isquêmicos (Solez et al., 1980; Kulka et al., 1996), a dexmedetomidina deveria, também, apresentar papel potencial na proteção renal (Villea et al., 2005). Tal hipótese não confirmada neste experimento. 


\subsubsection{Sódio Plasmático, Potássio plasmático e Osmolaridade Plasmática}

Analisando os resultados da osmolaridade plasmática (tabela e quadro 25, figura 26) houve distribuição normal. Portanto, foram utilizados média e desvio padrão, como parâmetros estatísticos. Os testes das hipóteses, previamente estabelecidas, demonstram que não houve alteração significativa da osmolalidade plasmática em nenhum momento ou grupo estudado durante todo experimento.

Define-se osmolaridade, como uma expressão do número de partículas osmoticamente ativas que atraem a água através de membranas semipermeáveis até estabelecer-se o equilíbrio, por litro de solvente, enquanto que osmolalidade é a medida do número de partículas osmoticamente ativas por quilograma de solvente.

A diferença entre osmolalidade e osmolaridade é menor que $1 \%$, entretanto estes termos podem ser sinônimos. Portanto, além de ser mais fácil expressar as concentrações dos líquidos corporais em relação a litros do que quilogramas de água, a prática em quase todos os estudos fisiológicos é utilizar osmolaridade em vez de osmolalidade (Guyton, 1996)

O valor normal da osmolalidade plasmática, no cão, varia entre 280 a 320 mOsm (Muir e de Morais, 1996). Neste experimento os valores obtidos nos momentos permaneceram dentro destes parâmetros, mostrando-se normais.

O sódio representa $90 \%$ de todos os cátions no plasma, portanto, sua concentração passa a ser a determinante mais importante da medida da osmolalidade plasmática, uma vez que os ânions igualam-se aos cátions. 
Neste experimento, a expansão do volume do fluido extracelular foi realizada com solução isotônica em relação ao plasma, o que não deve alterar a concentração plasmática deste íon, mesmo em situação de isquemia. Reis et al. (2003), realizaram experimento em ratos submetidos à isquemia renal com lesão tubular comprovada em microscopia eletrônica e observaram que não houve interferência na osmolaridade plasmática.

A secreção de hormônio antidiurético está intimamente relacionada à osmolaridade plasmática (limiar teórico de $280 \mathrm{mOsm} / \mathrm{Kg}$ ). Variações mínimas da osmolaridade plasmática, da ordem de $1 \%$ são capazes de promover a liberação de HAD em concentração suficiente para alterar significativamente a excreção de água.

Na tabela e quadro 23 e figura 24 , foi demonstrado que houve redução significativa da concentração de sódio plasmático apenas do momento 5, em relação aos outros momentos no grupo controle G1. Este efeito pode ter sido causado pelo aumento da secreção de ADH nos momentos finais da pesquisa, que provavelmente aumentou a absorção de água nos túbulos renais, proporcionando "hiponatremia diluicional". Também conhecida como hiponatremia hipotônica, ocorre pelo excesso de água a diluir o sódio plasmático e não pela sua perda, tendo como princípio fisiopatológico, o aumento da produção ou do efeito do hormônio antidiurético (Adler \& Verbalis, 2006). No G2 não ocorreu diminuição de sódio plasmático em nenhum momento do experimento. É provável que a dexmedetomidina, por aumentar a diurese por outros mecanismos, como já citados, possa ter contrabalanceado o efeito antidiurético da vasopressina. 
A análise estatística dos valores referentes ao potássio plasmático demonstrou que não houve alteração significativa do potássio plasmático em nenhum momento ou grupo estudado durante todo experimento (tabelas e quadro 24, figura 25).

O potássio é um dos principais reguladores da secreção de aldosterona. O efeito agudo da aldosterona sobre o potássio é aumentar a sua entrada em células por estimulação da atividade da bomba de sódio e potássio, que abaixa seus níveis séricos, porém, tem pouco efeito sobre sua excreção renal. A estimulação mais crônica da aldosterona das células do segmento conectante e das células principais aumenta o numero de canais de $\mathrm{K}^{+}$na membrana plasmática apical, aumentando dessa maneira a permeabilidade apical a este ânion, o que resulta em maior secreção de $\mathrm{K}^{+}$intratubular. Portanto, o efeito imediato da aldosterona é a redistribuição de $\mathrm{K}^{+}$de compartimentos extracelulares para intracelulares, mas, com estimulação prolongada da aldosterona, a eliminação renal de $\mathrm{K}^{+}$é aumentada.

Neste esperimento, a solução utilizada para hidratação dos cães, foi isotônica de ringer com lactato, portanto é pouco provável que tenha influenciado nos resultados entre os grupos e momentos estudados.

\subsubsection{Osmolaridade Urinária, Depuração Osmolar e Depuração de Água Livre}

Os resultados estatísticos demonstram que a depuração de água livre, que representa excreção de água livre de solutos, aumentou em G1 \& G2 após o desclampeamento, mantendo este aumento até o final do experimento. 
O efeito entre grupos no conjunto de momentos demonstrou perfil similar (tabela e quadro 28, figura 29).

Os testes das hipóteses, previamente estabelecidas, demonstram que houve diminuição significativa da osmolalidade urinária a partir do momento 3, mantendo esta redução até o final do experimento (M4 \& M5) em todos os grupos estudados (tabela e quadro 26; figura 27).

A depuração osmolar (corresponde ao volume de plasma que é liberado de todas as substâncias osmoticamente ativas na unidade de tempo, ou seja, equivale à depuração de íons) aumentou após o descampleamento (reperfusão) nos dois grupos (tabela e quadro 27; figura 28).

Corroborando com esta pesquisa, outros autores verificaram diminuição da osmolaridade urinária e aumento da depuração de água livre com a administração de dexmedetomidina (Villela et al., 2005) ou clonidina (Humphreys \& Reid, 1975; Kimura et al., 1981), porém estes autores observaram redução na secreção da vasopressina, diferentemente do que se observou neste experimento, onde houve um discreto aumento deste hormônio à partir de $\mathrm{M} 3$ em ambos os grupos (tabela e quadro 16, figura 17). Humphereys e Reid (1975) observaram também, que a osmolaridade urinária e depuração de água livre, não sofreram alterações com administração de 30 $\mu \mathrm{g} / \mathrm{kg}^{-1}$ de clonidina endovenosa em cães hipofisectomisados, e que também receberam infusão contínua de $\operatorname{HAD}\left(80 \mu \mathrm{g} \cdot \mathrm{kg} \cdot \mathrm{min}^{-1}\right)$. Portanto, concluíram que a clonidina diminui a osmolaridade urinária e depuração de água livre através da inibição do HAD, possivelmente por uma via indireta, mediante a presença de $\alpha_{2}$-agonistas na circulação sanguínea. 
Solez et al. (1980) estudaram dois grupos de ratos submetidos a isquemia renal e observaram que o grupo que recebeu clonidina $e$ vasopressina em forma de óleo, tiveram maior débito urinário, clearance de água livre e menor osmolaridade urinária do que o grupo que recebeu somente vasopressina. $\mathrm{O}$ efeito da clonidina não foi relacionado à atividade da renina $\mathrm{e}$ aumento da vasopressina no plasma, sugerindo que provavelmente, sua ação seja diretamente nos ductos renais, inibindo a ação do HAD a nível tubular.

Este estudo sustenta esta hipótese, uma vez que apresentou na presença de elevação do HAD plasmático, aumento do débito urinário, diminuição da osmolaridade urinária e aumento da depuração de água livre.

\subsubsection{Depuracáo de Sódio, Excreção Urinária e Fracionária de Sódio}

Em relação à depuração de sódio (tabela e quadro 29, figura 30) e à excreção urinária de sódio (tabela e quadro 31, figura 32), observaram-se comportamentos estatísticos semelhantes. Em ambos houve interação entre grupos e momentos, e, portanto, perfis similares. Ambos tiveram perfis iguais no efeito entre grupos no conjunto dos momentos e os momentos não diferiram no conjunto dos grupos.

Analisando os resultados da excreção fracionária de sódio (tabela e quadro 30, figura 31), podemos observar perfis não similares na interação entre os grupos e momentos. No efeito de grupo em cada momento, não houve diferença estatisticamente significativa, porém, a partir do momento 3 (reperfusão) no grupo da dexmetomidina, houve aumento estatisticamente 
significativo da excreçào fracionária de sódio em relação aos momentos iniciais, até o final do experimento.

A excreção fracionária de sódio é a porcentagem de uma substância que é excretada na urina, sendo o resultado efetivo da reabsorção e da excreção tubular da substância filtrada. É um dos índices utilizados para diferenciar a insuficiência pré-renal da doença renal intrínsica. Na primeira situação, quando ocorre restauração da função renal com a imediata correção da perfusão sistêmica, os valores de excreção são normais. Por outro lado, a doença intrínsica com necrose tubular, torna-se presumivelmente responsável pelo sódio urinário elevado, e do mesmo modo, a função renal não será imediatamente restaurada pela melhora da perfusão sistêmica.

A taxa de reabsorção e secreção de substâncias filtradas varia entre os segmentos do túbulo renal. No túbulo proximal, ocorre reabsorção isotônica de $80 \%$ de sódio e água, glicose, bicarbonato, fosfato e aminoácidos. Nos túbulos distal e coletor ocorrem reabsorção de água, controlada pelo hormônio antidiurético, e de uréia e sódio e, em troca, secreção de potássio (Vianna, 1991)

Em situações de baixa pressão sangüínea ou hipovolemia, é ativado o sistema renina-angitensina-aldosterona, que por sua vez aumenta a reabsorção de sódio e a excreção de potássio. A angitensina II também induz a constrição das arteríolas eferentes, provocando a redução da pressão hidrostática capilar peritubular, o que aumenta a reabsorção efetiva tubular, principalmente nos túbulos proximais. Além disso, essa constrição arteriolar eferente reduz o fluxo sangüíneo renal, que aumenta a fração de filtração no 
glomérulo, a concentração de proteínas e a pressão coloidosmótica nos capilares peritubulares. Estes eventos levam à elevação da força reabsortiva dos capilares peritubulares, assim como à reabsorção tubular de sódio e água. E, finalmente, a angiotensina II estimula diretamente a reabsorção de sódio através da ativação da bomba sódio-potássio ATPase na membrana basolateral da célula epitelial tubular e, também, estimula a troca de sódio pelo hidrogênio na membrana luminal, principalmente no túbulo proximal.

A organização anatômica do túbulo proximal e sua relação com o capilar peritubular facilitam o movimento dos elementos do liquido tubular para o sangue. O transporte vetorial é conseqüência direta da polarização da membrana da célula epitelial que possui dois domínios distintos, apical e basolateral. Os componentes da borda apical e basolateral são bioquímica, estrutural e fisiologicamente distintos. As substâncias transportadas através da via transcelular são captadas do lúmen urinário pela célula através da membrana plasmática apical e lançadas no líquido intersticial no lado sanguíneo da célula através da membrana plasmática basolateral. O epitélio, do lado basolateral, possui o mecanismo primário de transporte ativo, a bomba de $\mathrm{Na}^{+}-\mathrm{K}^{+}$e a enzima $\mathrm{Na}^{+}-\mathrm{K}^{+}$- ATPase, sendo esta distribuição polar desta enzima essencial para a eficiência da absorção do sódio (Reis et al., 2003). A área superficial disponível para o transporte de elementos do liquido tubular para dentro da célula é vasta, por causa das extensas dobras internas da membrana plasmática apical. Como resultado, a superfície apical de células tubulares proximais é coberta com numerosas projeções chamadas de "microvilosidades", criando uma membrana conhecida como "borda em 
escova". No lado sanguíneo da célula, existem também complexas dobras internas na membrana plasmática basolateral, as quais aumentam a área de superfície disponível para o transporte da célula ao liquido intersticial, onde a substância transportada se torna viável para ser absorvida pelo capilar peritubular (Molitoris, 1991 e 1992; Weinberg, 1991).

A isquemia leva à redistribuição da enzima $\mathrm{Na}^{+}-\mathrm{K}^{+}$- ATPase para a membrana apical, oque ocasiona diminuição na eficácia da reabsorção de sódio e leva à maior excreção deste íon pela urina. Este fenômeno já é observado após 10 minutos de isquemia renal (Dahl, Geerdes e Molitoris, 1991), tendo a situação agravada quanto maior o tempo de injúria, chegando a situações de irreversibilidade, com perda da polaridade e descamação celular, que determinará obstrução do lúmen tubular, comprometendo ainda mais o suprimento sanguíneo (Bonventre, 1993).

Neste experimento, ambos os grupos foram submetidos a um insulto isquêmico de trinta minutos com prováveis lesões semelhantes às descritas acima, o que justifica o aumento da excreção fracionária de sódio observado nos momentos 3 (reperfusão), 4 e 5 em ambos os grupos. Portanto, é provável que a dexmedetomidina não evitou, ou mesmo, não amenisou as lesões renais provocadas pela isquemia.

\subsubsection{Depuração de Potássio, Excreção Urinária e Fracionária de Potássio}

O comportamento da depuração e excreção urinária de potássio, foi de modo semelhante nos dois grupos, apresentando perfis similares na 
interação entre os grupos e momentos. Entre os momentos no conjunto dos grupos, tanto a depuração, quanto a excreção urinária de sódio, apresentaram redução significativa no momento 3 (após $30 \mathrm{~min}$ de isquemia) quando comparado com aos momentos iniciais, voltando aos valores normais até 0 final do experimento.

A análise estatística da excreção fracionária de potássio, que é a porcentagem da carga de potássio filtrada que foi excretada na urina, demonstrou perfis não similares entre os grupos e momentos. Entre os grupos, houve aumento siginificativo nos momentos 3 e 4 do G2 (DEX) em relação ao G1 (CONT). No efeito de momento em cada grupo, houve aumento significativo da excreção fracionária de potássio somente nos momentos 3 e 4 do G2, em relaçào aos momentos iniciais.

A excreção de potássio pelos túbulos renais é dependente da secreção distal pelas células principais, cujo controle é feito pela aldosterona. Este hormônio é produzido na supra-renal, pela ativação do eixo reninaangiotensina-aldosterona. Dessa maneira, a aldosterona estimula as células principais a secretar potássio e a reabsorver sódio (Malnic e Marcondes, 1986). A liberação de aldosterona também é estimulada por hipercalemia e tem papel importante na regulação da homeostase de $\mathrm{K}^{+}$. O efeito agudo da aldosterona sobre $\circ \mathrm{K}^{+}$é aumentar a sua entrada em células responsivas à aldosterona por estimulação da atividade da ATPase de $\mathrm{Na}^{+}, \mathrm{K}^{+}$, que abaixa os níveis séricos de $\mathrm{K}^{+}$, porem, tem pouco efeito sobre a excreção renal de $\mathrm{K}^{+}$. A estimulação mais crônica da aldosterona das células do segmento conectante e das células principais aumenta o numero de canais de $\mathrm{K}^{+}$na membrana plasmática apical, 
aumentando dessa maneira a permeabilidade apical ao $\mathrm{K}^{+}$, o que resulta em maior secreção de $\mathrm{K}^{+}$intratubular. Portanto, o efeito imediato da aldosterona é a resdistribuicao de $\mathrm{K}^{+}$de compartimentos extracelulares para intracelulares mas, com estimulação prolongada da aldosterona, a eliminação renal de $\mathrm{K}^{+}$é aumentada.

A expansão ou restrição de fuído do meio extraceluar pode modular a excreção de potássio. Neste experimento, a hidratação realizada nos cães, com solução isotônica de Ringer a uma velocidade de infusão de $18 \mathrm{~mL} . \mathrm{Kg}^{-1} \cdot \mathrm{h}^{-1}$,

poderia levar a maior velocidade do fluxo dentro da luz tubular, aumentando sua excreção, entretanto, este fenômeno não foi observado nesta pesquisa. Pelo contrário, houve até redução da excreção e depuração do potássio no momento 3 de ambos os grupos, apesar de estatisticamente nào significativo. A provável causa deste evento é a redução do fluxo sanguíneo renal ocasionado pelo insulto isquêmico ou devido à presença de células necróticas dentro do lúmen tubular, promovendo obstrução tubular distal e diminuição do ritmo de filtração glomerular (Bonventre, 1993; Edelstein, Ling e Schrier, 1997; Wilhelm et al., 1999).

Os aumentos estatisticamente significativos da excreção fracionária de potássio, observados somente nos momentos 3, 4 e 5 do G2 (DEX), demonstram que provavelmente a dexmedetomidina interferiu nestes resultados, pois o perfil entre os grupos não são similares (tabela e quadro 34, figura 35). É possível que este fármaco tenha proporcionado uma resposta mais adequada à liberação de aldosterona pós-isquemia, com melhor ação nos 
túbulos e maior excreção fracionária de potássio quando comparada ao grupo controle.

\subsubsection{Estudo Histopatológico do Rim}

Os grupos experimentais apresentaram resultados semelhantes em relação à histopatologia (tabelas 35 e 36; figuras 36, 37, 38 e 39). Em todos os grupos foram realizados vários cortes e empregadas as técnicas de coloração por hematoxilina-eosina e pelo ácido periódico de Schiff (PAS), sendo este último utilizado para coloração específica com a finalidade de pesquisar lesões renais. As lesões renais visíveis à microscopia de luz encontradas nesta pesquisa são semelhantes às observadas pós - episódio isquêmico por vários autores (Earley, 1970; Arendshorst, Finn e Goottschalk, 1975; Danohoe et al., 1978; Riley, 1978; Finn e Chevalier, 1979; Honda e Hishida, 1993; Thadhani, Pascual e Bonventre 1996; Módolo et al., 2000). Neste experimento, a análise dos resultados das lâminas, demonstrou dilataçào tubular em todos os cães, tanto do grupo controle (G1), quanto do grupo dexmedetomidina (G2). Dez lâminas dos cães do G1 e nove do G2 mostraram degeneração tubular, 5 lâminas do G1 e seis do G2 mostraram necrose, e finalmente, oito Lâminas do

G1 e nove do G2 demonstraram células inflamatórias. É provável que a dexmedetomidina não interferiu nestes resultados, pois se comportaram de maneira similar em ambos os grupos estudados. 


\section{CONCLUSÃO}

A administração de dexmedetomidina 15 minutos antes e durante 0 insulto isquêmico de 30 minutos, não interferiu nos mecanismos de proteção renal que envolvem o HAD das repercussões da isquemia-reperfusão em cães anestesiados. 


\section{Referências}

Aantaa R, Kanto J, Sheridan BC, Segal IS. Dexmedetomidine, an alpha 2adrenoceptor agonist, reduces anesthetic requirements for patients undergoing minor gynecologic surgery. Anesthesiology 1990; 73: 230-5.

Aantaa R, Jaakota ML, Kallio A, Kanto J. Reduction of the minimum alveolar concentration of isoflurane by dexmedetomidine. Anesthesiology 1977; 86: 1055-60.

Adler SM, Verbalis JG. Disorders of body water homeostasis in critical illness. Endocrinol Metab Clin North Am 2006;35: 873-94.

Aho $M$, Scheinin $M$, Lehtinen AM, Erkola $O$, Vuorinen J, Kortila $K$. Intramusculary administered dexmedetomidine attenuates hemodynamic stress hormone responses to gynecologic laparoscopy. Anesth Analg 1992; 75:932-9.

Achôa RV, Vane LA, Braz JRC. Efeitos da clonidina nas respostas cardiovasculares ao pinçamento aórtico infra-renal. Estudo experimental no Cão. Rev Bras Anestesiol 2003; 53: 610-22.

Arendshorst WJ, Finn WF, Gottschalk CW. Pathogenesis of acute renal failure following temporary renal ischemia in the rat. Circ Res 1975; 37(5): 558-68.

Babazono S, Braz JRC, Curi P R. Efeitos do diazepam, flunitrazepam e midazolam em associação com o fentanil durante a indução anestésica. Rev Bras Anest 1988; 38 (suppl): 105.

Barberis C, Mouillac B, Durroux T. Structural bases of vasopressin/oxytocin receptor function. J Endocrinol 1988;156: 223-9.

Barker JL, Crayton JW, Nicoll RA. Noradrenaline and acetylcholine responses of supraoptic neurosecretory cells. J Physiol 1971; 218:19-32. 
Barr JG, Kauker ML. Renal tubular site and mechanism of clonidine-induced diuresis in rats: clearance and micropuncture studies. J Pharmacol Exp Ther 1979; 209: 389-95.

Baylis PH \& Heath D. A. Plasma Arginine vasopressin response to insulininduced hypoglycemia. Lancet 1977; 2:428-30.

el-Beheiry H, Kim J, Milne B, Seegobin R. Prophylaxis against the systemic hypotension induced by propofol during rapid-sequence intubation. Can $\mathrm{J}$ Anaesth 1995;42: 875-8.

Belleville JP, Ward DS, Bloor BC, Maze M. Effects of intravenous dexmedetomidine in humans. Sedation, ventilation, and metabolic rate. Anesthesiology 1992; 77: 1125-33.

Blake DW, Ludbrook J, Van LAF. Dexmedetomidine and haemodynamic responses to acute central hypovolaemia in conscious rabbits. Clin Exp Pharmacol \& Phisiol 2000; 27: 801-9.

Bloor BC, Ward DS, Belleville JP, Maze M. Effects of intravenous dexmedetomidine in humans. II. Hemodynamic changes. Anesthesiology 1992; 77: 1134-42.

Bonventre JV, Zuk A. Ischemic acute renal failure an inflammatory disease? Kidney Int. 2004; 66: 480-5.

Bourque $\mathrm{CW}$ : Ionic basis for the intrinsic activation of rat supraoptic neurones by hyperosmotic stimuli. J Physiol 1989;417: 263-77.

Bowers KC, Allshire AP, Cobbold PH. Continuous measurements of cytoplasmatic ATP in single cariomyocytes during simulation of the "oxygen paradox". Cardiovasc Res 1993; 27:1836-9.

Brady HR, Brenner BM, Clarkson MR, Lieberthal W. Acute renal failure. In: Brenner BM. Brenner and Rector's the kidney. $6^{\text {th }}$ ed. Philadelphia: WB Saunder; 2000. p. 1201-62. 
Braz JRC, Vianna PTG, Colognesi JR, Yong LC. Efeitos do pentobarbital sódico sobre o fluxo sangüíneo renal. Fluxometria eletromagnética. Estudo experimental no cão. Rev Bras Anestesiol 1978; 28: 603-8.

Braz JRC, Takata IH, Sato JK, Gorayb SBS, Módolo NSP. Capnometria com cateter nasal em pacientes com respiração espontânea. Rev Bras Anestesiol 1995; 45: 83-7.

Braz JRC, Nascimento Jr P, Braz LG, Paiva FO, Vane, LA, Vianna PTG, Rodrigues Jr GR - The early systemic and gastrointestinal oxygenation effects of hemorrhagic shock resuscitation with hypertonic saline and hypertonic saline 6\% dextran-70: a comparative study in dogs. Anesth Analg 2004; 99: 536-46.

Brezis M. Cellular mechanisms of acute ischemic injury in the Kidney. Annu Rev Med 1993; 44: 27-37.

Briley EM, Lolait SJ, Axelrod J, Felder CC. The cloned vasopressin V1a receptor stimulates phospholipase $\mathrm{C}$, and phospholipase $\mathrm{D}$ though activation of receptor-operated calcium channels. Neuropeptides 1994;27: 63-74.

Brook $A H$ \& Share L. On the question of protein binding and the diffusibility of circulating antidiuretic hormone in the dog. Endocrinology 1966;78:779-85.

Brooks DP, Edwards RM, Depalma PD et al. The water diureticeffect of the alpha-2 adrenoceptor agonist, AGN 190851, isspecies-dependent. J Pharmacol Exp Ther 1991; $259: 1277-82$.

Cabral AD, Kapusta DR, Kenigs VA. Central alpha2-receptor mechanisms contribute to enhanced renal responses during ketamine-xylazine anesthesia. Am J Physiol 1998; 275: R1867-R74.

Castiglia YMM, Braz JRC, Vianna PTG, Lemonica L, Vane LA. Effect of highdose fentanyl on renal function in dogs. São Paulo Med J 1997; 115(3): 1433-9. 
Chabardes D, Montegut M, Imbert-Teboul M et al. Inhibition of alpha2-adrenergic agonists on AVP-induced cAMP accumulation in isolated collecting tubules of the rat kidney. Mol Cell Endocrinol 1984; 37: 263-75.

Chang KS, Davis RF. Propofol produces endothelium-independent vasodilatation and may act as a $\mathrm{Ca}^{+}$chanell blocker. Anesth Analg 1993; 76 : 24-32.

Chen M, Lee J, Huang BS. Clonidine and morphine increase atrial natridiuretic peptide secretion in anesthetized rats. Proc Soc Exp Biol Med 1989; 191:299303.

Chertow GM, Levy EM, Hammermeister KE, Grover F, Daley J. Independent association between acute renal failure and mortality following cardiac surgery. Am J Med 1998; 104: 343-8.

Claeys MA, Gepts E, Camu F. Haempdynamic changes during anaesthesia induced and maintenance with propofol. Br J Anaesth 1983;60:3-9.

Collard CD, Gelman S. Pathophysiology, clinical manifestations, and prevention of ischemia-reperfusion injury. Anesthesiology 2001; 94:1133-8.

Conlon PJ, Stafford-Smith M, White WD. Acute renal failure following cardiac surgery. Nephrol Dial Transplant, 1999;14:1158-62.

Cowley AW. Vasopressin and cardiovascular regulation. In Rev of Phisiol 1982; 26:189-242 .

Cowley AW. Vasopressin and blood pressure regulation. Clin Physiol Biochem 1988; 6:150-62.

Crawford ES, Crawford JL, Safi HJ. Thoracoabdominal aortic aneurysms: preoperative and intraoperative factors determining immediate and long-term results of operations in 605 patients. J Vasc Surg 1986; 3: 389-404. 
Curtis FG, Castiglia YMM, Stolf AA, Ronzella E, Vanni SMD, Nascimento Jr P. Dexmedetomidina e sufentanil como analgésicos per-operatórios. Estudo comparativo. Rev Bras Anestesiol 2002; 52: 525-84.

Dahl RH, Geerdes AE, Molitoris BA. Renal epithelial $\mathrm{Na}^{+-} \mathrm{K}^{+}-$ATPase: reversible dissociation from cytoskeleton during ischemia. Clin Res 1991; 39: $179-88$.

De Broe ME, Bonventre JV, Molitoris BA, Haller H. Evolving Basic concepts in ischemic injury. Kidney Int 2004; 66: 479.

Donohoe JF, Venkatachalam MA, Bernard DB, Levinsky NG. Tubular leakage and obstruction after renal ischemia: structural-functional correlations. Kidney Int 1978; 13(3): 208-22.

Dyck JB, Maze M, Haack C, Vuorilehto L, Shafer SI. The pharmacokinectics and hemodinamic effects of intravenous and intramuscular dexmedetomidine hydrochloride in adult human volunteers. Anesthesiology 1993; 78: 813-20.

Dubick MA, Wade CE. A rewiew of the efficacy and safety of $7,5 \% \mathrm{NaCl} / 6 \%$ dextran 70\% in experimental animals and in humans. J Trauma 1994; 36:323-30.

Dworkin LD, Sun AM, Bernner BA. The renal circulations. In: Brenner BM, editor. Brenner and Rector's the kidney. Philadelphia: WB Saunders; 2000. p. 277-318.

Earley LE. Pathogenesis of oliguric acute renal failure. N Engl J Med 1970; 282(24): 1370-1.

Ebert TJ, Muzi M, Berens $R$ et al. Sympathetic responses to induction of anesthesia in humans with propofol or etomidate. Anesthesiology, 1992;76: 725-33.

Ebert TJ, Muzi M, Goff DR et al. Does propofol really preserve baroreflex function in humans? Anesthesiology, 1992;7:337. 
Ebert TJ, Hall JE, Barney JA, Uhrich TD, Colinco MD. The effects of increasing plasma concentrations of dexmedetomidine in humans. Anesthesiology 2000; 93: 382-94.

Edelstein $\mathrm{CL}$, Ling $\mathrm{H}$, Schrier RW. The nature of renal cell injury. Kidney Int 1997; 51(5):1341-51.

Eger El. Isoflurane: a review. Anesthesiology 1981; 55: 559-76.

Evans RG, Haynes JM. Characterization of binding sites for [3H]-idazoxan, $[3 \mathrm{H}]-\mathrm{P}$-aminoclonidine and $[3 \mathrm{H}]-$ rauwolscine in the kidney of the dog. Clin Exp Pharmacol Physiol 1994; 21: 649-58.

Finn WF. Prevention of ischemic injury in renal transplantation. Kidney Int 1990; 37: 171-82.

Finn WF, Chevalier RL. Recovery from postischemic acute renal failure in the rat. Kidney Int 1979; 16(2): 113-23.

Fitzsimmons $\mathrm{MD}$ et al. Control of posterior pituitary vasopressin content: Implications for the regulation of the vasopressin gene. Endocrinology 1994; 134:1874-8.

Flacke JW, Bloor BC, Kripke BJ, Flacke WE, Warneck CM, Van Etten AP, Wong $\mathrm{DH}$, Katz RL. Comparasion of morphine, meperidine, fentanil, and sufentanil in balanced anesthesia: A double-blind study. Anesth Analg. 1985; 64:897-910.

Flacke JW, Flacke WE, Bloor BC, Mcintee DF. Hemodynamic effects of dexmedetomidine, an $\alpha_{2}$-adrenergic agonist, in autonomically denervated dogs. J Cardiovasc Pharmacol 1990; 16: 616-23.

Flacke WE, Flacke JW, Bloor BC, Mclntee, Sagan M. Effects of dexmedetomidine on systemic and coronary hemodynamics in the anesthetized dog. J Cardiothoracic Vasc Anesth 1993; 41-9. 
Frumento RJ, Playford HR, Wahlander S, Park H, Pascoe J, Slanden RN, Sommet J. Dexmedetomidine is associated with long-term decrease in serum creatinine following ortho-topic lung transplantation: 448. Crit Care Med 2004; 32: A124.

Garwood S. Renal insufficiency after cardiac surgery. Semin Cardiothorac Vasc Anesth $2004 ; 8: 227-41$.

Gelman S. The pathophysiology of aortic cross-clamping and unclamping. Anesthesiology 1995; 82: 1026-60.

Gertler R, Brown HC, Mitchell DH, Silvius E. Dexmedetomidine: a novel sedative-analgesic agent. BUMC Proceedings 2001; 14: 13-21.

Girolmo CA. Pharmacological characterization of a vaspressin V1 receptor in the isolated human gastric artery. Life Science 1997;60:63-8, 1997.

Godet G, Fleron MH, Vicaut E, Zubicki A, Bertrand M, Riou B, Kieffer E, Coriat P. Risk factors for acute postoperative renal failure in thoracic or thoracoabdominal aortic surgery: a prospective study. Anesth Analg 1997; 85: 1227-32.

Grounds RM, Moore M, Morgan M. The relative potencies of thiopentone and propofol. Eur J Anaesth. 1986;3:11-7

Gueler F, Rong S, Park JK, Fiebeler A, Menne J, Elger M, Mueller DN, Hampich F, Dechend R, Kunter U, Luft FC, Haller H. Postischemic acute renal failure is reduced by short-term statin treatment in a rat model. J Am Soc Nephrol 2002; 13: 2288-98.

Hayashi Y, Maze M. Alpha-2 adrenoreceptor agonist and anesthesia. $\mathrm{Br} \mathrm{J}$ Anaesth, 1993;71:108-18.

Haimovic H. Ischemia-reperfusion syndrome of skeletal muscle. J cardivasc Surgy (torino). 1990; 31:318-9. 
Hamaya $\mathrm{Y}$, Nishikawa T, Dohi S. Diuretic effect of clonidine during isoflurane, nitrous oxide, and oxygen anesthesia. Anesthesiology, 1994; 81: 811-9.

Hamazaki J, Tsuneyoshi I, Katai R, Hidaka T, Boyle Wa, Kanmura Y. Dual a2adrenergic agonist and aadrenergic antagonist actions of dexmedetomidine on human isolated endothelium-denuded gastroepiploic arteries. Anesth Analg 2002; 94: 1434-40.

Hara Y, Battey J, Gainer H. Structure of mouse vasopressin and oxytocin genes. J. Brain Res 1990; 8: 319-24.

Harper HA. Manual de química fisiológica. 4를. ed. São Paulo: Atheneu; 1977.

Honda N, Hishida A. Pathophysiology of experimental non-oliguric acute renal failure. Kidney Int 1993; 43: 513-21.

Housmans PR. Effects of dexmedetomidina on contractility, relaxation, and intracellular calcium transients of isolated ventricular myocardium. Anesthesiology. 1990; 73: 919-22.

Humphreys MH, Reid IA. Supression of antidiuretic hormone secretion by clonidina in the anesthetized dog. Kidney Int 1975; 7: 405-12.

Hupf H. Evidence for a vasopressin system in the rat heart. Circ. Re. 1999;84:365-70.

Ideura $\mathrm{T}$, Solez K, Heptinstall $\mathrm{RH}$. The effect of clonidine on tubular obstruction in postischemic acute renal failure in the rabbit demonstrated by microradiography microdissection. Am J Pathol 1980; 98: 123-50.

Ichikawa I, Kiyma S, Yoshida T. Renal antioxidant enzymes: their regulation and function. Kidney Int.1994; 45:1-9

Jalonen J, Hynynen $M$, Kuitunen A, Heikkilä $H$, Perttilä J, Salmenperä $M$, Valtonen M, Aantaa R, Kallio A. Dexmedetomidine as an anesthetic adjunct in coronary artery by-pass graffing. Anesthesiology 1997; 86:331-45. 
Jassen W, Roake J. The molecular and cellular basis of reperfusion injury following organ transplantation. Transplant Rev. 1998;12:14-33.

Jones DP. Renal metabolism during normoxia, hypoxia, and ischemic injury. Ann Rev Physiol. 1986: 48:33-50.

Jonge A, Timmermans PB, van Zweiten PA. Participation of cardiac presynaptic a2-adrenoreceptors in the bradycardic effects of clonidine and analogues. Naunyn Schmiedebergs Arch Pharmacol 1981;137:8-12.

Kallio A, Scheinin M, Koulu M, Ponkilainen R, Ruskoaho $H$, Vinamaki $O$, Scheinin $\mathrm{H}$. Effects of dexmedetomidine, a selective alpha 2-adrenoceptor agonist, on hemodynamic control mechanisms. Clin Phamacol Therap 1989; 46: 33-42.

Kauppila $\mathrm{T}$, Kemppainen $\mathrm{P}$, Tanila $\mathrm{H}$, Pertovaara A. Effects of systemic medetomidine, a alfa 2 adrenoceptor agonist, on experimental pain experimental in humans. Anesthesiology 1991; 74: 3-8.

Ketch T, Biaggioni I, Pobertson R, Pobertson D. Four faces of baroreflex fallure. Hypertensive crisis, volatile hypertension, orthostatic tachycardia, and malignant vagotonia. Circulation 2002; 105: 2518-23.

Kirchheim, HR. Systemic arterial baroreceptor reflexes Phisyol Rev 1976; 56: 100-76.

Kimura $\mathrm{T}$, Share $\mathrm{L}$, Wang BC et al - The role of central adrenoreceptors in the control of vasopressin release and blood pressure. Endocrinology, 1981; 108: 1829-36.

Kotrly KJ, Ebert TJ, Vucins E, Igler FO, Barney JA, Kampine JP. Baroreceptor reflex control of heart rate during isoflurane anesthesia in humans. Anesthesiology 1984; 61: 558-63. 
Kubo T, Misu Y. Pharmacological characterization on the a2-adrenoreceptor responsible for a decrease of blood pressure in the nucleus tractus solitary of the rat. Naunyn Schmiedebergs Arch Pharmacol, 1981; 317: 120-5.

Kovacs L \& Robertson GL. Syndrome of inappropriate antidiuresis. Endocrinol Metab Clin North Am 1992;21: 859-75.

Kover $G$, Tost $H$, Darvasi A. The effects of clonidine on the kidney function in the anesthetized dog. Acta Physiol Hung 1989; 74:229-41.

Kulka PJ, Tyba M, Zenz M. Preoperative a2-adrenergic receptor agonists prevent the deterioration of renal function after cardiac surgery: results of randomizaed, controlled trial. Crit Care Med 1996; 24: 947-52.

Kuusela E, Raekallio M, Antilla M, Falck L, Molsa S, Vainio O. Clinical effects and pharmacokinetics of medetomidine and its enantiomers in dogs. $J$ Vet Pharmacol Ther 2000; 23: 15-20.

Lauson HD. Metabolism of antidiuretic hormones. Am J Med 1967; 42: 713-44

Laubie $M$, Schimitt $H$, Drouillat $M$. Central sites and mechanisms of the hypotensive and bradycardic effects of the narcotic analgesic agent fentanyl. Arch Pharmacol 1977; 296: 255-61.

Landry DW, Levin HR, Gallant EM, Seo S, D'Alessandro D, Oz MC, Oliver JA. Vasopressin deficiency contributes to the vasodilation of septic shock. Circulation 1997. 1997;95:1122-5.

Lema G, Canessa R Urzua J. Renal dysfunction after vascular surgery. Curr Opin Anaesthesiol 1998; 11: 9-13.

Levy JH, Davis GK. Determination of hemodynamics and histamine release of rocuronium (ORG 9426) When administered in increased doses under $\mathrm{N}_{2} \mathrm{O} / \mathrm{O}_{2}$ sufentanil anesthesia. Anesth Analg 1994; 78: 318-21. 
Liard JF: Effects of intra-arterial arginine-vasopressin infusions on peripheral blood flows in conscious dogs. Clin Sci (Lond). 1986;71:713-21.

Lieberthal W. Biology of acute renal failure: therapeutic implications. Kidney Int 1997; 52(4):1102-15.

Lieberthal W, Wolf EF, Rennke HG, Valeri CR, Levinsky NG. Renal ischemia and reperfusion impair endothelium-dependent vascular relaxation. Am J Physiol 1989; 256: F894-900.

Lolait SJ et al. Molecular biology of vasopressin receptors. Amm. NY Acad Sci 1995;771:273-92.

Lond W, Messimer $\mathrm{K}$. The impact of ischemia/reperfusion on jury on specific and non-specific, early and late chronic events after organ transplantation. Transplant Rev 1996;10: 108-27.

McDougal WS. Renal perfusion/reperfusion injuries. J Urol 1988; 140(6): 132530.

Maddox DA, Brenner BM. Glomerular ultrafiltration. In: Brenner MB, editor. Brenner and Recto's the Kidney. $4^{\text {nd }}$ ed. Philadelphia: WB Saunders; 2000.p. 31974.

Mangano CM, Diamondstone LS, Ramsay JG et al. Renal dysfunction after myocardial revascularization: risk factors, adverse outcomes and hospital resource utilization. The Multicenter study of Perioperative Ischemia Research Group. Ann Intern Med 1998; 128: 194-203.

Mason J. The pathophysiology of ischemic acute renal failure. Renal Physiol. 1986; 9: 129-47.

Mason WT. Supraoptic neurones of rat hypothalamus are osmosensitive. Nature 1980; 287:154-7. 
Massone F. Anestesiologia veterinária: farmacologia e técnicas. $3^{\text {a }}$ ed. Rio de Janeiro: Guanabara Koogan; 1999.

Maze M, Tranquilli W. Alpha-2 adrenoceptor agonisits: Defining the role in clinical anesthesia. Anesthesiology 1991; 74: 581-605.

Masson J. The pathophysiology of ischemic acute renal failure. Renal Physio. 1996;9: 129-47.

Mendelsohn FA, Quirion R, Saavedra JM, Aguilera G, Catt KJ. Autoradiographic localization of angiotensin II receptors in rat brain. Proc. Natl. Acad Sci. 1984; 81: 1575-9.

Miller M \& Moses AM. Drug-induced states of impaired wayer excretion. Kidney Int 1976;10: 96-103.

Módolo NSP, Castiglia, YMM, Ganem EM, Braz JRC, Vianna PTG, Vane LA. Acute renal ischemia model in dogs: effects of metoprolol. Renal Failure 2001; 23: 1-10.

Módolo NSP, Castiglia YMM, Ganem EM, Braz JRC, Vianna PTG. Efeitos do alopurinol em rins isquêmicos de cães anestesiados com pentobarbital sódico. Rev Bras Anestesiol 2000; 50: 239-45.

Molitoris BA. Ischemia-induced loss of epithelial polarity: potential role of the actincytoskeleton. Am J Physiol 1991; 260: F769-78.

Molitoris BA. The potential role of ischemia in renal disease progression. Kidney Int 1992: S21-5.

Nascimento P, Braz JRC, Curi PR, Vane LA, Castiglia YMM. Efeitos da infusão contínua do propofol sobre a função renal do cão. Estudo comparativo com o pentobarbital sódico. Rev Bras Anestesiol 1994; 44: 163-70.

Osheroff PL. \& Phillips HS. Autoradiographic localization of relaxin binding sites in rat brain. Proc. Natl. Acad. Sci. USA. 1991;88:6413-7. 
Ostheimer GW, Shanahan EA, Guyton, RA, Daggett WM, Lowenstein E: Effects of fentanyl and droperidol on canine left ventricular performance. Anesthesiology 1975; 42: 288-91.

Ostrowski NL, Young WS 3rd, Knepper MA, Lolait SJ. Expression of vasopressin $\mathrm{V} 1 \mathrm{a}$ and $\mathrm{V} 2$ receptor messenger ribonucleic acid in the liver and kidney of embryonic, developing, and adult rats. Endocrinology 1993;133: 184959.

Pagel OS, Warltier DC. Negative inotropic effects of propofol as evaluated by the regional preload recruitable stroke work relationship in chronically instrumented dogs. Anesthesiology 1993; 78: 100-8.

Paris A, Tonner PH. Dexmedetomidine in anaesthesia. Curr Opin Anaesthesiol 2005; 18:412-18.

Perdrizet GA. The heat shock response and organ transplantation. Transplant Rev 1996; 10:78-98.

Prinzen FW, Lawrence CJ, Lange S. Effects of the alpha2-addrenergic agonist dexmedetomidine on nutrient blood flow to various organs in anaesthetized dogs. Anesth Anag 1996;83:1160-5.

Peskind ER, Raskind MA, Leake RD. Clonidine decreases plasma and cerebrospinal fluid arginine vasopressine but not oxytocin in humans. Neuroendocrinology 1987; 46: 395-400.

Radermacher J, Förstermann U, Frölich JC. Endothelium-derived relaxing factor influences renal vascular resistance. Am J Physiol 1990; 259 (1 Pt 2): F9-17.

Ramsay DJ. Posterior pituitary gland. In: Greenspan FS \& Forshan PH. Basic and clinical endocrinology. Los Altos, CS: Lange Medical Plublications, 1983, p. 120-129.

Reid IA, Nolan PL, Wolf JA, Keil LC. Supression of vasopressin secretion by clonidina:effect $\alpha$-adrenoceptor antagonist. Endocrinology 1979; 104: 1403-6. 
Reid IA, Ahn JN, Trinh T, Shackelford R, Weintraub M, Keil LC. Mechanism of suppression of vasopressin and adrenocoticotropic hormones secretion by clonidina in anesthetized dogs. J Pharm Exp Ther 1984; 229: 1-8.

Reitan JA, Stengert KB. Central vagalcontrol of fentanyl-induced bradycardia during halothane anesthesia. Anesth Analg 1978; 57: 31-6.

Reves JG, Glass PSA, Lubarsky DA. Nonbarbiturate intravenous anesthesics. In: Miller RD, editor. Anesthesia. $5^{\text {a }}$ ed. Philadelphia: Churchill Livingstone, 2000: 228-72.

Riley AL. Effect of ischemia on renal blood flow in the rat. Nephron 1978; 21(2): 107-13.

Rodrigues Jr GR, Amaral JLG, Castiglia YMM, Marques MEA. Eficácia da solução de cloreto de sódio a 7,5\% com e sem dextran 70 a 6\% na preservação da função renal de cães hipovolêmicos submetidos à isquemia-reperfusão. Rev Bras Anestesiol 2002; 52(1):41-54.

Roberston EN, Hull JM. A comparasion of rocuronium and vecuronium: The pharcodynamic, cardiovascular and intra-ocular effects. Eur J Anaesthesiol 1994; 9: 116-21.

Roman RJ, Cowley AW, Lecheme C. Water diuretic and natriuretic effect of clonidine in the rat. J Pharmacol Exp 1979; 211: 385-93.

Rouch AJ, Kudo LH, Hébert C. Dexmedetomidine Inhibits Osmotic Water Permeability in the rat Cortical Collecting Duct. J Pharmacol Exp 1997; 281: 6269.

Ruffolo Jr RR - Distribution and function of peripheral adrenoreceptores on the cardiovascular system. Pharmacol Biochem Beahav, 1985;22:827-833. 
Ryden H \& VERNEY EB. The inhibition of water diuresis by emotional stress and muscular exercise. Exp. Physiol 1988; 27: 343-74.

Sachs H, Fawcett P, Takabatake Y, Portanova R. Biosynthesis and release of vasopressin and neurophysin. Recent Prog Horm 1969; 25:447-91.

Saeki Y,Hasegawa Y, Shibamoto T, Yamaguchi Y, Hayashi T, Tanaka S, Wang H-G, Koyama S. The effects of sevoflurane, enflurane andisoflurane on baroreceptor-sympathethic reflex in rabbits. Anesth Analg 1996; 82: 342-48.

Scheinin H, Karhuvaara S, Olkkola KT, Kalio A, Anttila M, Vuorilehto L, Scheinin M. Pharmacodynamics and pharmacokinetics of intramuscular dexmedetomidine. Clin Pharmacol Ther 1992; 52: 537-46.

Scheinin M, Kallio A, Koulu M, Vikari J, Scheinin H. Sedative and cardiovascular effects of medetomidine, a novel selective alpha2 adrenoceptor agonist, in healthy volunteers. Br J Clin Pharmacol 1987; 4: 443-51.

Scherier RW. Vasopressin. Raven Press, New York, 1985.

Schmeling WT, Kampine JP, Roerig DL, Wartier DC. The effects of streoisomers of the $\alpha_{2}$ adrenergic agonist medetomidine on systemic and coronary hemodynamics in conscious dogs. Anesthesiology 1991; 75: 499-511.

Schmitz JM, Graham RM, Sagalowsky A et al. Renal alpha-1 and alpha-2 adrenergic receptors: biochemical and pharmacological correlations. J Pharmacol Exp Ther 1981; 219: 400-6.

Sellgren J, Ejnell $\mathrm{H}$, Ponten J, Sonander HG. Anesthetic modulation of cardiovascular response to microlaryngoscopy. Acta Anaesthesiol Scand 1995; 39: 381-9.

Sessler. DI. Temperature monitoring. In: Miller RD, editor. Anesthesia. $6^{\mathrm{a}}$ ed. Philadelphia: Churchill Livinsgstone, 2005, p.1367-89. 
Shroyer AL, Coombs LP, Peterson, ED, Eiken MC, DeLong ER, Chen A, Ferguson JrTB, Grover FL, Edwards FH. The Society of Thoracic Surgeons: 30day operative mortality and morbidity risk models. Ann Thorac Surg 2003; 75(6): 1856-65.

Smith I, Nathanson M, White PF. Sevoflurane a long-awaited volatile anaesthetic. Br J Anaesth 1996; 76: 435-45.

Smyth DD, Umemura S, Pettinger WA. $\alpha_{2}$ adrenoceptor antagonism of vasopressin-induced changes in sodium excretion. Am J Physiol 1985; 247: 767-72.

Solez K, Ideura T, Silvia CB, Hamilton B, Saito H. Clonidine renal ischemia to lessen acute renal failure and microvascular damage. Kidney Int 1980; 18: 30922.

Strandhoy JW, Morris M, Buckalew VM Jr. Reanl effects of antihypertensive guanabenz, in the dog. J Pharmacol Exp Ther 1982; 221: 347-52.

Svennson L, Sun J, Nadolny E, Kimmel WA. Prospective evaluation of minimal blood use for ascending aorta and aortic operations. Ann Thorac Surg 1995; 59: 1501-8.

Talke P, Chen R, Thomas B, Aggarwall A, Gottieb A, Thorborg P, Kallio A, Cheung $B$, Stanley $L$. The effects of hemodinamic and adrenergic for infusion perioperative dexmedetomidine after vascular surgery. Anesth Analg 2000; 90: 834-9.

Taniguchi T, Kidami Y, Kanakura H, Takemoto Y, Yamammoto K. Effects of dexmedetomidine on mortality rate and inflammatory responses to endotoxininduces shock in rats. Crit Care Med 2004; 32: 1322-6.

Thadhani R, Pascual M, Bonventre JV. Acute renal failure. N Engl J Med 1996; 334(22): 1448-60. 
Twerky RS. The pharmacology of anesthetics used for ambulatory surgery. In: Barash PG, Deutsch S, Tinker J, editors. Refresher Coursers in Anesthesiology in ASA Annual Meeting; Philadelphia: Pennsylvania, 1993. chap. 13; p. 159-75.

Umemura S, Marver D, Smyth DD et al. Alpha2-adrenoceptors and cellular cAMP levels in single nephron segments from the rat. Am J Physiol 1985; 249: F28-F33.

Vickery RG, Sheridan BC, Segal IS, Maze M. Anesthetic and hemodinamic effects of the stereoisomers of medetomidine, na alpha 2-adrenergic agonist, in halothane-anesthetizad dogs. Anesth Analg 1988; 67: 611-5.

Villela NR. Efeitos renais e sobre a concentração plasmática do hormônio antidiurético de duas doses de dexmedetomidina. Estudo experimental em cães anestesiados. [doutorado]. Botucatu:Faculdade de Medicina, Universidade Estadual Paulista; 2003.

Villela NR, Nascimanto P, Carvalho LR, Teixeira A. Efeitos da dexmedetomidina sobre o sistema renal e sobre a concentração plasmática do hormônio antidiurético. Estudo experimental em cães. Rev Bras Anestesiol 2005; 55: 429-40.

Weinberg JM. The cell biology of ischemic renal injury. Kidney Int. 1991;39:476500 .

Willigers HM, Prinzen Fw, Roekaerts PM. Comparison of the effects of dexmedetomidine and esmolol on myocardial oxygen consumption in dogs. Eur J Anaesth 2004; 21:957-66.

Wilhelm SM, Simonson MS, Robinson AV, Stowe NT, Schulak JA. Endothelin upregulation and localization following renal ischemia and reperfusion. Kidney Int 1999; 55(3): 1011-8.

Wood CE. \& Chen HG. Acidemia stimulates acth, vasopressin, and heart rate responses in fetal sheep. Am. J. Physiol 1989; 257: 344-9. 
Wouters PF, Marcus M, Ruyter HA, Flameng W, Van Aken H. Cardiovascular effects of propofol in choronically instrumented dogs. Anesth Analg. 1993; 76(S1): S470.

Xuan YT, Zhang J, Glass PAS. Propofol inhibition of endothelium- mediated formation of inositol phosphates in smooth muscle. Anesthesiology 1992;77: A597. 


\section{APÊNDICE}

Tabela 36 - Peso dos cães (kg)

\begin{tabular}{lc}
\hline G1 & Peso \\
\hline cão 1 & 22 \\
cão 2 & 21 \\
cão 3 & 23 \\
cão 4 & 15 \\
cão 5 & 21 \\
cão 6 & 29 \\
cão 7 & 18 \\
cão 8 & 29 \\
cão 9 & 18 \\
cão 10 & 18 \\
\hline
\end{tabular}

\begin{tabular}{lc}
\hline G2 & Peso \\
\hline cão 1 & 21 \\
cão 2 & 15 \\
cão 3 & 21 \\
cão 4 & 17 \\
cão 5 & 22 \\
cão 6 & 13 \\
cão 7 & 19 \\
cão 8 & 20 \\
cão 9 & 18 \\
cão 10 & 18 \\
\hline
\end{tabular}

Tabela 37- Comprimento dos cães (cm)

\begin{tabular}{lc}
\hline G1 & Comprimento \\
\hline cão 1 & 98 \\
cão 2 & 94 \\
cão 3 & 111 \\
cão 4 & 91,5 \\
cão 5 & 93 \\
cão 6 & 111,5 \\
cão 7 & 107 \\
cão 8 & 118 \\
cão 9 & 104 \\
cão 10 & 97 \\
\hline
\end{tabular}

\begin{tabular}{lc}
\hline G2 & Comprimento \\
\hline cão 1 & 94 \\
cão 2 & 91,5 \\
cão 3 & 93 \\
cão 4 & 53 \\
cão 5 & 111 \\
cão 6 & 93 \\
cão 7 & 100 \\
cão 8 & 101 \\
cão 9 & 96 \\
cão 10 & 99 \\
\hline
\end{tabular}


Tabela 38 - Superficie corporal $\left(\mathrm{m}^{2}\right)$

\begin{tabular}{lccccc}
\hline G1 & ASC & & G2 & ASC \\
\cline { 1 - 2 } \cline { 5 - 6 } cão 1 & 0,71 & & cão 1 & 0,71 \\
cão 2 & 0,71 & & cão 2 & 0,6 \\
cão 3 & 0,83 & & cão 3 & 0,7 \\
cão 4 & 0,6 & & cão 4 & 0,43 \\
cão 5 & 0,7 & & cão 5 & 0,81 \\
cão 6 & 0,92 & & cão 6 & 0,57 \\
cão 7 & 0,73 & & cão 7 & 0,71 \\
cão 8 & 0,95 & & cão 8 & 0,73 \\
cão 9 & 0,71 & & cão 9 & 0,67 \\
cão 10 & 0,66 & & cão 10 & 0,69 \\
\hline
\end{tabular}

Tabela $39-$ Sexo

\begin{tabular}{ll}
\hline G1 & Sexo \\
\hline cão 1 & Fêmea \\
cão 2 & Fêmea \\
cão 3 & Fêmea \\
cão 4 & Macho \\
cão 5 & Macho \\
cão 6 & Macho \\
cão 7 & Macho \\
cão 8 & Macho \\
cão 9 & Fêmea \\
cão 10 & Fêmea \\
\hline
\end{tabular}

\begin{tabular}{ll}
\hline G2 & Sexo \\
\hline cão 1 & Macho \\
cão 2 & Macho \\
cão 3 & Fêmea \\
cão 4 & Macho \\
cão 5 & Macho \\
cão 6 & Macho \\
cão 7 & Fêmea \\
cão 8 & Macho \\
cão 9 & Fêmea \\
cão 10 & Fêmea \\
\hline
\end{tabular}


Tabela 40 - Hematócrito (\%). Valores obtidos em cada cão nos momentos de cada grupo

\begin{tabular}{|c|c|c|c|c|c|}
\hline \multirow[t]{2}{*}{ GRUPO } & \multicolumn{4}{|c|}{ MOMENTOS } & \multirow[b]{2}{*}{ M5 } \\
\hline & M1 & M2 & M3 & M4 & \\
\hline \multicolumn{6}{|l|}{ G1 } \\
\hline \multicolumn{6}{|l|}{ Cão } \\
\hline 1 & 53 & 52 & 49 & 48 & 47 \\
\hline 2 & 44 & 48 & 50 & 45 & 45 \\
\hline 3 & 31 & 34 & 33 & 35 & 38 \\
\hline 4 & 34 & 29 & 32 & 35 & 35 \\
\hline 5 & 40 & 47 & 42 & 39 & 49 \\
\hline 6 & 55 & 54 & 50 & 50 & 50 \\
\hline 7 & 51 & 53 & 50 & 45 & 43 \\
\hline 8 & 45 & 53 & 50 & 45 & 41 \\
\hline 9 & 54 & 54 & 55 & 55 & 50 \\
\hline 10 & 52 & 52 & 56 & 56 & 55 \\
\hline \multicolumn{6}{|l|}{ G2 } \\
\hline \multicolumn{6}{|l|}{ Cão } \\
\hline 1 & 42 & 40 & 40 & 35 & 35 \\
\hline 2 & 28 & 35 & 35 & 36 & 35 \\
\hline 3 & 30 & 31 & 30 & 30 & 31 \\
\hline 4 & 44 & 51 & 50 & 50 & 50 \\
\hline 5 & 24 & 26 & 23 & 24 & 20 \\
\hline 6 & 28 & 32 & 30 & 35 & 35 \\
\hline 7 & 62 & 57 & 53 & 50 & 51 \\
\hline 8 & 40 & 43 & 38 & 38 & 39 \\
\hline 9 & 47 & 49 & 44 & 48 & 47 \\
\hline 10 & 54 & 44 & 41 & 40 & 39 \\
\hline
\end{tabular}


Tabela 41 - Saturação de pulso de oxigênio (\%). Valores obtidos em cada cão nos momentos de cada grupo

\begin{tabular}{|c|c|c|c|c|c|}
\hline \multirow[t]{2}{*}{ GRUPO } & \multicolumn{4}{|c|}{ MOMENTOS } & \multirow[b]{2}{*}{ M5 } \\
\hline & M1 & M2 & M3 & M4 & \\
\hline \multicolumn{6}{|l|}{ G1 } \\
\hline \multicolumn{6}{|l|}{ Cão } \\
\hline 1 & 99 & 99 & 99 & 98 & 99 \\
\hline 2 & 98 & 97 & 98 & 98 & 97 \\
\hline 3 & 99 & 99 & 99 & 99 & 99 \\
\hline 4 & 99 & 99 & 100 & 100 & 99 \\
\hline 5 & 99 & 99 & 100 & 99 & 99 \\
\hline 6 & 99 & 99 & 99 & 99 & 99 \\
\hline 7 & 98 & 97 & 96 & 97 & 95 \\
\hline 8 & 98 & 96 & 98 & 98 & 98 \\
\hline 9 & 99 & 99 & 99 & 96 & 97 \\
\hline 10 & 100 & 100 & 100 & 100 & 100 \\
\hline \multicolumn{6}{|l|}{ G2 } \\
\hline \multicolumn{6}{|l|}{ Cão } \\
\hline 1 & 99 & 99 & 99 & 100 & 97 \\
\hline 2 & 99 & 99 & 99 & 99 & 100 \\
\hline 3 & 98 & 98 & 99 & 99 & 99 \\
\hline 4 & 99 & 99 & 98 & 99 & 99 \\
\hline 5 & 99 & 97 & 98 & 98 & 98 \\
\hline 6 & 99 & 98 & 99 & 100 & 100 \\
\hline 7 & 98 & 100 & 99 & 99 & 99 \\
\hline 8 & 95 & 99 & 99 & 99 & 99 \\
\hline 9 & 97 & 99 & 99 & 99 & 99 \\
\hline 10 & 98 & 99 & 99 & 99 & 99 \\
\hline
\end{tabular}


Tabela 42 - Temperatura esofágica $\left({ }^{\circ} \mathrm{C}\right)$. Valores obtidos em cada cão nos momentos de cada grupo

\begin{tabular}{lccccc}
\hline \multirow{2}{*}{ GRUPO } & \multicolumn{5}{c}{ MOMENTOS } \\
\cline { 2 - 5 } G1 & M2 & M3 & M4 & M5 \\
\hline Cão & & & & \\
1 & & & & & \\
2 & 36,7 & 36,6 & 36,6 & 36,5 & 36,4 \\
3 & 36,8 & 36,7 & 36,6 & 36,5 & 36,5 \\
4 & 36,2 & 36,3 & 35,9 & 35,4 & 35,1 \\
5 & 35 & 35 & 33,7 & 33,5 & 33,4 \\
6 & 36,9 & 36,8 & 36 & 36,1 & 36,1 \\
7 & 36,9 & 36,9 & 36,8 & 36,7 & 36,6 \\
8 & 37,3 & 37 & 36,8 & 36,6 & 36,7 \\
9 & 35,9 & 35,6 & 35,2 & 35 & 34,8 \\
10 & 36,9 & 36,9 & 36,5 & 36,5 & 36,6 \\
G2 & 36,1 & 35,9 & 35,4 & 35,2 & 35,1 \\
Cão & & & & & \\
1 & & & & & \\
2 & 35,7 & 35,3 & 34,9 & 34,5 & 34,3 \\
3 & 37,9 & 37,2 & 36,5 & 36,4 & 36,3 \\
4 & 35,7 & 35 & 34,7 & 34,5 & 34,4 \\
5 & 36,3 & 36,1 & 35,4 & 35 & 34,8 \\
6 & 36,2 & 36,4 & 35,4 & 35,6 & 35,4 \\
7 & 36,5 & 36,1 & 35,1 & 34,9 & 34,8 \\
8 & 37 & 36,2 & 35,4 & 35,3 & 35,1 \\
9 & 37,5 & 37,1 & 36,7 & 36,4 & 36,2 \\
10 & 37,4 & 37,2 & 36,9 & 36,9 & 36,8 \\
\hline & 36,8 & 36,3 & 35,9 & 35,7 & 35,6 \\
\hline
\end{tabular}


Tabela 43 - Freqüência cardíaca $\left(\right.$ bat.min $\left.{ }^{-1}\right)$. Valores obtidos em cada cão nos momentos de cada grupo

\begin{tabular}{lccccc}
\hline \multirow{2}{*}{ GRUPO } & \multicolumn{5}{c}{ MOMENTOS } \\
\cline { 2 - 6 } & M1 & M2 & M3 & M4 & M5 \\
\hline G1 & & & & & \\
Cão & & & & & \\
1 & 137 & 139 & 142 & 155 & 146 \\
2 & 123 & 131 & 144 & 138 & 128 \\
3 & 72 & 107 & 113 & 117 & 110 \\
4 & 88 & 98 & 132 & 120 & 117 \\
5 & 125 & 141 & 129 & 136 & 127 \\
6 & 78 & 113 & 114 & 106 & 100 \\
7 & 120 & 125 & 127 & 128 & 127 \\
8 & 104 & 99 & 123 & 120 & 120 \\
9 & 86 & 101 & 150 & 162 & 148 \\
10 & 133 & 164 & 167 & 166 & 171 \\
G2 & & & & & \\
Cão & & & & & \\
1 & 105 & 65 & 52 & 58 & 66 \\
2 & 146 & 66 & 105 & 103 & 130 \\
3 & 100 & 54 & 70 & 92 & 90 \\
4 & 82 & 47 & 57 & 46 & 45 \\
5 & 162 & 97 & 107 & 95 & 107 \\
6 & 111 & 92 & 122 & 122 & 133 \\
7 & 146 & 59 & 53 & 50 & 54 \\
8 & 107 & 85 & 82 & 79 & 78 \\
9 & 80 & 76 & 88 & 82 & 87 \\
10 & 72 & 39 & 66 & 53 & 72 \\
\hline
\end{tabular}


Tabela 44 - Pressão arterial média ( $\mathrm{mmHg}$ ). Valores obtidos em cada cão nos momentos de cada grupo

\begin{tabular}{lccccc}
\hline \multirow{2}{*}{ GRUPO } & \multicolumn{5}{c}{ MOMENTOS } \\
\cline { 2 - 6 } & M1 & M2 & M4 & M5 \\
\hline G1 & & & & & \\
Cão & & & & & \\
1 & 126 & 127 & 131 & 130 & 126 \\
2 & 96 & 97 & 102 & 119 & 106 \\
3 & 121 & 122 & 104 & 102 & 112 \\
4 & 101 & 101 & 109 & 112 & 117 \\
5 & 97 & 111 & 96 & 109 & 105 \\
6 & 109 & 113 & 126 & 125 & 122 \\
7 & 95 & 99 & 102 & 110 & 105 \\
8 & 154 & 175 & 174 & 169 & 171 \\
9 & 108 & 113 & 128 & 129 & 107 \\
10 & 105 & 129 & 125 & 111 & 125 \\
G2 & & & & & \\
Cão & & & & & \\
1 & 121 & 104 & 115 & 117 & 131 \\
2 & 128 & 115 & 146 & 150 & 130 \\
3 & 107 & 112 & 112 & 105 & 106 \\
4 & 143 & 123 & 135 & 123 & 123 \\
5 & 104 & 106 & 92 & 93 & 97 \\
6 & 111 & 108 & 134 & 138 & 140 \\
7 & 113 & 107 & 135 & 127 & 114 \\
8 & 111 & 105 & 113 & 123 & 113 \\
9 & 106 & 109 & 100 & 119 & 107 \\
10 & 102 & 101 & 106 & 100 & 101 \\
\hline
\end{tabular}


Tabela 45 - Pressão média átrio direito $(\mathrm{mmHg})$. Valores obtidos em cada cão nos momentos de cada grupo

\begin{tabular}{llllll}
\hline \multirow{2}{*}{ GRUPO } & \multicolumn{5}{c}{ MOMENTOS } \\
\cline { 2 - 6 } & M1 & M2 & M3 & M4 & M5 \\
\hline G1 & & & & & \\
Cão & 2 & 5 & 5 & 5 & 3 \\
1 & 3 & 3 & 2 & 3 & 2 \\
2 & 5 & 3 & 3 & 4 & 3 \\
3 & 3 & 3 & 3 & 2 & 3 \\
4 & 4 & 6 & 4 & 4 & 4 \\
5 & 5 & 3 & 2 & 3 & 2 \\
6 & 6 & 4 & 6 & 7 & 7 \\
7 & 3 & 5 & 4 & 4 & 4 \\
8 & 3 & 2 & 3 & 3 & 3 \\
9 & 2 & 2 & 2 & 2 & 1 \\
10 & & & & & \\
G2 & & & & & \\
Cão & 6 & 5 & 6 & 7 & 5 \\
1 & 2 & 5 & 4 & 4 & 5 \\
2 & 5 & 6 & 5 & 4 & 6 \\
3 & 6 & 5 & 5 & 6 & 6 \\
4 & 2 & 3 & 3 & 3 & 3 \\
5 & 3 & 5 & 2 & 1 & 2 \\
6 & 4 & 4 & 5 & 4 & 5 \\
7 & 2 & 4 & 4 & 5 & 4 \\
8 & 3 & 3 & 2 & 2 & 2 \\
9 & 3 & 5 & 2 & 3 & 2 \\
10 & & & & &
\end{tabular}


Tabela 46 - Pressão média de artéria pulmonar (mmHg). Valores obtidos em cada cão nos momentos de cada grupo

\begin{tabular}{lccccc}
\hline \multirow{2}{*}{ GRUPO } & \multicolumn{5}{c}{ MOMENTOS } \\
\cline { 2 - 6 } & M1 & M3 & M4 & M5 \\
\hline G1 & & & & & \\
Cão & & & & & \\
1 & 16 & 17 & 15 & 15 & 16 \\
2 & 16 & 15 & 13 & 12 & 13 \\
3 & 16 & 15 & 16 & 16 & 15 \\
4 & 15 & 15 & 14 & 14 & 15 \\
5 & 13 & 17 & 11 & 12 & 12 \\
6 & 17 & 18 & 18 & 18 & 17 \\
7 & 17 & 16 & 16 & 18 & 17 \\
8 & 13 & 18 & 17 & 16 & 16 \\
9 & 12 & 11 & 11 & 8 & 8 \\
10 & 10 & 10 & 10 & 9 & 9 \\
G2 & & & & & \\
Cão & & & & & \\
1 & 19 & 15 & 15 & 17 & 19 \\
2 & 15 & 13 & 16 & 17 & 17 \\
3 & 15 & 14 & 13 & 12 & 13 \\
4 & 14 & 13 & 11 & 12 & 11 \\
5 & 10 & 12 & 12 & 12 & 12 \\
6 & 12 & 14 & 18 & 16 & 14 \\
7 & 20 & 14 & 14 & 15 & 14 \\
8 & 10 & 11 & 15 & 12 & 11 \\
9 & 11 & 12 & 10 & 9 & 9 \\
10 & 12 & 11 & 11 & 10 & 10 \\
\hline
\end{tabular}


Tabela 47 - Pressão de artéria pulmonar ocluída $(\mathrm{mmHg})$. Valores obtidos em cada cão nos momentos de cada grupo

\begin{tabular}{|c|c|c|c|c|c|}
\hline \multirow[t]{2}{*}{ GRUPO } & \multicolumn{4}{|c|}{ MOMENTOS } & \multirow[b]{2}{*}{ M5 } \\
\hline & M1 & M2 & M3 & M4 & \\
\hline \multicolumn{6}{|l|}{ G1 } \\
\hline \multicolumn{6}{|l|}{ Cão } \\
\hline 1 & 4 & 6 & 7 & 6 & 5 \\
\hline 2 & 4 & 4 & 6 & 6 & 5 \\
\hline 3 & 8 & 6 & 6 & 5 & 6 \\
\hline 4 & 5 & 4 & 4 & 4 & 4 \\
\hline 5 & 6 & 7 & 7 & 8 & 7 \\
\hline 6 & 6 & 7 & 6 & 6 & 6 \\
\hline 7 & 4 & 5 & 3 & 6 & 4 \\
\hline 8 & 8 & 10 & 5 & 6 & 6 \\
\hline 9 & 4 & 2 & 1 & 1 & 1 \\
\hline 10 & 1 & 1 & 2 & 1 & 1 \\
\hline \multicolumn{6}{|l|}{ G2 } \\
\hline \multicolumn{6}{|l|}{ Cão } \\
\hline 1 & 7 & 6 & 7 & 6 & 6 \\
\hline 2 & 6 & 7 & 6 & 4 & 6 \\
\hline 3 & 7 & 6 & 7 & 6 & 4 \\
\hline 4 & 6 & 6 & 6 & 6 & 6 \\
\hline 5 & 3 & 3 & 5 & 5 & 4 \\
\hline 6 & 4 & 7 & 5 & 5 & 6 \\
\hline 7 & 5 & 5 & 6 & 5 & 6 \\
\hline 8 & 5 & 5 & 5 & 6 & 6 \\
\hline 9 & 5 & 5 & 2 & 2 & 2 \\
\hline 10 & 3 & 5 & 5 & 6 & 1 \\
\hline
\end{tabular}


Tabela 48 - Índice cardíaco $\left(\mathrm{mL} \cdot \mathrm{min}^{-1} \cdot \mathrm{m}^{2}\right)$. Valores obtidos em cada cão nos momentos de cada grupo

\begin{tabular}{lccccc}
\hline \multirow{2}{*}{ GRUPO } & \multicolumn{5}{c}{ MOMENTOS } \\
\cline { 2 - 6 } & M1 & M2 & M3 & M4 & M5 \\
\hline G1 & & & & & \\
Cão & & & & & \\
1 & 5,1 & 5,3 & 5,4 & 5,6 & 5,4 \\
2 & 4,1 & 3,6 & 2,6 & 2,7 & 2,5 \\
3 & 4 & 4,5 & 4,2 & 4,3 & 4,2 \\
4 & 4,8 & 5,7 & 5 & 4,4 & 4,5 \\
5 & 4,7 & 5,7 & 6,4 & 5,7 & 6 \\
6 & 4,4 & 4,4 & 4 & 3,6 & 3,7 \\
7 & 4,9 & 4,8 & 4,7 & 5,2 & 4,4 \\
8 & 4,3 & 6,5 & 5,4 & 4,7 & 4,9 \\
9 & 2,8 & 2,5 & 1,9 & 1,3 & 1,3 \\
10 & 2,4 & 3,2 & 3 & 2,7 & 2,6 \\
G2 & & & & & \\
Cão & & & & & \\
1 & 4 & 4,2 & 5 & 4,2 & 4,8 \\
2 & 6,1 & 4,1 & 5,9 & 6,7 & 5,4 \\
3 & 5,3 & 3,9 & 3,3 & 3,7 & 3,6 \\
4 & 4,7 & 3,3 & 3,2 & 2,7 & 3 \\
5 & 5 & 4,7 & 3,7 & 3,1 & 3,3 \\
6 & 4 & 3,7 & 5 & 4,3 & 4,1 \\
7 & 6,1 & 3,2 & 2,1 & 2 & 2,5 \\
8 & 2,8 & 2,7 & 2,2 & 1,9 & 2,2 \\
9 & 3,5 & 3,3 & 2,9 & 2,4 & 2,4 \\
10 & 3 & 2,2 & 2,8 & 2,8 & 3,4 \\
\hline
\end{tabular}


Tabela 49 - Índice de resistência vascular sistêmica (dina.s. $\mathrm{cm}^{-5} \cdot \mathrm{m}^{2}$ ). Valores obtidos em cada cão nos momentos de cada grupo

\begin{tabular}{|c|c|c|c|c|c|}
\hline \multirow[t]{2}{*}{ GRUPO } & \multicolumn{4}{|c|}{ MOMENTOS } & \multirow[b]{2}{*}{ M5 } \\
\hline & M1 & M2 & M3 & M4 & \\
\hline \multicolumn{6}{|l|}{ G1 } \\
\hline \multicolumn{6}{|l|}{ Cão } \\
\hline 1 & 1935,70 & 1855,60 & 1913,00 & 1825,20 & 1824,00 \\
\hline 2 & 1815,80 & 2113,20 & 3033,70 & 3403,00 & 3372,60 \\
\hline 3 & 2311,70 & 2116,50 & 1903,30 & 1826,50 & 2078,30 \\
\hline 4 & 1643,40 & 1378,40 & 1694,60 & 1975,90 & 2032,60 \\
\hline 5 & 1582,70 & 1469,80 & 1182,00 & 1511,70 & 1386,40 \\
\hline 6 & 1871,60 & 2004,40 & 2488,50 & 2683,70 & 2570,20 \\
\hline 7 & 1443,20 & 1566,70 & 1643,90 & 1594,50 & 1777,80 \\
\hline 8 & 2777,10 & 2076,00 & 2519,40 & 2786,10 & 2735,20 \\
\hline 9 & 3029,10 & 3578,20 & 5389,70 & 7662,10 & 6279,10 \\
\hline 10 & 2317,50 & 1786,80 & 1692,80 & 2012,50 & 2058,20 \\
\hline \multicolumn{6}{|l|}{ G2 } \\
\hline \multicolumn{6}{|l|}{ Cão } \\
\hline 1 & 2317,50 & 3941,60 & 4592,90 & 4716,90 & 4842,80 \\
\hline 2 & 1637,70 & 2144,60 & 1893,90 & 1694,20 & 1804,00 \\
\hline 3 & 1531,10 & 2182,00 & 2616,20 & 2209,00 & 2204,40 \\
\hline 4 & 2309,00 & 2752,60 & 3180,90 & 3434,20 & 3161,40 \\
\hline 5 & 1627,10 & 1746,00 & 1945,60 & 2318,70 & 2260,30 \\
\hline 6 & 2182,30 & 2239,80 & 2130,00 & 2547,60 & 2659,10 \\
\hline 7 & 1437,00 & 2488,50 & 4794,30 & 4877,10 & 3349,20 \\
\hline 8 & 3126,20 & 2940,20 & 3966,40 & 4907,30 & 3966,40 \\
\hline 9 & 2332,10 & 2515,40 & 2696,80 & 3856,90 & 3428,30 \\
\hline 10 & 2624,30 & 3488,50 & 3003,50 & 2772,20 & 2294,80 \\
\hline
\end{tabular}


Tabela 50 - Concentração plasmática da vasopressina $\left(\right.$ pg.mL $\left.{ }^{-1}\right)$. Valores obtidos em cada cão nos momentos de cada grupo

\begin{tabular}{lccccc}
\hline \multirow{2}{*}{ GRUPO } & \multicolumn{5}{c}{ MOMENTOS } \\
\cline { 2 - 5 } & M1 & M2 & M3 & M4 & M5 \\
\hline G1 & & & & \\
Cão & & & & \\
1 & 8,20 & 4,43 & 5,51 & 5,14 & 4,86 \\
2 & 5,48 & 5,20 & 5,56 & 6,18 & 6,55 \\
3 & 5,56 & 4,96 & 7,56 & 6,08 & 7,43 \\
4 & 5,32 & 4,28 & 5,03 & 5,14 & 4,73 \\
5 & 3,45 & 4,21 & 4,22 & 5,02 & 4,72 \\
6 & 5,53 & 4,98 & 5,59 & 5,29 & 6,47 \\
7 & 7,10 & 6,78 & 6,00 & 6,85 & 6,23 \\
8 & 7,13 & 5,42 & 7,92 & 8,28 & 7,16 \\
9 & 6,91 & 6,19 & 11,89 & 10,67 & 9,93 \\
10 & 8,23 & 10,95 & 10,97 & 13,63 & 9,85 \\
G2 & & & & \\
Cão & & & & \\
1 & 6,47 & 6,52 & 6,19 & 5,33 & 5,39 \\
2 & 4,82 & 5,08 & 4,08 & 5,71 & 4,49 \\
3 & 3,72 & 2,80 & 3,76 & 5,16 & 6,13 \\
4 & 7,68 & 4,75 & 5,28 & 5,41 & 6,02 \\
5 & 2,38 & 2,84 & 2,48 & 3,79 & 3,18 \\
6 & 6,05 & 5,63 & 5,70 & 5,98 & 6,14 \\
7 & 5,56 & 5,43 & 5,14 & 4,45 & 6,32 \\
8 & 9,31 & 5,71 & 5,40 & 5,88 & 5,88 \\
9 & 7,25 & 4,95 & 7,24 & 10,54 & 11,00 \\
10 & 6,26 & 3,05 & 7,62 & 5,38 & 5,87 \\
\hline
\end{tabular}


Tabela 51 - Resistência vascular renal $\left(\mathrm{mmHg} \cdot \mathrm{mL}^{-1} \cdot \mathrm{min}^{-1}\right)$. Valores obtidos em cada cão nos momentos de cada grupo

\begin{tabular}{lccccc}
\hline \multirow{2}{*}{ GRUPO } & \multicolumn{5}{c}{ MOMENTOS } \\
\cline { 2 - 5 } G1 & M2 & M3 & M4 & M5 \\
\hline Cão & & & & \\
1 & & & & \\
2 & 0,36 & 0,37 & 0,49 & 0,44 & 0,50 \\
3 & 7,88 & 12,12 & 12,27 & 200,88 & 92,68 \\
4 & 1,16 & 0,41 & 1,56 & 0,73 & 0,73 \\
5 & 1,60 & 1,54 & 4,05 & 1,75 & 2,09 \\
6 & 0,41 & 0,28 & 1,09 & 0,87 & 0,67 \\
7 & 0,19 & 0,18 & 0,29 & 1,29 & 0,38 \\
8 & 0,72 & 0,49 & 4,03 & 1,44 & 1,14 \\
9 & 2,20 & 0,93 & 10,35 & 4,16 & 1,86 \\
10 & 0,87 & 1,21 & 10,74 & 5,13 & 3,40 \\
G2 & 2,10 & 2,21 & 7,39 & 2,87 & 3,05 \\
Cão & & & & \\
1 & & & & & \\
2 & 0,95 & 0,48 & 1,19 & 1,66 & 1,92 \\
3 & 0,66 & 0,63 & 2,16 & 3,70 & 2,54 \\
4 & 1,90 & 2,25 & 15,58 & 5,44 & 5,07 \\
5 & 0,73 & 0,63 & 4,66 & 1,46 & 1,01 \\
6 & 2,55 & 3,34 & 16,72 & 11,53 & 11,03 \\
7 & 0,94 & 1,74 & 3,09 & 1,50 & 1,52 \\
8 & 0,54 & 0,60 & 1,25 & 1,25 & 0,92 \\
9 & 1,60 & 1,87 & 5,49 & 2,31 & 1,84 \\
10 & 0,78 & 1,14 & 1,40 & 5,81 & 2,83 \\
\hline & 0,67 & 0,91 & 2,32 & 1,22 & 1,26 \\
\hline & & & &
\end{tabular}


Tabela 52 - Fluxo sanguíneo renal $\left(\mathrm{ml}^{\mathrm{min}} \mathrm{m}^{-1} \cdot \mathrm{Kg}^{-1}\right)$. Valores obtidos em cada cão nos momentos de cada grupo

\begin{tabular}{lccccc}
\hline \multirow{2}{*}{ GRUPO } & \multicolumn{5}{c}{ MOMENTOS } \\
\cline { 2 - 5 } & M1 & M2 & M3 & M4 & M5 \\
\hline G1 & & & & \\
Cão & & & & \\
1 & 15,72 & 15,44 & 12,22 & 13,31 & 11,51 \\
2 & 0,58 & 0,38 & 0,40 & 0,03 & 0,05 \\
3 & 4,52 & 12,95 & 2,89 & 6,06 & 6,63 \\
4 & 4,20 & 4,37 & 1,79 & 4,28 & 3,74 \\
5 & 6,90 & 11,51 & 2,59 & 3,68 & 4,62 \\
6 & 19,88 & 21,86 & 15,02 & 3,34 & 11,03 \\
7 & 7,36 & 11,21 & 1,40 & 4,26 & 5,13 \\
8 & 2,42 & 6,52 & 0,58 & 1,40 & 3,18 \\
9 & 6,88 & 5,18 & 0,66 & 1,40 & 1,75 \\
10 & 2,78 & 3,24 & 0,94 & 2,15 & 2,28 \\
G2 & & & & & \\
Cão & & & & & \\
1 & 7,10 & 12,05 & 5,38 & 3,91 & 3,78 \\
2 & 12,85 & 12,12 & 4,50 & 2,70 & 3,41 \\
3 & 2,68 & 2,37 & 0,34 & 0,92 & 1,00 \\
4 & 11,54 & 11,49 & 1,70 & 4,97 & 7,19 \\
5 & 1,85 & 1,44 & 0,25 & 0,37 & 0,40 \\
6 & 9,08 & 4,78 & 3,34 & 7,09 & 7,09 \\
7 & 11,00 & 9,37 & 5,67 & 5,37 & 6,52 \\
8 & 3,48 & 2,81 & 1,03 & 2,67 & 3,07 \\
9 & 7,54 & 5,32 & 3,98 & 1,14 & 2,10 \\
10 & 8,48 & 6,16 & 2,54 & 4,55 & 4,46 \\
\hline & & & &
\end{tabular}


Tabela 53 - Depuração de para-aminohipurato de sódio $\left(\mathrm{mL} \cdot \mathrm{min}^{-1} \cdot \mathrm{Kg}^{-1}\right)$. Valores obtidos em cada cão nos momentos de cada grupo

\begin{tabular}{lccccc}
\hline \multirow{2}{*}{ GRUPO } & \multicolumn{5}{c}{ MOMENTOS } \\
\cline { 2 - 5 } & M1 & M2 & M3 & M4 & M5 \\
\hline G1 & & & & \\
Cão & & & & \\
1 & 7,39 & 7,41 & 6,23 & 6,92 & 6,10 \\
2 & 0,48 & 0,75 & 0,20 & 0,02 & 0,03 \\
3 & 3,12 & 5,55 & 1,94 & 3,94 & 4,11 \\
4 & 2,77 & 3,10 & 1,22 & 2,78 & 2,43 \\
5 & 4,14 & 6,10 & 1,50 & 2,24 & 2,35 \\
6 & 8,95 & 10,06 & 7,51 & 1,67 & 5,51 \\
7 & 3,61 & 2,27 & 1,70 & 2,34 & 2,92 \\
8 & 1,33 & 3,06 & 0,29 & 0,77 & 1,87 \\
9 & 3,17 & 2,38 & 0,30 & 0,63 & 0,87 \\
10 & 1,33 & 1,55 & 0,41 & 0,95 & 1,03 \\
G2 & & & & & \\
Cão & & & & & \\
1 & 4,12 & 7,23 & 3,23 & 2,54 & 2,46 \\
2 & 9,25 & 7,88 & 2,93 & 1,73 & 1,65 \\
3 & 1,87 & 1,63 & 0,24 & 0,64 & 0,69 \\
4 & 1,45 & 1,40 & 0,26 & 0,76 & 1,03 \\
5 & 1,41 & 1,07 & 0,19 & 0,28 & 0,32 \\
6 & 6,54 & 3,25 & 2,34 & 4,61 & 4,61 \\
7 & 4,18 & 4,03 & 2,67 & 2,68 & 3,19 \\
8 & 2,09 & 1,60 & 0,64 & 1,65 & 1,87 \\
9 & 3,99 & 2,71 & 2,23 & 0,59 & 1,11 \\
10 & 3,90 & 3,45 & 1,50 & 2,73 & 2,72 \\
\hline
\end{tabular}


Tabela 54 - Depuração de creatinina $\left(\mathrm{mL} \cdot \mathrm{min}^{-1} \mathrm{Kg}^{-1}\right)$. Valores obtidos em cada cão nos momentos de cada grupo

\begin{tabular}{lccccc}
\hline \multirow{2}{*}{ GRUPO } & M1 & M2 & M3 & M4 & M5 \\
\cline { 2 - 5 } G1 & & & & \\
Cão & & & & \\
1 & 1,94 & 2,14 & 0,36 & 1,10 & 1,12 \\
2 & 0,29 & 0,33 & 0,10 & 0,00 & 0,00 \\
3 & 0,73 & 2,38 & 0,7 & 1,41 & 1,55 \\
4 & 0,58 & 0,82 & 0,35 & 0,74 & 0,72 \\
5 & 1,00 & 1,08 & 0,35 & 0,45 & 0,54 \\
6 & 2,39 & 1,71 & 1,27 & 2,17 & 1,50 \\
7 & 2,02 & 1,85 & 0,29 & 0,61 & 0,67 \\
8 & 0,39 & 0,7 & 0,16 & 0,27 & 0,46 \\
9 & 0,88 & 0,92 & 0,16 & 0,69 & 1,08 \\
10 & 1,3 & 1,52 & 0,19 & 0,74 & 0,63 \\
G2 & & & & \\
Cão & & & & & \\
1 & 0,70 & 0,53 & 0,12 & 0,30 & 0,46 \\
2 & 2,44 & 2,63 & 0,39 & 0,76 & 1,65 \\
3 & 1,46 & 1,04 & 0,25 & 0,57 & 0,65 \\
4 & 1,45 & 1,4 & 0,26 & 0,76 & 1,03 \\
5 & 0,69 & 0,66 & 0,09 & 0,11 & 0,12 \\
6 & 1,46 & 1,59 & 0,81 & 2,83 & 2,12 \\
7 & 1,39 & 0,98 & 1,02 & 1,2 & 1,44 \\
8 & 1,02 & 0,61 & 0,28 & 0,43 & 0,74 \\
9 & 1,67 & 1,18 & 0,81 & 0,61 & 0,81 \\
10 & 1,18 & 2,69 & 0,43 & 0,8 & 0,84 \\
\hline & & & & &
\end{tabular}


Tabela 55 - Fração de filtração. Valores obtidos em cada cão nos momentos de cada grupo

\begin{tabular}{|c|c|c|c|c|c|}
\hline \multirow[t]{2}{*}{ GRUPO } & \multicolumn{4}{|c|}{ MOMENTOS } & \multirow[b]{2}{*}{ M5 } \\
\hline & M1 & M2 & M3 & M4 & \\
\hline \multicolumn{6}{|l|}{ G1 } \\
\hline \multicolumn{6}{|l|}{ Cão } \\
\hline 1 & 0,26 & 0,29 & 0,06 & 0,16 & 0,18 \\
\hline 2 & 0,89 & 1,67 & 0,51 & 0,19 & 0,13 \\
\hline 3 & 0,23 & 0,28 & 0,36 & 0,36 & 0,38 \\
\hline 4 & 0,21 & 0,26 & 0,29 & 0,27 & 0,30 \\
\hline 5 & 0,24 & 0,18 & 0,23 & 0,2 & 0,23 \\
\hline 6 & 0,27 & 0,17 & 0,17 & 1,3 & 0,27 \\
\hline 7 & 0,56 & 0,35 & 0,41 & 0,26 & 0,23 \\
\hline 8 & 0,29 & 0,23 & 0,55 & 0,35 & 0,25 \\
\hline 9 & 0,28 & 0,39 & 0,54 & 1,10 & 1,24 \\
\hline 10 & 0,97 & 0,98 & 0,46 & 0,78 & 0,61 \\
\hline \multicolumn{6}{|l|}{ G2 } \\
\hline \multicolumn{6}{|l|}{ Cão } \\
\hline 1 & 0,17 & 0,07 & 0,04 & 0,12 & 0,19 \\
\hline 2 & 0,26 & 0,33 & 0,13 & 0,44 & 0,75 \\
\hline 3 & 0,78 & 0,64 & 1,04 & 0,89 & 0,95 \\
\hline 4 & 0,22 & 0,25 & 0,31 & 0,31 & 0,29 \\
\hline 5 & 0,49 & 0,62 & 0,47 & 0,39 & 0,38 \\
\hline 6 & 0,22 & 0,49 & 0,35 & 0,61 & 0,46 \\
\hline 7 & 0,33 & 0,24 & 0,38 & 0,45 & 0,45 \\
\hline 8 & 0,49 & 0,38 & 0,44 & 0,26 & 0,39 \\
\hline 9 & 0,42 & 0,44 & 0,36 & 1,03 & 0,73 \\
\hline 10 & 0,3 & 0,78 & 0,29 & 0,29 & 0,31 \\
\hline
\end{tabular}


Tabela 56 - Débito urinário $\left(\mathrm{mL} \cdot \mathrm{min}^{-1} \cdot \mathrm{kg}^{-1}\right)$. Valores obtidos em cada cão nos momentos de cada grupo

\begin{tabular}{lccccc}
\hline \multirow{2}{*}{ GRUPO } & \multicolumn{5}{c}{ MOMENTOS } \\
\cline { 2 - 5 } & M1 & M2 & M4 & M5 \\
\hline G1 & & & & \\
Cão & & & & \\
1 & 0,016 & 0,024 & 0,012 & 0,0036 & 0,005 \\
2 & 0,01 & 0,01 & 0,01 & 0,00 & 0,00 \\
3 & 0,012 & 0,021 & 0,013 & 0,029 & 0,035 \\
4 & 0,008 & 0,011 & 0,006 & 0,017 & 0,014 \\
5 & 0,01 & 0,011 & 0,009 & 0,018 & 0,023 \\
6 & 0,05 & 0,041 & 0,031 & 0,037 & 0,037 \\
7 & 0,032 & 0,044 & 0,001 & 0,041 & 0,067 \\
8 & 0,006 & 0,006 & 0,002 & 0,004 & 0,006 \\
9 & 0,015 & 0,022 & 0,004 & 0,007 & 0,011 \\
10 & 0,07 & 0,1 & 0,011 & 0,026 & 0,05 \\
G2 & & & & \\
Cão & & & & & \\
1 & 0,012 & 0,011 & 0,004 & 0,01 & 0,014 \\
2 & 0,012 & 0,024 & 0,027 & 0,062 & 0,12 \\
3 & 0,029 & 0,073 & 0,054 & 0,089 & 0,095 \\
4 & 0,014 & 0,012 & 0,009 & 0,014 & 0,015 \\
5 & 0,016 & 0,015 & 0,006 & 0,009 & 0,009 \\
6 & 0,072 & 0,03 & 0,045 & 0,049 & 0,066 \\
7 & 0,008 & 0,01 & 0,02 & 0,021 & 0,029 \\
8 & 0,05 & 0,017 & 0,017 & 0,037 & 0,046 \\
9 & 0,036 & 0,036 & 0,05 & 0,027 & 0,033 \\
10 & 0,013 & 0,027 & 0,019 & 0,062 & 0,093 \\
\hline
\end{tabular}


Tabela 57 - Sódio plasmático $\left(\mu \mathrm{Eq} \cdot \mathrm{min}^{-1}\right)$. Valores obtidos em cada cão nos momentos de cada grupo

\begin{tabular}{|c|c|c|c|c|c|}
\hline \multirow[t]{2}{*}{ GRUPO } & \multicolumn{4}{|c|}{ MOMENTOS } & \multirow[b]{2}{*}{ M5 } \\
\hline & M1 & M2 & M3 & M4 & \\
\hline \multicolumn{6}{|l|}{ G1 } \\
\hline \multicolumn{6}{|l|}{ Cão } \\
\hline 1 & 152 & 148 & 152 & 135 & 135 \\
\hline 2 & 152 & 158 & 155 & 148 & 148 \\
\hline 3 & 118 & 134 & 112 & 125 & 112 \\
\hline 4 & 144 & 143 & 142 & 144 & 134 \\
\hline 5 & 146 & 141 & 131 & 145 & 141 \\
\hline 6 & 135 & 129 & 133 & 135 & 138 \\
\hline 7 & 144 & 140 & 141 & 132 & 121 \\
\hline 8 & 144 & 147 & 144 & 134 & 145 \\
\hline 9 & 150 & 151 & 152 & 150 & 148 \\
\hline 10 & 142 & 144 & 138 & 140 & 142 \\
\hline \multicolumn{6}{|l|}{ G2 } \\
\hline \multicolumn{6}{|l|}{ Cão } \\
\hline 1 & 150 & 150 & 144 & 148 & 148 \\
\hline 2 & 146 & 146 & 146 & 137 & 148 \\
\hline 3 & 150 & 150 & 147 & 152 & 150 \\
\hline 4 & 144 & 148 & 148 & 146 & 150 \\
\hline 5 & 146 & 144 & 143 & 142 & 144 \\
\hline 6 & 146 & 141 & 147 & 145 & 144 \\
\hline 7 & 145 & 145 & 137 & 139 & 140 \\
\hline 8 & 153 & 153 & 146 & 148 & 146 \\
\hline 9 & 145 & 143 & 143 & 142 & 139 \\
\hline 10 & 144 & 148 & 147 & 145 & 146 \\
\hline
\end{tabular}


Tabela 58 - Potássio plasmático ( $\mu$ Eq. min $\left.^{-1}\right)$. Valores obtidos em cada cão nos momentos de cada grupo

\begin{tabular}{lccccc}
\hline \multirow{2}{*}{ GRUPO } & \multicolumn{5}{c}{ MOMENTOS } \\
\cline { 2 - 6 } G1 & M2 & M3 & M4 & M5 \\
\hline Cão & & & & \\
1 & 3,4 & 3,3 & 3 & 2,7 & 2,8 \\
2 & 2,43 & 3,16 & 3,33 & 3,4 & 3,17 \\
3 & 3,29 & 3,33 & 3,52 & 3,83 & 3,6 \\
4 & 2,68 & 2,81 & 2,96 & 3,03 & 2,8 \\
5 & 3,72 & 3,27 & 3,36 & 3,33 & 3,53 \\
6 & 3,3 & 3,11 & 3,35 & 3,54 & 3,4 \\
7 & 2,43 & 2,71 & 2,76 & 2,94 & 2,73 \\
8 & 3,67 & 3,52 & 3,64 & 3,68 & 3,45 \\
9 & 3,29 & 2,72 & 2,81 & 2,93 & 2,85 \\
10 & 3,59 & 3,56 & 3,54 & 3,52 & 3,46 \\
G2 & & & & & \\
Cão & & & & & \\
1 & 3,9 & 3,7 & 4,2 & 4,1 & 4,3 \\
2 & 3,35 & 3,28 & 3,97 & 3,1 & 3,08 \\
3 & 3,72 & 3,27 & 3,36 & 3,33 & 3,53 \\
4 & 3,83 & 3,53 & 3,89 & 3,94 & 3,94 \\
5 & 3,37 & 3,73 & 3,81 & 3,93 & 4,13 \\
6 & 2,52 & 3,2 & 2,91 & 2,96 & 3,19 \\
7 & 3,28 & 3,65 & 3,54 & 3,69 & 3,64 \\
8 & 3,59 & 3,84 & 4,15 & 4,28 & 4,04 \\
9 & 3,13 & 3,95 & 3,9 & 3,77 & 3,43 \\
10 & 3,45 & 3,09 & 3,78 & 3,52 & 3,56 \\
\hline
\end{tabular}


Tabela 59 - Osmolalidade plasmática $\left(\mathrm{mOsm} \cdot \mathrm{Kg}^{-1} \cdot \mathrm{H}_{2} \mathrm{O}^{-1}\right)$. Valores obtidos em cada cão nos momentos de cada grupo

\begin{tabular}{|c|c|c|c|c|c|}
\hline \multirow[t]{2}{*}{ GRUPO } & \multicolumn{4}{|c|}{ MOMENTOS } & \multirow[b]{2}{*}{ M5 } \\
\hline & M1 & M2 & M3 & M4 & \\
\hline \multicolumn{6}{|l|}{ G1 } \\
\hline \multicolumn{6}{|l|}{ Cão } \\
\hline 1 & 301 & 294 & 297 & 307 & 292 \\
\hline 2 & 292 & 289 & 287 & 293 & 291 \\
\hline 3 & 298 & 311 & 275 & 375 & 267 \\
\hline 4 & 289 & 283 & 283 & 283 & 280 \\
\hline 5 & 297 & 304 & 304 & 301 & 298 \\
\hline 6 & 298 & 293 & 289 & 287 & 292 \\
\hline 7 & 294 & 292 & 292 & 290 & 291 \\
\hline 8 & 288 & 287 & 287 & 283 & 288 \\
\hline 9 & 301 & 298 & 301 & 298 & 300 \\
\hline 10 & 252 & 233 & 231 & 246 & 242 \\
\hline \multicolumn{6}{|l|}{ G2 } \\
\hline \multicolumn{6}{|l|}{ Cão } \\
\hline 1 & 298 & 294 & 296 & 291 & 286 \\
\hline 2 & 277 & 260 & 270 & 276 & 263 \\
\hline 3 & 283 & 278 & 289 & 288 & 289 \\
\hline 4 & 283 & 286 & 283 & 288 & 285 \\
\hline 5 & 292 & 291 & 289 & 287 & 289 \\
\hline 6 & 269 & 271 & 269 & 266 & 276 \\
\hline 7 & 285 & 285 & 287 & 288 & 283 \\
\hline 8 & 287 & 269 & 283 & 268 & 285 \\
\hline 9 & 285 & 285 & 283 & 284 & 285 \\
\hline 10 & 252 & 233 & 231 & 246 & 242 \\
\hline
\end{tabular}


Tabela 60 - Osmolalidade urinária (mOsm. $\mathrm{Kg}^{-1} \cdot \mathrm{H}_{2} \mathrm{O}^{-1}$ ). Valores obtidos em cada cão nos momentos de cada grupo

\begin{tabular}{|c|c|c|c|c|c|}
\hline \multirow[t]{2}{*}{ GRUPO } & \multicolumn{4}{|c|}{ MOMENTOS } & \multirow[b]{2}{*}{ M5 } \\
\hline & M1 & M2 & M3 & M4 & \\
\hline \multicolumn{6}{|l|}{ G1 } \\
\hline \multicolumn{6}{|l|}{ Cão } \\
\hline 1 & 819 & 842 & 527 & 508 & 417 \\
\hline 2 & 745 & 736 & 550 & 470 & 435 \\
\hline 3 & 1093 & 1051 & 665 & 598 & 599 \\
\hline 4 & 645 & 583 & 450 & 355 & 325 \\
\hline 5 & 1233 & 1471 & 772 & 586 & 450 \\
\hline 6 & 464 & 454 & 395 & 428 & 371 \\
\hline 7 & 359 & 378 & 341 & 267 & 226 \\
\hline 8 & 631 & 741 & 702 & 537 & 532 \\
\hline 9 & 866 & 690 & 646 & 590 & 623 \\
\hline 10 & 345 & 256 & 335 & 363 & 237 \\
\hline \multicolumn{6}{|l|}{ G2 } \\
\hline \multicolumn{6}{|l|}{ Cão } \\
\hline 1 & 484 & 439 & 430 & 404 & 393 \\
\hline 2 & 1077 & 881 & 526 & 324 & 255 \\
\hline 3 & 489 & 246 & 211 & 229 & 202 \\
\hline 4 & 682 & 780 & 533 & 516 & 577 \\
\hline 5 & 409 & 431 & 350 & 278 & 276 \\
\hline 6 & 445 & 386 & 303 & 370 & 318 \\
\hline 7 & 1030 & 1592 & 719 & 707 & 641 \\
\hline 8 & 499 & 562 & 360 & 328 & 334 \\
\hline 9 & 604 & 624 & 445 & 539 & 500 \\
\hline 10 & 345 & 256 & 335 & 363 & 237 \\
\hline
\end{tabular}


Tabela 61 - Depuração de água livre $\left(\mathrm{mL} \cdot \mathrm{min}^{-1}\right)$. Valores obtidos em cada cão nos momentos de cada grupo

\begin{tabular}{lccccc}
\hline \multirow{2}{*}{ GRUPO } & \multicolumn{5}{c}{ MOMENTOS } \\
\cline { 2 - 5 } & M1 & M3 & M4 & M5 \\
\hline G1 & & & & \\
Cão & & & & \\
1 & $-0,6$ & $-0,97$ & $-0,2$ & $-0,52$ & $-0,47$ \\
2 & $-0,13$ & $-0,1$ & $-0,04$ & $-0,07$ & $-0,09$ \\
3 & $-0,71$ & $-1,17$ & $-0,43$ & $-0,4$ & $-0,99$ \\
4 & $-0,16$ & $-0,18$ & $-0,06$ & $-0,06$ & $-0,03$ \\
5 & $-0,44$ & 0,18 & 0,31 & 0,38 & 0,6 \\
6 & $-0,81$ & $-0,66$ & $-0,33$ & $-0,53$ & $-0,29$ \\
7 & $-0,13$ & $-0,23$ & $-0,03$ & 0,06 & 0,27 \\
8 & $-0,21$ & $-0,3$ & $-0,1$ & $-0,11$ & $-0,14$ \\
9 & $-0,5$ & $-0,53$ & $-0,08$ & $-0,13$ & $-0,22$ \\
10 & $-0,46$ & $-0,2$ & $-0,09$ & $-0,22$ & 0,02 \\
G2 & & & & & \\
Cão & & & & & \\
1 & $-0,13$ & $-0,1$ & $-0,04$ & $-0,07$ & $-0,09$ \\
2 & $-0,5$ & $-0,88$ & $-0,38$ & $-0,16$ & 0,05 \\
3 & $-0,44$ & 0,18 & 0,31 & 0,38 & 0,6 \\
4 & $-0,33$ & $-0,35$ & $-0,13$ & $-0,18$ & $-0,26$ \\
5 & $-0,14$ & $-0,16$ & $-0,03$ & 0,01 & 0,01 \\
6 & $-0,61$ & $-0,16$ & $-0,07$ & $-0,25$ & $-0,13$ \\
7 & $-0,42$ & $-0,86$ & $-0,56$ & $-0,58$ & $-0,71$ \\
8 & $-0,74$ & $-0,36$ & $-0,09$ & $-0,17$ & $-0,16$ \\
9 & $-0,72$ & $-0,76$ & $-0,51$ & $-0,43$ & $-0,45$ \\
10 & $-0,46$ & $-0,87$ & $-0,25$ & $-0,8$ & $-0,29$ \\
\hline
\end{tabular}


Tabela 62 - Depuração de sódio $\left(\mathrm{mL} \cdot \mathrm{min}^{-1}\right)$. Valores obtidos em cada cão nos momentos de cada grupo

\begin{tabular}{lccccc}
\hline \multirow{2}{*}{ GRUPO } & \multicolumn{5}{c}{ MOMENTOS } \\
\cline { 2 - 5 } & M1 & M2 & M3 & M4 & M5 \\
\hline G1 & & & & \\
Cão & & & & \\
1 & 0,47 & 0,59 & 0,26 & 1,05 & 1,41 \\
2 & 0,06 & 0,02 & 0,17 & 0,03 & 0,05 \\
3 & 0,31 & 0,91 & 0,46 & 0,78 & 0,94 \\
4 & 0,25 & 0,35 & 0,21 & 0,24 & 0,24 \\
5 & 0,21 & 0,21 & 0,35 & 0,60 & 0,68 \\
6 & 1,50 & 1,07 & 0,95 & 0,89 & 0,83 \\
7 & 0,33 & 0,43 & 0,10 & 0,31 & 0,58 \\
8 & 0,05 & 0,13 & 0,03 & 0,06 & 0,04 \\
9 & 0,31 & 0,52 & 0,04 & 0,07 & 0,14 \\
10 & 1,49 & 2,17 & 0,12 & 0,21 & 0,50 \\
G2 & & & & & \\
Cão & & & & & \\
1 & 0,13 & 0,08 & 0,05 & 0,06 & 0,08 \\
2 & 0,27 & 0,70 & 0,74 & 1,28 & 2,06 \\
3 & 0,80 & 1,11 & 0,89 & 1,65 & 1,69 \\
4 & 0,26 & 0,17 & 0,22 & 0,16 & 0,19 \\
5 & 0,07 & 0,10 & 0,07 & 0,10 & 0,10 \\
6 & 0,19 & 0,12 & 0,29 & 0,32 & 0,40 \\
7 & 0,08 & 0,20 & 0,53 & 0,50 & 0,69 \\
8 & 1,61 & 0,41 & 0,35 & 0,77 & 0,88 \\
9 & 1,40 & 1,22 & 1,45 & 0,80 & 0,85 \\
10 & 0,43 & 0,74 & 0,41 & 1,41 & 1,91 \\
\hline
\end{tabular}


Tabela 63 - Excreção fracionária de sódio $\left(\mu\right.$ Eq. $\left.\mathrm{min}^{-1}\right)$. Valores obtidos em cada cão nos momentos de cada grupo

\begin{tabular}{lccccc}
\hline \multirow{2}{*}{ GRUPO } & \multicolumn{5}{c}{ MOMENTOS } \\
\cline { 2 - 5 } & M1 & M2 & M3 & M4 & M5 \\
\hline G1 & & & & \\
Cão & & & & \\
1 & 1,11 & 1,25 & 3,32 & 4,36 & 5,72 \\
2 & 1,00 & 0,32 & 7,94 & 44,69 & 56,31 \\
3 & 1,82 & 1,67 & 2,86 & 2,42 & 2,64 \\
4 & 2,82 & 2,81 & 4,04 & 2,19 & 2,2 \\
5 & 0,61 & 0,58 & 2,94 & 3,95 & 3,68 \\
6 & 2,16 & 2,16 & 2,57 & 1,41 & 1,91 \\
7 & 0,92 & 1,3 & 1,85 & 2,83 & 4,82 \\
8 & 0,44 & 0,64 & 0,74 & 0,82 & 0,31 \\
9 & 1,94 & 3,12 & 0 & 0,58 & 0,74 \\
10 & 6,37 & 7,92 & 3,64 & 1,55 & 4,44 \\
G2 & & & & \\
Cão & & & & & \\
1 & 1,02 & 0,81 & 2,11 & 1,12 & 0,97 \\
2 & 0,75 & 1,78 & 12,6 & 11,21 & 8,3 \\
3 & 2,61 & 5,1 & 16,89 & 13,75 & 12,41 \\
4 & 1,06 & 0,7 & 4,89 & 1,22 & 1,06 \\
5 & 0,45 & 0,7 & 3,44 & 4,25 & 3,7 \\
6 & 0,98 & 0,57 & 2,77 & 0,88 & 1,46 \\
7 & 0,3 & 1,1 & 2,73 & 2,18 & 2,53 \\
8 & 7,91 & 3,39 & 6,32 & 8,92 & 5,96 \\
9 & 4,67 & 5,75 & 9,94 & 7,33 & 5,86 \\
10 & 2,03 & 1,52 & 5,33 & 9,76 & 12,61 \\
\hline & & & &
\end{tabular}


Tabela 64 - Excreção urinária de sódio $\left(\mu\right.$ Eq. $\left.\mathrm{min}^{-1}\right)$. Valores obtidos em cada cão nos momentos de cada grupo

\begin{tabular}{|c|c|c|c|c|c|}
\hline \multirow[t]{2}{*}{ GRUPO } & \multicolumn{4}{|c|}{ MOMENTOS } & \multirow[b]{2}{*}{ M5 } \\
\hline & M1 & M2 & M3 & M4 & \\
\hline \multicolumn{6}{|l|}{ G1 } \\
\hline \multicolumn{6}{|l|}{ Cão } \\
\hline 1 & 72,11 & 86,84 & 40,03 & 142,40 & 190,35 \\
\hline 2 & 9,28 & 3,52 & 25,83 & 4,17 & 7,00 \\
\hline 3 & 36,00 & 122,35 & 51,60 & 98,00 & 105,60 \\
\hline 4 & 35,34 & 49,50 & 30,15 & 34,96 & 31,83 \\
\hline 5 & 30,33 & 29,88 & 45,76 & 87,71 & 95,19 \\
\hline 6 & 202,01 & 138,00 & 125,96 & 119,88 & 114,48 \\
\hline 7 & 48,16 & 60,57 & 13,63 & 41,07 & 70,37 \\
\hline 8 & 7,11 & 19,23 & 4,93 & 8,64 & 5,92 \\
\hline 9 & 46,13 & 78,00 & 6,00 & 10,80 & 21,40 \\
\hline 10 & 211,81 & 312,07 & 17,20 & 28,93 & 71,47 \\
\hline \multicolumn{6}{|l|}{ G2 } \\
\hline \multicolumn{6}{|l|}{ Cão } \\
\hline 1 & 19,2 & 11,6 & 6,56 & 8,96 & 11,91 \\
\hline 2 & 40,04 & 102,67 & 107,6 & 175,14 & 304,2 \\
\hline 3 & 120 & 167,13 & 130,33 & 250,13 & 254 \\
\hline 4 & 37,8 & 24,8 & 31,97 & 23,1 & 27,87 \\
\hline 5 & 10,05 & 14,62 & 9,73 & 14,6 & 14,05 \\
\hline 6 & 27,07 & 16,63 & 42,83 & 46,72 & 58,03 \\
\hline 7 & 11,52 & 29,68 & 72,43 & 69,2 & 96,88 \\
\hline 8 & 247 & 63,33 & 51,67 & 113,49 & 128,8 \\
\hline 9 & 203,52 & 174,72 & 207,25 & 114,24 & 118,8 \\
\hline 10 & 62,16 & 108,96 & 60,67 & 203,84 & 278,33 \\
\hline
\end{tabular}


Tabela 65 - Excreção urinária de potássio $\left(\mu\right.$ Eq. $\left.\mathrm{min}^{-1}\right)$. Valores obtidos em cada cão nos momentos de cada grupo

\begin{tabular}{|c|c|c|c|c|c|}
\hline \multirow[t]{2}{*}{ GRUPO } & \multicolumn{4}{|c|}{ MOMENTOS } & \multirow[b]{2}{*}{ M5 } \\
\hline & M1 & M2 & M3 & M4 & \\
\hline \multicolumn{6}{|l|}{ G1 } \\
\hline \multicolumn{6}{|l|}{ Cão } \\
\hline 1 & 34,01 & 29,74 & 15,86 & 51,2 & 45,04 \\
\hline 2 & 12,04 & 20,064 & 3,9267 & 0,1667 & 0,2667 \\
\hline 3 & 47,87 & 46,92 & 29,82 & 81,67 & 90,88 \\
\hline 4 & 13,78 & 15,42 & 8,3 & 32,55 & 21,58 \\
\hline 5 & 6,83 & 9,25 & 8,45 & 13,31 & 17,23 \\
\hline 6 & 46,65 & 81,24 & 36,81 & 74,84 & 61,02 \\
\hline 7 & 23,85 & 34,53 & 8,12 & 26,47 & 29,61 \\
\hline 8 & 20,75 & 13,96 & 4,5 & 9,7 & 20,37 \\
\hline 9 & 43,97 & 25,6 & 6,8667 & 13,973 & 18,28 \\
\hline 10 & 68,81 & 71,71 & 23,04 & 62,02 & 62,8 \\
\hline \multicolumn{6}{|l|}{ G2 } \\
\hline \multicolumn{6}{|l|}{ Cão } \\
\hline 1 & 25 & 24,1 & 8,22 & 23,63 & 31,92 \\
\hline 2 & 47,09 & 51,66 & 33,24 & 50,23 & 61,02 \\
\hline 3 & 51,72 & 44,16 & 18,36 & 35,65 & 32,8 \\
\hline 4 & 37,8 & 34,26 & 11,21 & 44,05 & 52,57 \\
\hline 5 & 54,67 & 39,54 & 9,52 & 16,28 & 18,48 \\
\hline 6 & 29,31 & 18,68 & 21 & 32,9 & 33,96 \\
\hline 7 & 37,9 & 58,09 & 85,01 & 92,56 & 97,78 \\
\hline 8 & 78,4 & 37,13 & 26 & 60,85 & 82,71 \\
\hline 9 & 44,61 & 48,96 & 56,55 & 39,7 & 41,52 \\
\hline 10 & 36,89 & 52,9 & 41,43 & 123,31 & 75,33 \\
\hline
\end{tabular}


Tabela 66 - Depuração de potássio $\left(\mathrm{mL} \cdot \mathrm{min}^{-1}\right)$. Valores obtidos em cada cão nos momentos de cada grupo

\begin{tabular}{lccccc}
\hline \multirow{2}{*}{ GRUPO } & \multicolumn{5}{c}{ MOMENTOS } \\
\cline { 2 - 5 } & M1 & M2 & M4 & M5 \\
\hline G1 & & & & \\
Cão & & & & \\
1 & 10 & 9,01 & 5,29 & 18,96 & 16,09 \\
2 & 4,96 & 6,3494 & 1,1792 & 0,049 & 0,0841 \\
3 & 14,55 & 14,09 & 8,47 & 21,32 & 25,24 \\
4 & 5,14 & 5,49 & 2,8 & 10,74 & 7,71 \\
5 & 1,84 & 2,83 & 2,51 & 4 & 4,88 \\
6 & 14,14 & 26,12 & 10,99 & 21,14 & 17,95 \\
7 & 9,82 & 12,74 & 2,94 & 9 & 10,84 \\
8 & 5,65 & 3,97 & 1,24 & 2,63 & 5,9 \\
9 & 13,37 & 9,4118 & 2,4437 & 4,7691 & 6,414 \\
10 & 19,17 & 20,14 & 6,51 & 17,62 & 18,15 \\
G2 & & & & \\
Cão & & & & \\
1 & 6,41 & 6,51 & 1,96 & 5,76 & 7,42 \\
2 & 14,06 & 15,75 & 8,37 & 16,2 & 19,81 \\
3 & 9,87 & 9,71 & 2,88 & 11,18 & 13,34 \\
4 & 13,9 & 13,5 & 5,46 & 10,71 & 9,29 \\
5 & 16,22 & 10,6 & 2,5 & 4,14 & 4,47 \\
6 & 11,63 & 5,84 & 7,22 & 11,11 & 10,65 \\
7 & 11,56 & 15,92 & 24,01 & 25,08 & 26,86 \\
8 & 21,84 & 9,67 & 6,27 & 14,22 & 20,47 \\
9 & 14,25 & 12,39 & 14,5 & 10,53 & 12,1 \\
10 & 10,69 & 17,12 & 10,96 & 35,03 & 21,16 \\
\hline & & & &
\end{tabular}


Tabela 67 - Excreção fracionária de potássio $\left(\mu\right.$ Eq. $\left.\min ^{-1}\right)$. Valores obtidos em cada cão nos momentos de cada grupo

\begin{tabular}{|c|c|c|c|c|c|}
\hline \multirow[t]{2}{*}{ GRUPO } & \multicolumn{4}{|c|}{ MOMENTOS } & \multirow[b]{2}{*}{ M5 } \\
\hline & M1 & M2 & M3 & M4 & \\
\hline \multicolumn{6}{|l|}{ G1 } \\
\hline \multicolumn{6}{|l|}{ Cão } \\
\hline 1 & 23,44 & 19,14 & 66,75 & 78,36 & 65,28 \\
\hline 2 & 81,39 & 91,621 & 56,151 & 77,809 & 100,15 \\
\hline 3 & 86,65 & 25,74 & 52,62 & 65,75 & 70,81 \\
\hline 4 & 59,11 & 44,6 & 53,39 & 96,79 & 71,35 \\
\hline 5 & 5,4 & 7,71 & 21,13 & 26,12 & 26,58 \\
\hline 6 & 20,4 & 52,68 & 29,83 & 33,6 & 41,26 \\
\hline 7 & 26,99 & 38,27 & 56,36 & 82,01 & 89,92 \\
\hline 8 & 49,99 & 19,54 & 26,64 & 33,65 & 44,26 \\
\hline 9 & 84,38 & 56,834 & 84,849 & 38,398 & 32,994 \\
\hline 10 & 81,91 & 73,63 & 190,31 & 132,28 & 160,06 \\
\hline \multicolumn{6}{|l|}{ G2 } \\
\hline \multicolumn{6}{|l|}{ Cão } \\
\hline 1 & 50,88 & 68,28 & 90,65 & 106,74 & 89,65 \\
\hline 2 & 38,41 & 39,93 & 143,12 & 142,12 & 80,05 \\
\hline 3 & 45,35 & 61,83 & 104,08 & 89,45 & 68,07 \\
\hline 4 & 40,04 & 40,78 & 65,17 & 86,54 & 76,2 \\
\hline 5 & 106,87 & 73,01 & 126,2 & 171,18 & 169,45 \\
\hline 6 & 61,27 & 28,24 & 68,54 & 30,21 & 38,63 \\
\hline 7 & 43,76 & 85,47 & 123,91 & 110,02 & 98,18 \\
\hline 8 & 107,05 & 79,26 & 111,88 & 165,33 & 138,33 \\
\hline 9 & 47,41 & 58,36 & 99,45 & 95,9 & 83,02 \\
\hline 10 & 50,34 & 35,35 & 141,59 & 243,28 & 139,95 \\
\hline
\end{tabular}

